Rafael Corsi Ferrão

\title{
Desenvolvimento de Mancal Magnético para Rodas de Reação
}



Rafael Corsi Ferrão

\section{Desenvolvimento de Mancal Magnético para Rodas de Reação}

Dissertação apresentda à Escola Politécnica da Universidade de São Paulo para o obtenção do título de Mestre em Engenharia. Área de Engenharia de Sistemas.

Orientador: Prof. Dr. José Jaime da Cruz

São Paulo

2015 
Este exemplar foi revisado e corrigido em relação à versão original, sob responsabilidade única do autor e com a anuência de seu orientador.

São Paulo, de de

Assinatura do autor:

Assinatura do orientador:

Catalogação-na-publicação

Ferrão, Rafael Corsi

Desenvolvimento de Mancal Magnético para Rodas de Reação / R. C. Ferrão -- versão corr. -- São Paulo, 2015.

$95 \mathrm{p}$.

Dissertação (Mestrado) - Escola Politécnica da Universidade de São Paulo. Departamento de Engenharia de Sistemas Eletrônicos.

1.Mancal Magnético 2.Roda de Reação 3.Modelagem Eletromagnética I.Universidade de São Paulo. Escola Politécnica. Departamento de Engenharia de Sistemas Eletrônicos II.t. 
Para Elisa, com amor. 


\section{Agradecimentos}

Agradeço ao meu orientador, José Jaime da Cruz, por seu apoio e dedicação no desenvolvimento dessa dissertação.

Agradeço o Dr. Leonardo Pinheiro pelas tardes gastas na discussão sobre o mancal magnético e pelo grande envolvimento e colaboração no projeto.

Um obrigado a Carol Marcatto por ter aceito fazer uma iniciação científica no tema, e colaborado com o projeto.

Agradeço aos meus colegas do Instituto Mauá de Tecnologia (Sergio Ribeiro Augusto, Vanderlei Cunha Parro, Rodrigo Alvite Romano) por todo o incentivo e confiança que me foi dado.

Agradeço à minha família por sempre apoiar os meus estudos.

E um agradecimento especial à Juliana por ser sempre companheira. 
Esta dissertação tem como objetivo o projeto de um mancal magnético para rodas de reação com aplicação na malha de controle de atitude de satélites.

Mancais magnéticos são alternativas aos mancais tradicionais tais como os de esferas ou de lubrificação seco pois trabalham sem contato mecânico entre o rotor e o estator, minimizando assim a friç̧ão entre ambas as partes. Além da minimização do atrito, o ganho em confiabilidade e vida útil da roda de reação é considerável por não apresentar desgastes mecânicos.

Devido às consequências de qualquer fricção no movimento relativo entre a inércia (parte rotativa da roda de reação) e o satélite, o mancal torna-se um componente crítico da roda de reação. A fricção se traduz não apenas num maior consumo de potência elétrica, como também na introdução de uma zona morta de atuação em torque, bem como na limitação da vida útil da roda de reação devido ao gradual desgaste do mancal.

O mancal proposto possui dois graus de liberdade axiais ativamente controlados e faz uso de ímãs para a estabilização passiva dos demais graus de liberdade.

Ao longo do desenvolvimento são apresentados modelos não lineares dos campos magnéticos e das forças atuantes no mancal são encontrados. Com esses modelos, uma otimização é realizada a fim de encontrar melhores características. Um modelo não linear da dinâmica do rotor é desenvolvido e um controle PID capaz de estabilizar o rotor em seu ponto de equilíbrio é apresentado com o objetivo de demonstrar a viabilidade da topologia proposta.

Palavras-chave: Mancal Magnético, Rodas de Reação, Modelagem Eletromagnética, Controle Multivariável 


\begin{abstract}
The main objective of this work is to project a magnetic bearing for reaction wheels with application in satellite attitude control.

Magnetic bearings are alternatives to traditional bearings such as ball or dry lubrication because they work without mechanical contact between the rotor and the stator thereby minimizing friction between both parts. In addition to minimizing friction, the gain in reliability and lifetime of the reaction wheel is considerable as a consequence of the absence of wear.

Because of the consequences of any friction in the relative movement between the inertia (of the reaction wheel) and the satellite ( which is rigidly connected to the satellite body), the bearing becomes a critical component of the reaction wheel. The friction gives rise not only to a greater consumption of electric power, as well as the introduction of a torque dead zone operation, in a reduced lifetime of the reaction wheel due to gradual wear of the bearing.

The proposed bearing has two axial degrees of freedom actively controlled and makes use of magnets for the passive stabilization of other degrees of freedom.

Nonlinear models of magnetic fields and forces acting on the bearing are presented. With these models, an optimization is performed to find the best bearing characteristics. A nonlinear model rotor dynamics is developed and a PID control capable of stabilizing the active degrees of freedom presented.
\end{abstract}

Keywords: Magnetic Bearing, Reaction Wheel, Multivariable Control, Electromagnetic modeling. 


\section{Lista de Figuras}

1.1 Esquema geral de uma roda de reação . . . . . . . . . . . . . . . . 3

1.2 Corte da topologia proposta por Bernus et al. (1998) a: estator externo; b: rotor; c: estator interno; d: ímãs permanentes . . . . . . . . . . . . 8

1.3 Corte da topologia proposta por Scharfe et al. (2001) a: estator externo; b: ímãs; c: bobinas; d: estator interno . . . . . . . . . . . . . . . . . . 9

1.4 Fluxo de desenvolvimento . . . . . . . . . . . . . . . . 13

2.1 Corte ilustrativo do mancal magnético . . . . . . . . . . . . . . 18

2.2 Corte radial ilustrativo do mancal magnético . . . . . . . . . . . . . . 19

2.3 Corte ilustrativo do mancal magnético . . . . . . . . . . . . . 19

2.4 Circuíto magnético do estator externo . . . . . . . . . . . . . 20

2.5 Fluxo magnético no estator externo e rotor . . . . . . . . . . . 22

2.6 Corte em perspectiva do estator interno . . . . . . . . . . . . . 24

2.7 Fluxo magnético . . . . . . . . . . . . . . . . . . . . 24

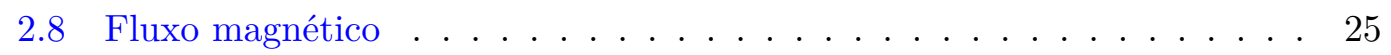

2.9 Circuito eletromagnético estator interno e rotor . . . . . . . . . 26

2.10 Ilustração do batente proposto . . . . . . . . . . . . . . . 28

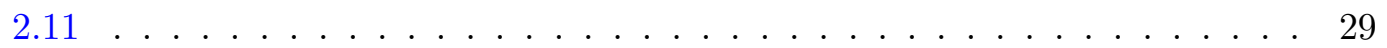

2.12 Modelo Comsol do circuito passivo Malha utilizada nos cálculos . . . . . 30

2.13 Partes do mancal . . . . . . . . . . . . . . . . . . . . . 32 
2.14 Componentes do protótipo . . . . . . . . . . . . . . 33

2.15 Protótipo montado, vista superior . . . . . . . . . . . . . 34

3.1 Circuito magnético passivo suposto . . . . . . . . . . . . 35

3.2 Curva de desmagnetização típica de ímãs de terra rara . . . . . . . . . 36

3.3 Curva de magnetização para o ferro $1020 \ldots \ldots$. . . . . . . . . 37

3.4 Deslocamento em X e Y . . . . . . . . . . . . . . . 40

3.5 Validação do modelo, deslocamento axial. . . . . . . . . . . . . . . . 43

3.6 Validação do modelo, variação de parâmetros: largura do ímã e comprimento do entreferro. . . . . . . . . . . . . . . . . . 44

3.7 Evolução dos parâmetros ao longo da otimização . . . . . . . . . . . . 47

3.8 Evolução dos pesos ao longo da otimização . . . . . . . . . . . . . . . 48

3.9 Força atuante no rotor dado uma translação radial . . . . . . . . . . . . 49

3.10 Força atuante no rotor dado uma translação axial . . . . . . . . . . . . 50

3.11 Mapa de forças devido a movimentação no plano . . . . . . . . . . . . 51

3.12 Campo magnético via simulação em elementos finitos para deslocamentos na vertical ............................. 52

3.13 Torque resultante da inclinação do rotor . . . . . . . . . . . 53

4.1 Dimensões do mancal . . . . . . . . . . . . . . . . . . . 55

4.2 Circuito magnético do circuito ativo . . . . . . . . . . 56

4.3 Forças resultante no rotor no eixo y . . . . . . . . . . . . 61

4.4 Modulo da força resultante devido ao deslocamento do rotor e a variação na corrente aplicada nas bobinas . . . . . . . . . . . . 63

4.5 Força magnética $(\mathrm{N})$ x Variação de parâmetros . . . . . . . . . . . . . . 64

4.6 Comparativo entre modelos quanto a variação da geometria . . . . . . . 64

4.7 Área útil para embobinamento de cada núcleo . . . . . . . . . . . . 66

4.8 Evolução dos parâmetros construtivos do mancal ao longo da otimização 68 
4.9 Evolução dos pesos propostos para o funcional ao longo da otimização · 68

4.10 Força resultante da aplicação de uma corrente quando o rotor está deslocado $0.3 \mathrm{~mm}$ (máxima distância) . . . . . . . . . . . 70

4.11 Força resultante da aplicação de uma corrente para diversos pontos de operação do rotor . . . . . . . . . . . . . . . . . . 71

4.12 Vetor campo magnético no polo principal quando variada a corrente, rotor com deslocamento de $0.3 \mathrm{~mm}$ de sua posição. . . . . . . . . . . 72

4.13 Vetor campo magnético de uma secção radial do mancal quando aplicada uma corrente de $4 \mathrm{~A}$ no polo principal . . . . . . . . . . 72

5.1 Forças atuantes no rotor . . . . . . . . . . . . . . 74

5.2 Distribuição das correntes nas bobinas . . . . . . . . . . . 77

5.3 Diagrama de blocos do modelo linearizado para deslocamentos em x e y 81

5.4 Diagrama de blocos do controlador e do estimador . . . . . . . . . . . 82

5.5 Análise do sistema controlado, diagrama de bode e lugar das raízes . . . 85

5.6 Resposta temporal do sistema em malha fechada com condições iniciais

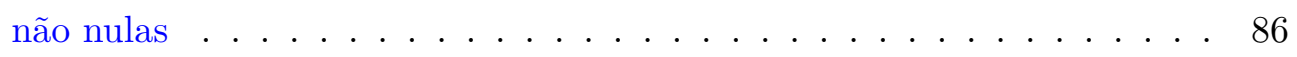

A.1 Campo magnético via simulação em elementos finitos para deslocamentos

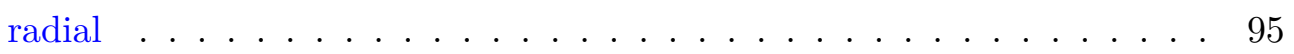




\section{Lista de Tabelas}

2.1 Especificações de requisito da roda de reação $\ldots \ldots$. . . . . . . . . 16

2.2 Símbolos utilizados na descrição do mancal . . . . . . . . . . . . . . 29

2.3 Nomenclatura partes mancal . . . . . . . . . . . . . . . . . . 31

3.1 Valores iniciais, máximos e mínimos utilizado na otimização. Valores em milímetros. . . . . . . . . . . . . . . . 46

3.2 Dimensões obtidas pela otimização. Valores em milímetros. . . . . . . 49

4.1 Valores iniciais, máximos e mínimos utilizados na otimização. Valores em milímetros. . . . . . . . . . . . . . . . . 66

4.2 Mancal ativo obtido devido a otimização, valores em milímetros . . . . . 69

5.1 Coeficientes do ajuste à curva de ganho $\mathrm{Kb} \quad \ldots \ldots \ldots$. . . . . . . 78

5.2 Indutância calculada para um único polo em diversos pontos de operação via elementos finitos. Corrente aplicada de 4A no polo principal . . . . . 79

5.3 Indutância mutua calculada para um único polo em diversos pontos de operação via elementos finitos. Corrente aplicada de 4A no polo principal 79

5.4 Ganhos do controlador PID . . . . . . . . . . . . . . . . 83 


\section{Sumário}

1 Introdução 1

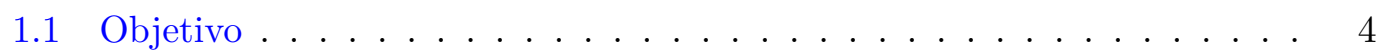

1.2 Justificativa . . . . . . . . . . . . . . . . . . . 4

1.3 Revisão bibliográfica . . . . . . . . . . . . . . . . 6

1.3.1 Graus de liberdade . . . . . . . . . . . . . . . . 6

1.3.2 Topologias com Aplicação em Rodas de Reação . . . . . . . . . . 8

1.3.3 Modelagem Eletromagnética . . . . . . . . . . . . . . . 10

1.3.4 Sensoriamento . . . . . . . . . . . . . . . . . 10

1.3.5 Mancais auxiliares . . . . . . . . . . . . . . 11

1.3.6 Técnicas de controle . . . . . . . . . . . . . . . . . . 11

1.3 .7 Eletrônica . . . . . . . . . . . . . . . . . . . . . . 12

1.4 Metodologia . . . . . . . . . . . . . . . . . . 12

1.5 Sumário Estruturado . . . . . . . . . . . . . . . . . . . . . 13

2 Mancal magnético $\quad 15$

2.1 Especificações . . . . . . . . . . . . . . . . . . . . . . . 15

2.2 Visão Geral . . . . . . . . . . . . . . . . . . . . . . . 17

2.3 Estator externo . . . . . . . . . . . . . . . . . . 20

2.4 Rotor . . . . . . . . . . . . . . . . . . . 23

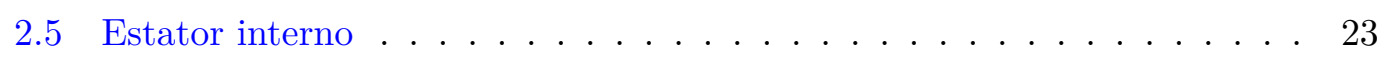




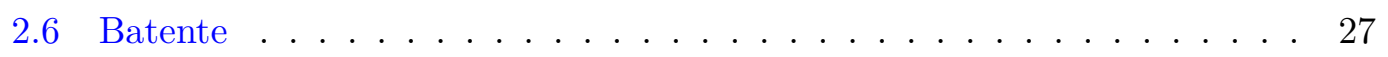

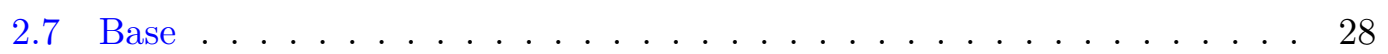

2.8 Dimensões . . . . . . . . . . . . . . . . . . . . . . . . . . . 28

2.9 Modelo em Elementos Finitos . . . . . . . . . . . . . . . . . . . . 29

2.10 Prototipagem . . . . . . . . . . . . . . . . . 31

3 Estator Externo e Rotor $\quad 35$

3.1 Modelagem Magnética . . . . . . . . . . . . . . . . . 36

3.1.1 Campo Magnético no Entreferro . . . . . . . . . . . . . . 38

3.1.2 Decomposição do Vetor Campo Magnético B em X e Z . . . . . . 39

3.2 Força. . . . . . . . . . . . . . . . . . 40

3.2 .1 Força Radial . . . . . . . . . . . . . . . . . . . . . . . . 41

3.2 .2 Força Axial . . . . . . . . . . . . . . . . . . . . . 41

3.3 Convergência . . . . . . . . . . . . . . . . . . . 41

3.4 Validação do Modelo . . . . . . . . . . . . . . . . . . . . . . . . . . 42

3.5 Otimização dos Parâmetros . . . . . . . . . . . . . . . . . 44

3.6 Mancal Passivo Resultante da Otimização . . . . . . . . . . . . . . . . . 48

4 Estator Interno $\quad 54$

4.1 Modelagem Magnética . . . . . . . . . . . . . . . . . 55

4.2 Forças .............................. 60

4.3 Indutância . . . . . . . . . . . . . . . . . . . . 61

4.4 Convergência . . . . . . . . . . . . . . . . . . 62

4.5 Validação do Modelo . . . . . . . . . . . . . . . . . . . . . 62

4.6 Otimização dos Parâmetros . . . . . . . . . . . . . . . . 64

4.7 Mancal Ativo Resultante da Otimização . . . . . . . . . . . . . . . . . . 69 
Sumário

5 Modelagem Dinâmica e Controlador $\quad 73$

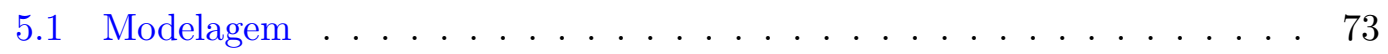

5.1 .1 Rigidez Passiva: $K_{p} \ldots \ldots \ldots \ldots \ldots$

5.1 .2 Rigidez Ativa $: F_{b} \ldots \ldots \ldots \ldots \ldots 77$

5.1 .3 Dinâmica do Atuador . . . . . . . . . . . . . . . . 78

5.1 .4 Modelo Linear . . . . . . . . . . . . . . . . . 80

5.1.5 Modelo Dinâmico Não Linear . . . . . . . . . . . . . . . . . . 81

5.2 Projeto do Controlador . . . . . . . . . . . . . . . . . 81

5.2 .1 Estimador . . . . . . . . . . . . . . . . 82

5.2 .2 Controlador . . . . . . . . . . . . . . . . . . 83

6 Considerações Finais $\quad 87$

$\begin{array}{lr}\text { Referências Bibliográficas } & 90\end{array}$

$\begin{array}{ll}\text { A Estator Externo - FEM } & 94\end{array}$ 


\section{Símbolos}

Símbolo Significado

\begin{tabular}{cl}
\hline \hline$g_{n e}$ & Entreferro nominal externo \\
$g_{n i}$ & Entreferro nominal interno \\
$h_{f e e}$ & Altura do ferro estator externo \\
$h_{f e i}$ & Altura do ferro estator interno \\
$h_{m}$ & Altura do ímã \\
$h_{n}$ & Altura do polo da bobina \\
$r_{e e i}$ & Raio do polo estator externo \\
$r_{r e}$ & Raio do polo do ferro rotor \\
$r_{n}$ & Raio do polo da bobina \\
$r_{e i}$ & Raio do ferro estator interno \\
$w_{f e e}$ & Largura do ferro estator externo \\
$w_{f e i}$ & Largura do ferro estator interno \\
$w_{r f}$ & Largura do ferro rotor \\
$w_{r r}$ & Largura do anel retorno rotor \\
$w_{m}$ & Largura do ímã \\
$w_{n}$ & Largura do polo da bobina \\
$S_{m}$ & Área do ímã \\
&
\end{tabular}


$S_{r f} \quad$ Área do ferro rotor

$S_{r i} \quad$ Área do ferro rotor, secção vertical

$S_{r r} \quad$ Área do anel retorno rotor, secção horizontal

$S_{g e} \quad$ Área do entreferro externo

$\mathcal{F}_{c} \quad$ Fluxo magnético ímã

$R_{p} \quad$ Relutância no íma

$R_{g e} \quad$ Relutância entreferro externo

$R_{g i} \quad$ Relutância entreferro interno

$R_{e f} \quad$ Relutância ferro estator externo

$R_{r f} \quad$ Relutância ferro rotor

$R_{r r} \quad$ Relutância anel retorno rotor

$R_{l m} \quad$ Relutância vazamento ímã

$R_{l g} \quad$ Relutância vazamento entreferro externo

$R_{r} \quad$ Relutância do rotor entre dois núcleos

$R_{m} \quad$ Relutância do polo

$R_{f i} \quad$ Relutância do estator interno, entre dois polos

$R_{r i} \quad$ Relutância do rotor, entre dois polos

$P_{l m} \quad$ Permeância do vazamento do ímã

$N \quad$ Número de voltas na bobina

$I_{m} \quad$ Corrente na bobina do polo

$H_{c} \quad$ Coercitividade do íma

$H_{m} \quad$ Campo magnético efetivo ímã

$B_{r} \quad$ Fluxo máximo fornecido pelo ímã

$B_{m} \quad$ Vetor campo magnético efetivo ímã

$B_{g x} \quad$ Vetor Campo magnético estator externo, componente $\mathrm{x}$

$B_{g z} \quad$ Vetor Campo magnético estator externo, componente z

$\mu_{0} \quad$ Permeabilidade do vácuo 


$\begin{array}{ll}\mu_{m} & \text { Permeabilidade do ímã } \\ \mu_{e f} & \text { Permeabilidade do ferro estator externo } \\ \mu_{r f} & \text { Permeabilidade do ferro rotor } \\ \mu_{r r} & \text { Permeabilidade do anel retorno rotor } \\ F_{e x} & \text { Força de atração em x devido o estator externo } \\ F_{e z} & \text { Força de atração em y devido o estator externo }\end{array}$




\section{Capítulo 1}

\section{Introdução}

Os sistemas de controle de atitude e órbita estão entre os elementos mais críticos de qualquer sistema espacial. O desenvolvimento de um sistema de controle de atitude em território nacional permanece incompleto (Veloso e Rollemberg, 2009) e a venda de seus componentes ao nosso país é, frequentemente, recusada por países detentores dessa tecnologia.

Basicamente, um sistema de controle de atitude é formado por sensores, atuadores e uma central responsável pelo processamento dos sinais dos sensores e comando dos atuadores, segundo uma lei de controle (Rycroft, 1992). Os sensores mais comuns são detectores de horizonte, sensores magnéticos, sensores solares, giroscópios e rastreadores estelares (Larson e Wertz, 1999).

Os principais atuadores incluem: propulsores, torques magnéticos e rodas de reação (Larson e Wertz, 1999), a quase totalidade destes componentes de controle possui atualmente alguma iniciativa de desenvolvimento no país, seja por instituições governamentais ou por grupos de pesquisa independentes (Republica Brasileira, 2011). A principal exceção são as rodas de reação que praticamente não tem projetos de desenvolvimento em andamento e, no entanto, representam um componente indispensável na realização de manobras, na estabilização e no controle de atitude em três eixos. 
Rodas de reação são dificilmente substituíveis pois apresentam larga faixa de operação em torque (ao contrário de atuadores magnéticos) e são alimentadas pela energia renovável fornecida por painéis solares (ao contrário de propulsores baseados em um estoque finito de combustível) (Ismail e Varatharajoo, 2010). Por estes motivos, rodas de reação estão presentes em praticamente qualquer satélite que apresente requerimentos mínimos de desempenho em atitude.

Uma roda de reação pode ser descrita como um atuador inercial com funcionamento baseado no princípio de conservação do momento angular. A atuação da roda de reação sobre o satélite se realiza por intercâmbio do momento angular, limitado ao eixo de rotação da roda. Devido à grande diferença entre a inércia do satélite e da roda de reação, um controle de atitude com muita precisão é possível com esse sistema.

Rodas de reação são tipicamente constituídas de um motor elétrico, geralmente um motor sem escovas, um mancal e um elemento de inércia. O elemento de inércia e o motor são montados sobre o mancal que deve garantir a precisa rotação em torno de um eixo. O motor e o mancal são considerados os sistemas mais críticos, influenciando diretamente a qualidade da roda de reação e o cumprimento dos requisitos. A velocidade de rotação do sistema é controlada por uma eletrônica de acionamento do motor. Rodas de reação podem ser comandadas de duas maneiras distintas: por rotação ou por torque. Quando comandada por torque, a roda de reação deve ser capaz de estimar o torque útil gerado por ela (o torque efetivo menos as perdas).

Este projeto de pesquisa buscou projetar um mancal magnético que pudesse fazer parte de uma roda de reação para satélites de médio porte. Para tanto, é necessário que o mancal satisfaça os requisitos impostos para uma roda de reação, tais como: mínimo desbalanceamento, baixo consumo, alta velocidade e atrito reduzido.

A Fig.1.1 ilustra um esquema genérico de uma roda de reação. No caso, quatro são os subsistemas: eletrônica de acionamento, motor, mancal e inércia. A eletrônica é responsável pelo controle e pelo acionamento do motor que, por sua vez, possui um 
sensor de velocidade e um de corrente.

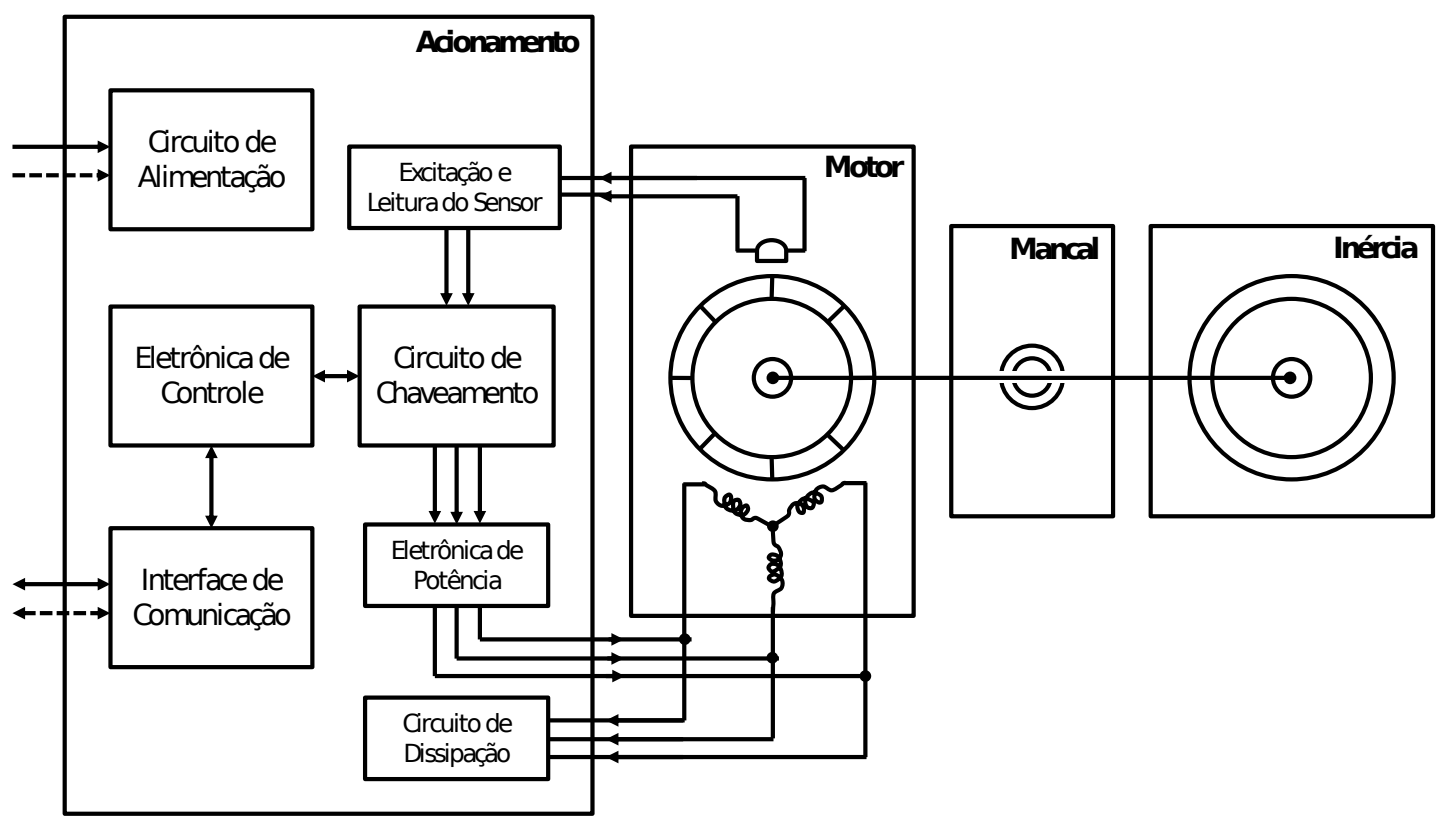

Figura 1.1: Esquema geral de uma roda de reação

O controle de atitude com rodas de reação demanda que esse tipo de atuador opere em toda sua escala de velocidade, inclusive na inversão de seu sentido de rotação (passagem pelo zero), de uma forma estável e controlada. A zona morta, efeito do atrito estático do mancal, deve ser minimizada a fim de se obter um bom funcionamento da roda de reação. A zona morta pode ser compensada (no caso do mancal por rolamento) pela implementação de leis de controle com malhas de velocidade e corrente, além de um estimador de atrito (Carrara, 2010).

O projeto de uma roda de reação começa pelo estudo e definição do momento angular a ser utilizado na roda de reação; essa escolha leva em consideração os distúrbios sofridos pelo satélite e a precisão necessária na missão. Com o momento angular definido, especifica-se a inércia o mancal, e por último projeta-se um motor capaz de girar o conjunto formado pelo mancal e a inércia. 


\subsection{Objetivo}

Essa dissertação acompanha o esforço de projetar um mancal magnético para uma roda de reação que está sendo desenvolvida no Núcleo de Sistemas Eletrônicos Embarcados (NSEE) do Instituto Mauá De Tecnologia (IMT) com apoio do Instituto Nacional De Pesquisas Espaciais (INPE).

O projeto, envolve o desenvolvimento de uma topologia capaz de ser utilizada numa roda de reação para satélites de médio porte, mais especificamente para a plataforma multi missão.

\subsection{Justificativa}

A suspensão do rotor com relação ao estator representa uma parte crítica em rodas de reação (Taniwaki, Shigemune and Ohkami, 2003) devido às consequências de qualquer fricção no movimento relativo entre estes dois componentes. Com efeito, a fricção se traduz não apenas em um maior consumo de potência elétrica como também na introdução de uma zona morta de atuação em torque, bem como na limitação da vida útil da roda de reação devido ao gradual desgaste do mancal.

Uma solução mecânica para a interface entre o rotor e o estator é o mancal por rolamento. Apesar de sua aparente simplicidade, apresenta desafios para a obtenção dos valores máximos de friç̧ão admitidos, em vista das exigências de consumo, controlabilidade e vida útil da roda de reação (Krishnan et al., 2010). No caso de aplicações aerospaciais, a lubrificação do rolamento representa também considerável dificuldade devido à impossibilidade de utilização de lubrificantes tradicionais em condições de baixa ou nenhuma pressão atmosférica, que leva à perda dos componentes voláteis destes lubrificantes e sua consequente degradação. Outra dificuldade se deve à tendência de migração dos lubrificantes na ausência de gravidade, o que costuma ser abordado com estratégias de recaptura ou relubrificação. Sistemas desse tipo apresentam grande 
complexidade e seu comportamento orbital é de difícil validação em laboratório.

As dificuldades associadas ao uso de mancal de rolamento residem também em sua modelagem, consequência da variação de viscosidade do lubrificante em função da temperatura do mancal, o que torna o coeficiente de fricção dependente da velocidade de rotação e das condições térmicas em geral (Carrara e Milani, 2007). O mancal por rolamento apresenta, por outro lado, grande vantagem construtiva devido à compactação do sistema e não necessidade de eletrônica extra para o seu controle.

Para contornar os problemas de lubrificação em baixa pressão, algumas rodas de reação utilizam um sistema hermeticamente selado pressurizado com um gás inerte (Krishnan et al., 2010). Esta solução relaxa os requisitos de lubrificação, porém impõe uma força de arrasto extra na roda e não resolve o problema da migração dos lubrificantes na ausência de gravidade. Uma pesquisa detalhada dos lubrificantes de classe espacial e estratégias de selamento e relubrificação deve ser realizada.

Outra solução é a utilização de um mancal magnético (Bangcheng et al., 2012), que é uma alternativa sem contato mecânico entre o rotor e o estator, pela qual o rotor é mantido suspenso magneticamente. O ganho em confiabilidade e vida útil da roda de reação é considerável (Marble e Tow, 2006), sendo a vida útil basicamente limitada pela durabilidade da eletrônica. A operação sem contato elimina a necessidade de lubrificante e possibilita consequentemente a operação em vácuo, o que se traduz em simplificação nos requisitos da concepção mecânica.

A ausência de fricção faz com que deixe de existir a zona morta de aplicação de torque em baixas velocidades, eliminando não-linearidades da lei de controle, além de possibilitar a diminuição da causa de efeitos de desbalanceamento e vibrações mecânicas. Consequentemente, gera um ganho em simplicidade dos algoritmos e em desempenho do controle de atitude. A contrapartida é a adição de uma malha ou mais de controle para a suspensão eletromagnética. O ganho de eficiência trazido pela ausência de fricção também é contrabalançado, ao menos parcialmente, pelo consumo de potência dos 
atuadores deste tipo de mancal.

\subsection{Revisão bibliográfica}

Estudo iniciais sobre mancais magnéticos são datados do século XIX (Weise e Pinckley, 1989), porém só recentemente começaram a ter grandes aplicações na sociedade. Essas aplicações vão desde motores de alta eficiência até equipamentos médicos. Mancais magnéticos fazem uso extensivo de campos magnéticos e tiveram uma grande evolução quando os ímãs de terras raras tornaram-se acessíveis, possibilitando o aumento da geração de campos magnéticos permanentes (Furlani, 2001).

Mancais magnéticos podem ser classificados em dois grandes grupos: os que utilizam da força de relutância e os que utilizam da força de Lorentz. O primeiro grupo é chamado de mancais magnéticos ativos (em inglês, AMBs) e o segundo são os mancais magnéticos passivos (PMBs) (Schweitzer et al., 2009).

Os AMBs funcionam com um controle ativo de algumas das forças atuantes no mancal a fim de estabilizar o sistema (controle em malha fechada). Já os mancais puramente passivos geram as forças necessárias para estabilizar o rotor apenas via ímãs. Mancais magnéticos puramente passivos (seis graus de liberdade) que utilizam somente ímãs são impossíveis, dado que sempre um dos graus de liberdade torna-se instável (Teorema de Earnshaw's) (Schweitzer et al., 2009, pg. 20).

\subsubsection{Graus de liberdade}

Os mancais magnéticos podem ser classificados pelo número de graus de liberdade controlados ativamente (Schweitzer et al., 2009):

a) Mancal puramente passivo

Este mancal totalmente passivo é formado por um rotor contendo um conjunto de imãs permanentes em disposição de Halbach (Detoni, 2012), o que gera potenci- 
alização do campo magnético adjacente ao rotor. Um conjunto de enrolamentos passivos no estator é excitado por esse campo magnético girante. Na eventualidade de qualquer deslocamento do rotor, o enrolamento reage com o campo magnético, gerado pela atração/repulsão do rotor, ocasionando a volta à posição de equilíbrio. $\mathrm{O}$ sistema é estável a partir de uma velocidade de rotação mínima do rotor (velocidade crítica). O fato desta topologia não funcionar em baixas velocidades angulares a torna pouco adaptada para aplicação em rodas de reação.

b) Mancal ativo num grau de liberdade

Nesse caso, o rotor é levitado em apenas um de seus grau de liberdade, necessitando que os demais graus de liberdade sejam estabilizados externamente (com por exemplo o uso de mancais mecânicos). Trata-se de uma configuração que necessita de uma eletrônica de controle relativamente simples e de baixo consumo de potência.

c) Mancal ativo em dois graus de liberdade

Aqui, o rotor e o estator compõem um circuito magnético em configuração atrativa, em geral com ímãs permanentes no rotor acoplados a um circuito magnético de baixa relutância no estator. O sistema é estável axialmente mas necessita controle ativo na direção radial. Essa configuração resulta num mancal de boa rigidez radial, com arquitetura simplificada e pequenas dimensões, principalmente na direção longitudinal.

d) Mancal ativo em cinco graus de liberdade

Este mancal totalmente ativo é formado por atuadores eletromagnéticos nas duas direções radiais, na direção axial e nos dois modos de rotação radiais. A principal vantagem de sua aplicação em rodas de reação é a possibilidade de atuação em mais de um eixo de rotação, devido à capacidade de manobra do componente de inércia. Trata-se no entanto de um sistema de controle de grande complexidade, com 
consequente redução de confiabilidade.

\subsubsection{Topologias com Aplicação em Rodas de Reação}

Encontram-se na literatura três topologias distintas para utilização de mancais magnéticos em rodas de reação. Os mancais propostos para esse tipo de aplicação possuem, em sua maioria, dois graus de liberdade ativos e fazem uso de ímãs permanentes para a geração de campos magnéticos para minimizar o consumo elétrico ativo do sistema. Em seguida, analisamos os principais pontos desses mancais.

A topologia proposta por Bernus et al. (1998) trabalha com dois graus de liberdades ativos, com ímãs permanentes no rotor e dois estatores: um interno com bobinas para o controle do fluxo magnético no rotor (por consequência na direção radial) e outro externo para estabilização axial que também contribui com a rigidez axial.

Nessa topologia (Fig. 1.2), um fluxo magnético contínuo é gerado no rotor por ímãs permanentes ali instalados, as bobinas no estator interno conseguem gerar campos aditivos e subtrativos no rotor (dependente do sentido da corrente). Se o campo for aditivo, pode-se aumentar a rigidez do eixo longitudinal, caso o campo for subtrativo, consegue-se diminuir sua rigidez, tornando assim mais fácil o deslocamento radial do rotor.

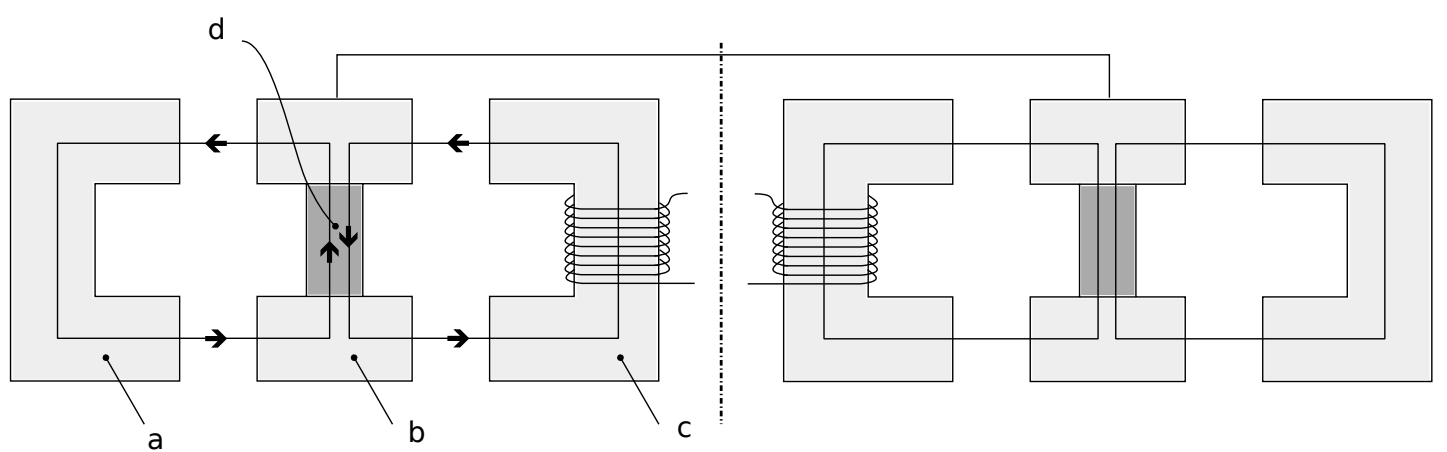

Figura 1.2: Corte da topologia proposta por Bernus et al. (1998) a: estator externo; b: rotor; c: estator interno; d: ímãs permanentes

A topologia proposta por Scharfe et al. (2001) difere por ter somente um estator e 
pelos ímãs permanentes estarem localizados no estator e não no rotor, como ilustrado na Fig. 1.3.

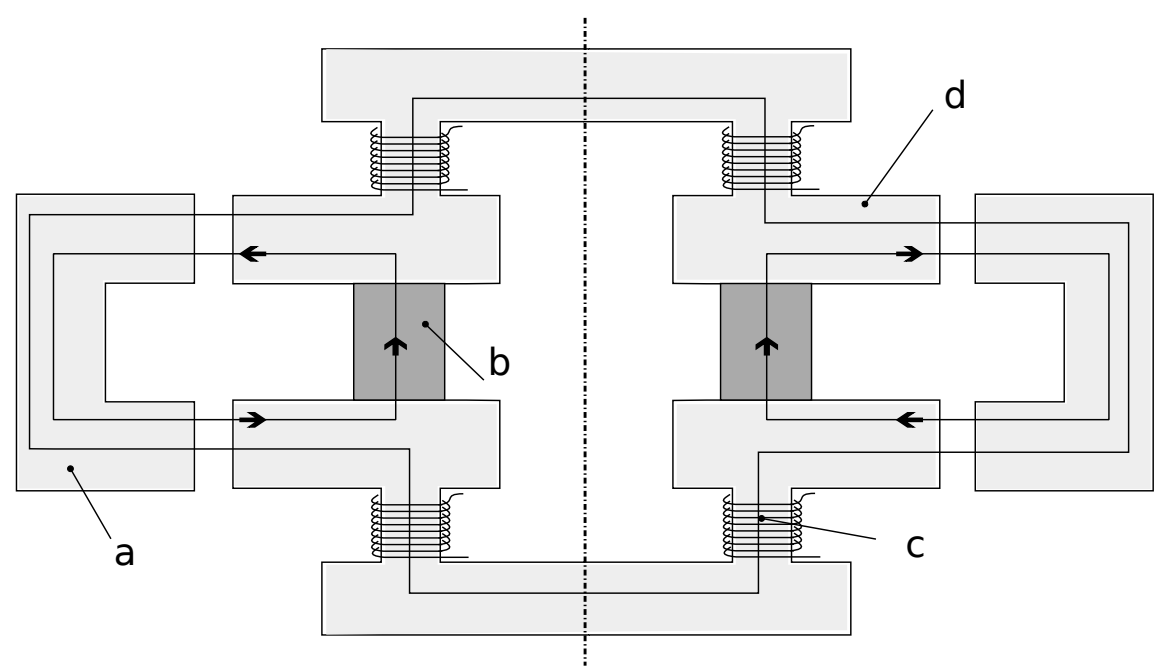

Figura 1.3: Corte da topologia proposta por Scharfe et al. (2001) a: estator externo; b: ímãs; c: bobinas; d: estator interno

Com essa arquitetura é possível utilizar as bobinas tanto para exercer uma força atrativa no rotor quanto para tornar a sua rigidez mais branda, facilitando a atração do rotor. É possível também aumentar a rigidez axial por permitir a inserção um fluxo positivo em ambas as bobinas, esse fluxo soma-se com o fluxo gerado pelos ímãs permanentes.

Mais recentemente, uma nova arquitetura foi proposta por Bangcheng et al. (2012) para ser utilizada em uma roda de reação de um satélite ágil. O rotor é composto de duas partes, uma externa utilizada para estabilizar o mancal na direção axial e outra interna para controle de posição na direção radial. Diferente das outras propostas, essa não utiliza um perfil em "C " para estabilização dos graus de liberdade passivos, mas sim, faz uso de um perfil plano com ímãs permanentes tanto no rotor quanto no estator. Ímãs permanentes também são usados nos polos do mancal; esses criam um fluxo (bias) constante diminuindo a corrente necessária para controlar o rotor.

Os mancais magnéticos descritos anteriormente são únicos na roda de reação, dife- 
rente da topologia utilizada em mancais mecânicos onde utiliza-se dois mancais contrapostos no eixo.

\subsubsection{Modelagem Eletromagnética}

Devido às não linearidades do mancal magnético (por exemplo a sua rigidez em função do deslocamento), a modelagem analítica é de difícil obtenção e uma abordagem por elementos finitos é recomendada (Pilat, 2007). Com esse tipo de análise é possível verificar o acoplamento das forças e momentos envolvidos além das características térmicas do sistema.

Modelos analíticos (Tezuka et al., 2013; Chiba e Fukao, 2005) auxiliam no entendimento e na escolha dos parâmetros construtivos e magnéticos do mancal. A solução de um modelo analítico quando comparada à de um modelo com elementos finitos é computacionalmente mais rápida.

Com o modelo analítico é possível a utilização de métodos de otimização (Wu et al., 2009; Fang et al., 2014) para a obtenção de um mancal com melhores propriedades, dentre elas menor potência, maior rigidez e dimensões dentro das especificações.

\subsubsection{Sensoriamento}

Devido ao controle da posição do rotor em mancais magnéticos, o sensoriamento de sua posição é essencial para o funcionamento do sistema. Duas linhas de sensoriamento são encontradas na literatura: mancais auto sensoriados (Vischer e Bleuler, 1993) e os que utilizam sensores de posição dedicados para esse fim.

Os mancais magnéticos sem sensores (sensorless) utilizam geralmente as bobinas de seus polos para sensoriar a posição do rotor. Diversas técnicas podem ser empregadas (Hofer et al., 2009; Mukhopadhyay, 2005) entre elas: medição da indutância dos polos pela injeção de um sinal com uma portadora de frequência mais elevada ou a medição da força contra-eletromotriz induzida nas bobinas. 
Já os mancais sensoriados utilizam sensores de deslocamentos exclusivos para a medição da posição do rotor e, por consequência, do tamanho do entreferro (Sivadasan, 1996). Os sensores podem ser de dois tipos: capacitivos ou indutivos, dependendo do material construtivo do sistema. Opera-se geralmente com sensores na distribuição diferencial, visando minimizar os efeitos de suas não linearidades.

\subsubsection{Mancais auxiliares}

Mancais auxiliares são importantes em mancais magnéticos, pois são eles que evitam colisões entre as partes fixas e as rotativas em caso de algum tipo de falha. Mancais magnéticos projetados para operar em altas rotações não possuem bom rendimento na inicialização (baixa rotação) e se utilizam dos mancais auxiliares nessa zona até atingirem a sua velocidade de operação. Os mancais auxiliares podem ser compostos por rolamentos esféricos (Sun et al., 2004) ou por elementos sólidos auto-lubrificantes como Teflon.

\subsubsection{Técnicas de controle}

O controle de mancais magnéticos é uma área fértil da engenharia de controle; as não linearidades do sistema tornam os projetos nada triviais.

Técnicas de controle clássicas são utilizadas com bastante frequência em mancais magnéticos. Controle do tipo PID (Tezuka et al., 2013) possui ampla utilização pela sua fácil implementação na forma analógica e consolidada técnica. O controle do tipo feedforward é utilizado em casos onde há o acoplamento entre os graus de liberdade, podendo ser utilizado para o desacoplamento deles. Outras técnicas propostas na literatura situam-se na área de controle multivariável, e fazem uso de controle robusto (Jimenez-Lizafrraga e Alcorta, 2007), controle ótimo (Schuhmann et al., 2012) e controle não linear (Rundell e Drakunov, 1996). 


\subsubsection{Eletrônica}

A eletrônica em sistemas espaciais consiste normalmente de uma parte crucial do sistema, sendo bastante sensível aos efeitos da radiação (Stassinopoulos e Raymond, 1988). Falhas em sensores, por exemplo, representam um dos maiores problemas para o bom funcionamento de sistemas aeroespaciais em seu pleno potencial (Balaban et al., 2009), e estão muitas vezes relacionadas ao cancelamento de missões devido ao mau funcionamento de sistemas. Além dos sensores, memórias podem ter seus dados alterados devido ao impacto de uma partícula de alta energia, podendo causar falha crítica no sistema.

\subsection{Metodologia}

A metodologia adotada neste trabalho envolve a utilização de simulações em elementos finitos para o desenvolvimento das partes magnéticas do mancal, uma modelagem fenomenológica foi feita para a realização da otimização dos parâmetros físicos do sistema.

O desenvolvimento do projeto foi executado como ilustrado na Fig. 1.4, onde primeiramente as especificações de projeto foram levantadas e uma topologia de mancal proposta com base no levantamento bibliográfico.

Um protótipo foi construído a fim de avaliar a topologia proposta, verificou-se com ele que as premissas de estabilidade e força foram alcançadas. A construção desse protótipo foi realizada na oficina mecânica da Escola de Engenharia Mauá (EEM). Devido a ausência de fomento, a prototipagem não pode ser efetuada seguindo todas as especificações de rigor mecânico, o que gerou falhas na montagem.

O material utilizado também foi influenciado por esse fator, utilizou-se no caso o aço 1020 para as partes magnéticas (de amplo uso comercial) e alumínio para as partes não magnéticas. 
Na etapa de otimização, dividiu-se o projeto em duas partes: na primeira considerouse somente a parte passiva (estator externo e rotor) até que um conjunto com rigidez suficiente na direção axial e com menor força de atração na direção radial fosse atingido. Com esses valores buscou-se um estator interno capaz de exercer força de atração suficiente no rotor para estabilizá-lo em seu ponto de operação.

Com um modelo em elementos finitos (FEM) calculou-se com exatidão os parâmetros magnéticos do mancal proposto a serem utilizados na modelagem dinâmica do rotor.

Com o modelo dinâmico, um controlador capaz de estabilizar o rotor em seu ponto de operação foi proposto, com ele, mostrou-se a viabilidade de controlar o mancal dentro das restrições de potência propostas.

A Fig. 1.4 mostra o fluxo do desenvolvimento do mancal.

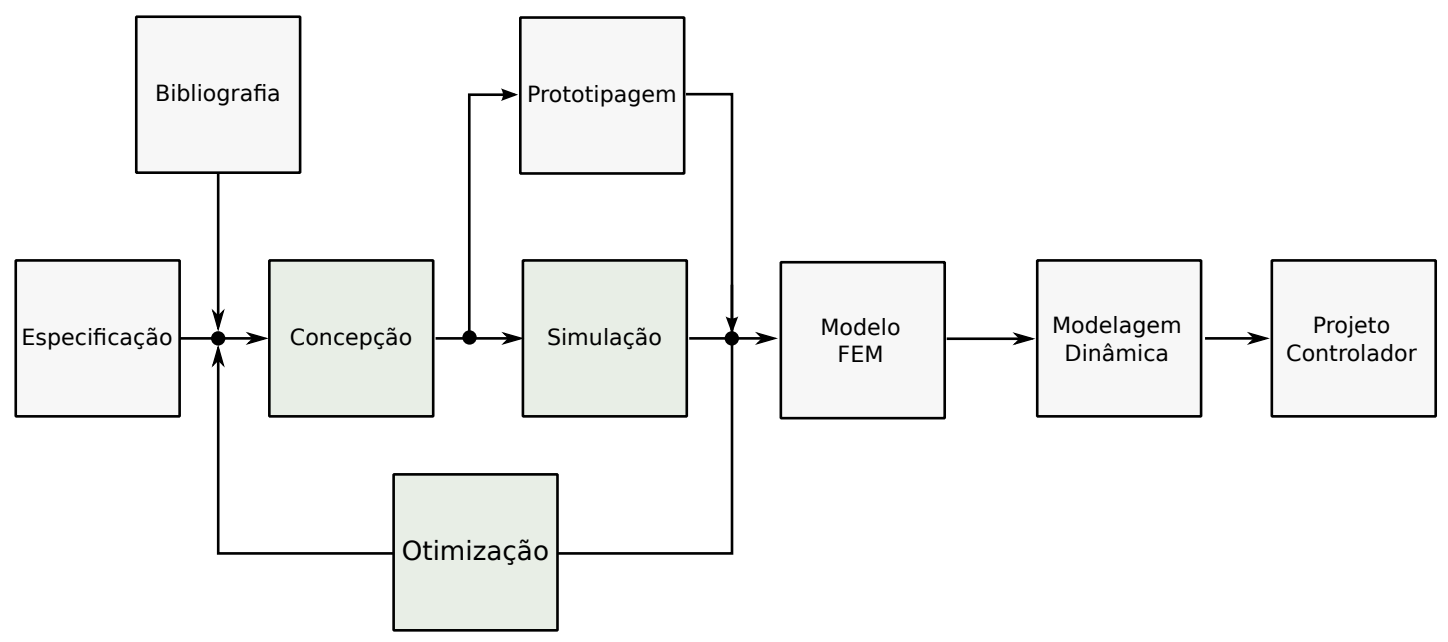

Figura 1.4: Fluxo de desenvolvimento

\subsection{Sumário Estruturado}

No segundo capítulo, o mancal magnético proposto foi descrito e suas propriedades construtivas apresentadas. Nele podemos verificar conceitualmente todos os componentes que constituem o sistema proposto. 
O capítulo 3 apresenta um modelo não linear para representar a interação entre o estator externo e o rotor. Esse conjunto é responsável pela estabilização do rotor nos graus de liberdades passivamente estáveis. No modelo analítico foi aplicada uma otimização nos parâmetros construtivos do mancal visando encontrar um mancal compacto e com boa rigidez passiva. A partir de um modelo em elementos finitos obteve-se as relações de força por deslocamento.

No capítulo 4 desta dissertação, um modelo fenomenológico que modela a interação entre o estator interno e o rotor está apresentado. Similarmente ao capítulo anterior, foi aplicada uma otimização visando a obtenção dos parâmetros construtivos do estator interno. Com o modelo em elementos finitos, chega-se às equações de força resultante dessa otimização do mancal.

No quinto capítulo, a partir das dimensões e das equações de forças definidas anteriormente, um modelo dinâmico para o rotor está apresentado. Esse modelo foi utilizado para o projeto de uma malha de controle capaz de estabilizar o rotor em seu ponto de operação.

O último capítulo constitui-se de uma revisão do desenvolvimento da dissertação e apresentação de considerações finais sobre o projeto. 


\section{Capítulo 2}

\section{Mancal magnético}

O mancal magnético proposto deve satisfazer as especificações da Sec. 2.1, onde se deseja atingir os requisitos de uma roda de reação para um satélite de classe II, baseado nos dados da plataforma multimissão (PMM) do INPE (Veloso e Rollemberg, 2009), possibilitando que o satélite possa rejeitar pertubações orbitais e executar manobras de posicionamento.

\subsection{Especificações}

O acionamento da roda de reação deve ser possível em ambos os sentidos de rotação e com a mesma eficiência. Requer também que o eixo de rotação tenha inclinação menor do que 0,1 grau com relação à superfície de fixação da roda. A precisão de alinhamento é necessária para a adequada atuação da roda de reação no eixo sob controle.

A roda de reação deve ter dimensões limitadas em 250mm de diâmetro por 100mm de altura com massa total que não deve exceder $4 \mathrm{~kg}$. Na concepção das partes construtivas da roda de reação foi considerada a necessidade de operação contínua por longos períodos de tempo (em torno de quatro anos).

A Tab. 2.1 é um resumo das especificações da roda de reação, nela estão as ca- 
racterísticas mecânicas e elétricas de uma roda de reação especificada pelo Instituto Nacional de Pesquisas Espaciais (INPE).

\begin{tabular}{lccl} 
Parâmetro & \multicolumn{3}{c}{ Valor } \\
\hline \hline Torque & nominal & 0,1 & {$[\mathrm{Nm}]$} \\
Momento angular & nominal & 10 & {$[\mathrm{Nms}]$} \\
Rotação & máxima & \pm 4000 & {$[\mathrm{rpm}]$} \\
Oscilação do torque & máximo & 10 & {$[\%]$} \\
Torque de fricção do mancal & máximo & 0,01 & {$[\mathrm{Nm}]$} \\
Desbalanceamento residual & estático & 0,2 & {$[\mathrm{~g} . \mathrm{cm}]$} \\
& dinâmico & 20 & {$\left[\mathrm{~g} . \mathrm{cm}^{2}\right]$} \\
Consumo de potência & mínima & 3 & {$[\mathrm{~W}]$} \\
& nominal & 30 & {$[\mathrm{~W}]$} \\
Tensão de alimentação & máxima & 100 & {$[\mathrm{~W}]$} \\
& nominal & 20 à 40 & {$[\mathrm{~V}]$}
\end{tabular}

Tabela 2.1: Especificações de requisito da roda de reação

A seguir um explicativo de cada especificação :

Torque: A magnitude do torque disponibilizado pela roda de reação determina sua capacidade de atuação em vista de perturbações, e consequentemente o desempenho do sistema controle de atitude.

Momento Angular: A faixa de operação em momento angular determina a capacidade de manobra e o período de operação autônoma das rodas.

Velocidade de Rotação: A velocidade máxima de rotação especificada atende a um compromisso de de minimização da massa e das dimensões para o momento máximo desejado, bem como à limitação do jitter de atitude devido ao desbalanceamento do componente de inércia.

Oscilação de Torque: A oscilação de torque é indesejável por representar uma limitação para o desempenho do controle de atitude. 
Torque de friç̧ão: A limitação de torque de fricção visa a minimização de perdas, com impacto na eficiência da roda de reação.

Desbalanceamento residual: Implica em uma oscilação no eixo de rotação e por consequência gera distúrbios no satélite.

Tensão de Alimentação: Níveis de alimentação comummente encontrados em satélites.

\subsection{Visão Geral}

O mancal magnético proposto neste trabalho é, em parte, uma junção das topologias propostas por Bernus et al. (1998) e Scharfe et al. (2001). O mancal possui quatro graus de liberdade passivamente estáveis: sendo eles seus deslocamentos angulares (tilt, roll, pitch) e seu deslocamento na direção axial, os outros dois graus de liberdade (os deslocamentos radiais) são estabilizados ativamente. O torque imposto para a rotação do rotor não é abordado neste trabalho mas será desenvolvido por um motor elétrico de corrente contínua sem escovas, instalado no interior do mancal.

O circuito magnético do mancal é composto por dois estatores: um interno ao rotor, outro externo. O estator externo é responsável pela estabilização dos graus de liberdade passivos, já o interno por possibilitar o controle das posições radiais. Optou-se por instalar os ímãs no estator externo visando um maior fluxo magnético nos modos passivamente estáveis do mancal, além de visar o melhor balanceamento do rotor (se comparada com a instalação dos ímãs no rotor). A Fig. 2.1 ilustra o mancal proposto. O rotor é a parte móvel do mancal e onde é fixada a parte móvel do motor. Adotouse uma geometria plana visando uma melhor rigidez nos modos instáveis do mancal, possibilitando também a montagem em modo painel. Optou-se por um mancal externo ao motor para conseguir uma rigidez dentro dos limites de massa e dimensões e que 
atingisse as especificações da roda de reação.

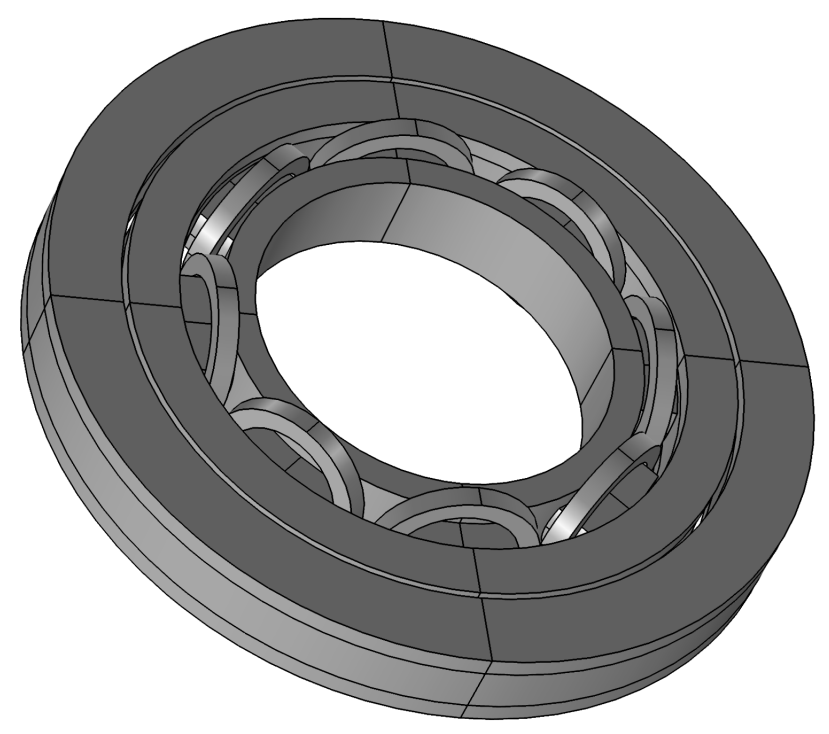

Figura 2.1: Perspectiva das partes magnéticas do mancal

A Fig. 2.2 e a Fig. 2.3 ilustram consecutivamente os cortes axial e radial do mancal proposto. Verifica-se que os ímãs permanentes estão localizados no estator externo, criando um fluxo magnético que circula pelo rotor e estabiliza o eixo axial.

Mancais magnéticos podem ser projetados para usar forças magnéticas atrativas ou repulsivas. Uma melhor relação massa/ rigidez pode ser alcançada pela utilização de forças magnéticas atrativas, e este é o papel das bobinas localizadas no estator interno. Oito núcleos são utilizados para exercer força de atração suficiente no rotor para mover da posição de equilíbrio (rotor batido) e estabilizar no ponto de operação.

Um batente foi projetado para evitar que as partes magnéticas (metálicas) se choquem em caso de falha na malha de controle ou em situações em que o sistema encontrase desligado. O batente limita a excursão máxima do rotor em seus graus de liberdade: axial, radial e tilt. O batente não interfere no circuito magnético do sistema e está localizado no estator externo. Toda parte fixa do sistema está solidária em uma base 


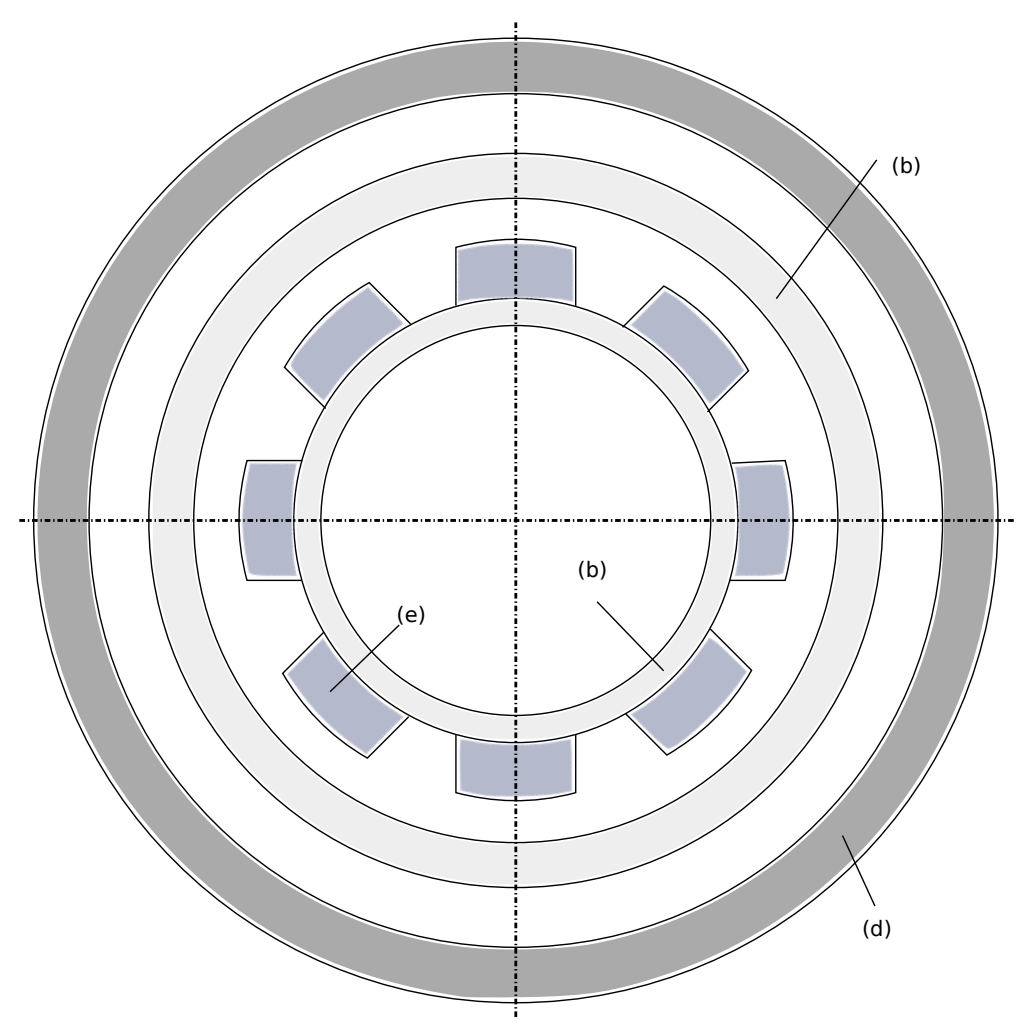

Figura 2.2: Corte radial ilustrativo do mancal magnético. Onde: b) rotor, c) estator interno, d) ímã permanente, e) bobinas

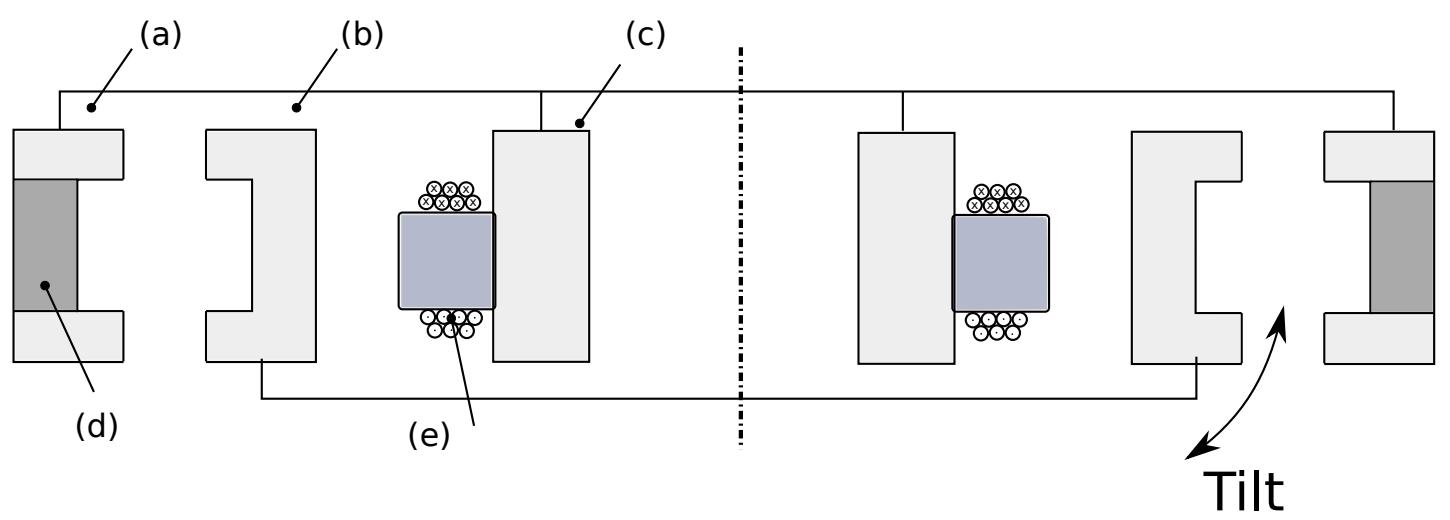

Figura 2.3: Corte ilustrativo do mancal magnético. Onde: a) estator externo, b) rotor, c) estator interno, d) ímã permanente, e) bobinas

também não magnética.

Uma eletrônica de acionamento, sensoriamento e processamento foi alocada na parte inferior da base, tornando o sistema compacto. A eletrônica possui drivers para controle 
das correntes nas bobinas e também um sistema de sensoriamento para medir a posição do rotor. Um sistema microprocessado foi proposto para realizar o controle e gestão do sistema.

\subsection{Estator externo}

O estator externo, responsável pela estabilização dos graus de liberdade passivamente estáveis, é formado por três partes : ferro topo, ímãs, ferro base. A combinação dessas partes faz com que o estator tenha uma secção em formato de C. Os ferros (topo e base) servem para guiar o campo magnético através do gap e pelo rotor.

O circuíto magnético de uma secção do estator externo é ilustrado na Fig. 2.4. Verificamos que o fluxo magnético gerado pelo ímã permanente busca o caminho com menor relutância para fechar o circuito magnético. Esse caminho ocorre pelos ferros do estator externo, passando pelo entreferro e pelo rotor.
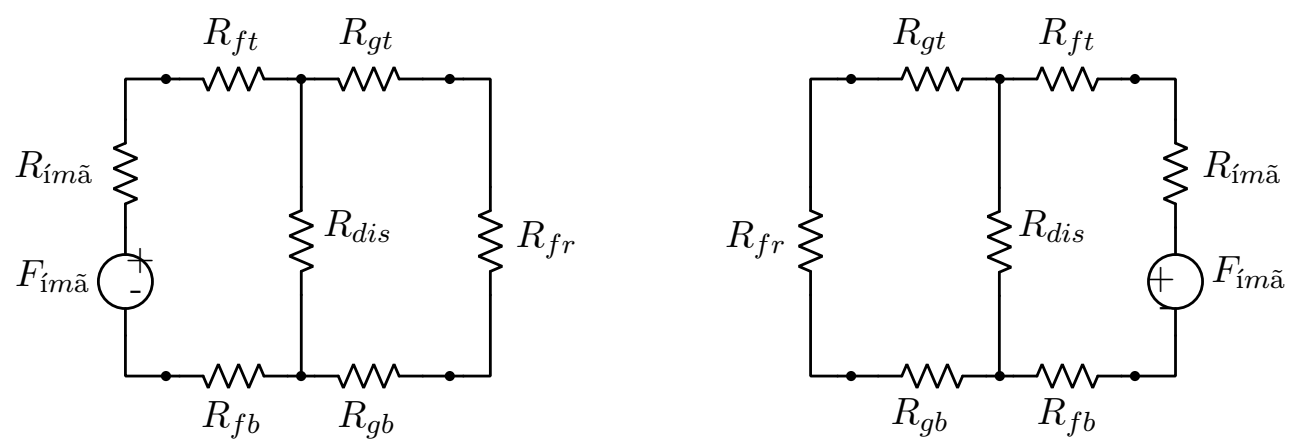

Figura 2.4: Circuíto magnético do estator externo

Podemos identificar neste circuito seis principais relutâncias, sendo elas :

- $R_{\text {ímã }}$ : Relutância do ímã permanente

- $R_{\text {disp }}$ : Relutância de dispersão

- $R_{f t}$ : Relutância devido ao ferro topo

- $R_{g t}$ : Relutância do entreferro superior 
- $R_{f b}$ : Relutância devido ao ferro base

- $R_{g b}$ : Relutância do entreferro inferior

Além das relutâncias, tem-se como fonte geradora de campo magnético o ímã localizado entre os ferros: $F_{i m a}$. Devido ao fluxo magnético permanente o rotor sofre atração em ambos os lados, no ponto de equilíbrio, ou seja, com um entreferro simétrico em ambos os lados, a força resultante tenderia a ser nula e o rotor permaneceria em equilíbrio no ponto de operação.

Esse modo de operação é chamado diferencial e possibilita que a força resultante no rotor devido aos ímãs permanentes torne-se linear. Para tanto, projetou-se o estator externo do mancal para trabalhar sempre com o ferro saturado. Na saturação o valor do campo magnético torna-se praticamente constante para pequenas variações no comprimento do entreferro.

Com isso, o fator da força que é proporcional ao quadrado do campo magnético torna-se praticamente constante, obtendo um força de atração radial no rotor linear com o deslocamento.

Além da linearização obtêm-se um aumento na rigidez axial sem um grande aumento na rigidez radial, o que exigiria uma maior energia da parte ativa para estabilizar o rotor em seu ponto de operação.

No caso de um deslocamento axial ocorre um aumento no comprimento do entreferro e, por consequência, em sua relutância $\left(R_{g}\right)$, essa condição foge da zona de menor relutância gerando uma força restaurativa no rotor para restabelecer um circuito com menor relutância magnética.

A Fig. 2.5 ilustra as forças atuantes no rotor em dois cenários diferentes, na primeira (a) com o rotor no ponto de equilíbrio (com o mesmo entreferro ao longo de toda circunferência) e em (b) com o rotor deslocado axialmente. Verificou-se nesse caso que a resultante da força não é nula mas sim possui uma componente em y. Essa componente 
é a responsável pela estabilização dos graus de liberdade passivos.
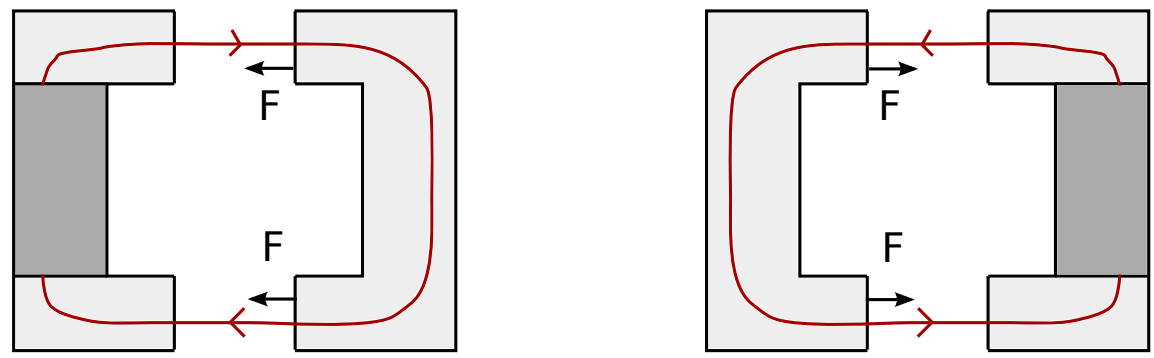

(a) rotor no ponto de equílibro
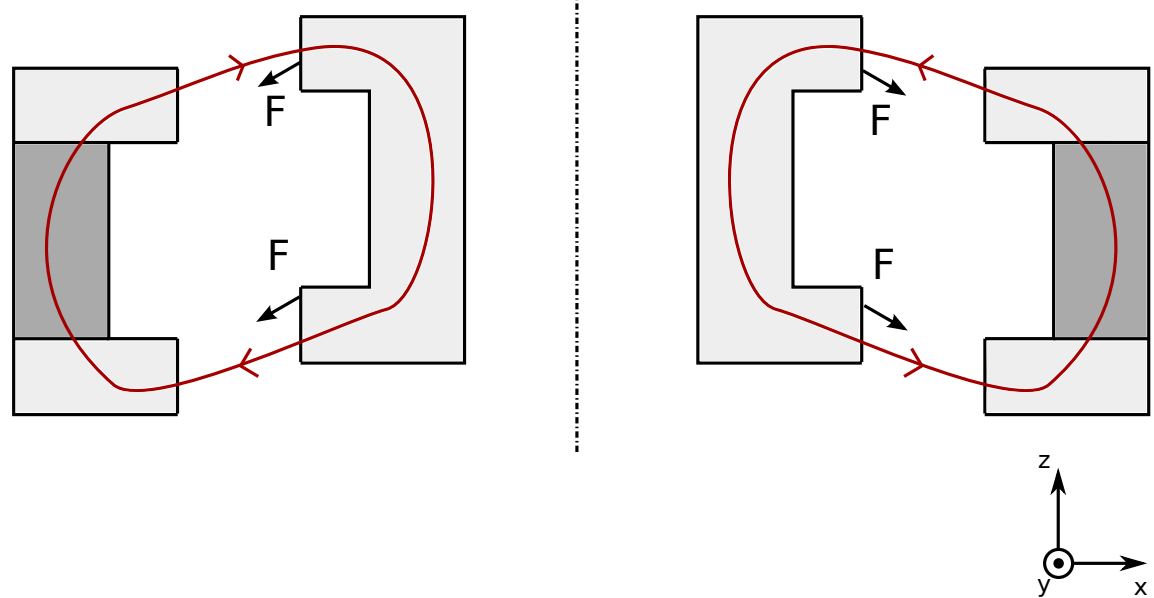

(b) rotor transladado axialmente

Figura 2.5: Fluxo magnético no estator externo e rotor

O circuito passivo deve possuir rigidez axial suficiente para manter o rotor alinhado em ambientes com gravidade (para validação em solo) e rigidez radial menor para um baixo gasto energético do circuito ativo na estabilização do rotor.

A estabilidade de inclinação do rotor é garantida pela topologia plana, que prioriza o deslocamento axial ao radial para movimentos angulares. Com isso, uma pequena inclinação causa um grande deslocamento no eixo z e um pequeno deslocamento nos eixos x e y, gerando um torque restaurativo.

Caso o mancal não fosse projetado com esse ideal, uma inclinação causaria uma aproximação cruzada dos ferros (rotor e estator externo) tornando o mancal instável 
ao tilt.

\subsection{Rotor}

O rotor foi projetado com perfil em $\mathrm{C}$ e sofre tanto a força de atração do estator externo quanto a do interno, porém com campos em diferentes orientações. O rotor é projetado para que seu ferro trabalhe na zona de não saturação; a saturação nesse caso é indesejada pois limitaria o fluxo total através dos circuitos magnéticos e também resultaria, quando em rotação, em uma região de aquecimento e frenagem.

O rotor do mancal magnético deve ser projetado para suportar a fixação do rotor do motor sem escovas assim como a inércia da roda de reação.

\subsection{Estator interno}

O estator interno é formado por oito polos distribuídos homogeneamente a cada 45 graus e interligados por um anel de circulação interno. Os polos funcionam como atuadores (eletroímãs) para a estabilização do rotor no eixo radial (x, z); cada polo é formado por um núcleo. Uma vista em corte de meio mancal é ilustrada na Fig. 2.6.

O estator interno foi concebido para atuar sempre com três polos ativos por eixo de atuação; essa abordagem faz com que o fluxo do campo magnético que percorre o rotor seja maximizado no eixo onde se deseja realizar a atração. A Fig. 2.7 mostra o caminho do fluxo que flui pelo rotor quando o estator interno opera com três de seus polos ativos: $(\mathrm{A}),(\mathrm{B}),(\mathrm{C})$. Os polos $(\mathrm{A})$ e $(\mathrm{C})$ nesse exemplo trabalham com polaridade inversa ao (B) para forçar que o fluxo feche na maior parte por (B) e não por outros polos, maximizando assim a força de atração $F_{B}$.

A corrente aplicada nos polos (A) e (C) é por definição do projeto a metade da corrente no polo principal (B). Isso é feito para evitar que o polo (B) opere com um valor elevado do módulo do campo magnético, já que o campo que o atravessa é composto 


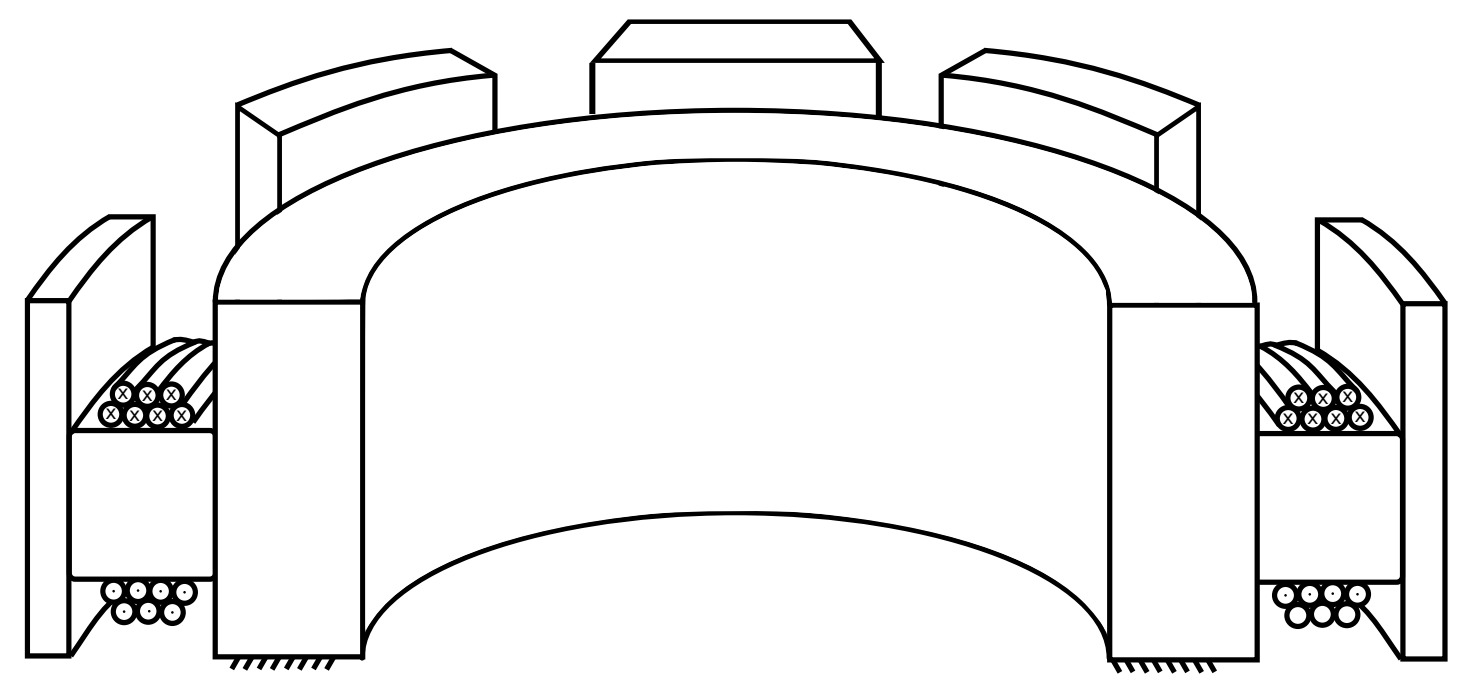

Figura 2.6: Corte em perspectiva do estator interno

pela totalidade do induzido em sua bobina mais a parte referente aos campos de (A) e (C).

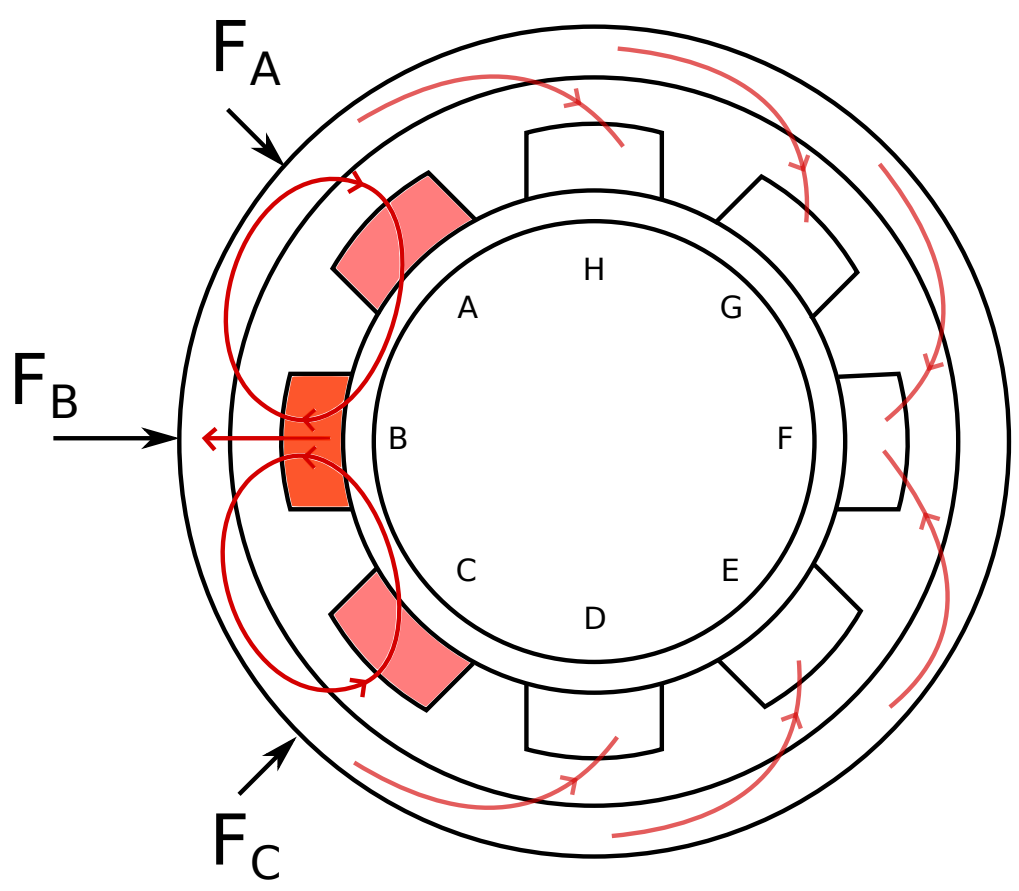

Figura 2.7: Fluxo magnético

As forças geradas $F_{A}$ e $F_{C}$ possuem componentes em x e y; as componentes y são 
de mesma intensidade e se cancelam, restando uma componente aditiva em x. As forças resultantes são portanto:

$$
\begin{aligned}
& F_{x}=F_{B}+F_{A x}+F_{C x} \\
& F_{y}=0=F_{C y}-F_{A y}
\end{aligned}
$$

Nesse modo de operação pode-se gerar forças exclusiva em apenas um dos eixos $(\mathrm{x}, \mathrm{y})$. É possível também atuar simultaneamente nos dois eixos, para isso basta induzir da mesma maneira um novo campo em $(\mathrm{H})$ e $(\mathrm{G})$. Desse modo, o campo total no núcleo da bobina (A) será equivalente ao dos polos primários. A Fig. 2.8 ilustra o campo magnético e as forças resultantes geradas no caso da atuação simultânea.

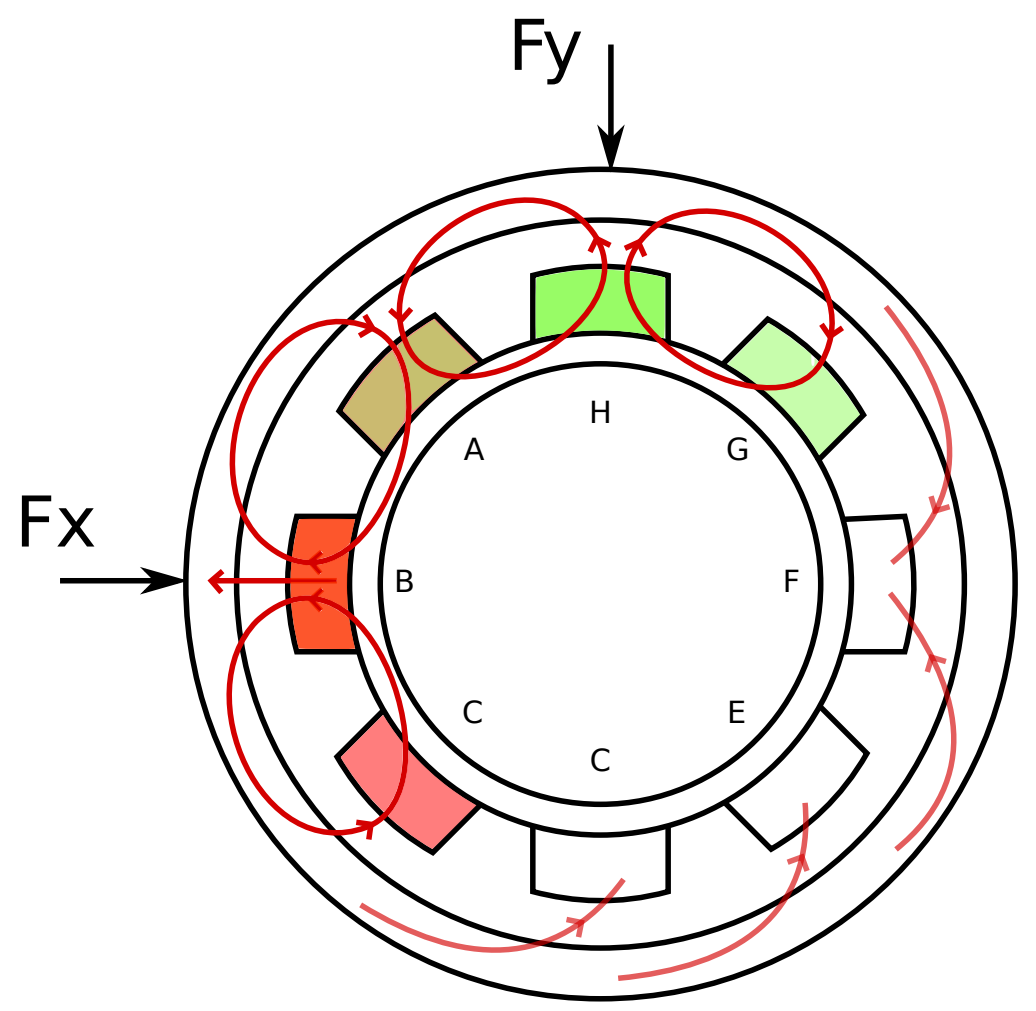

Figura 2.8: Fluxo magnético 
O circuito magnético entre o estator interno e o rotor pode ser visto na Fig. 2.9. Verifica-se que o circuito é formado de quatro principais elementos: a bobina, fonte geradora de campo magnético (c), a relutância do entreferro, que depende da distância entre os polos e o rotor (b), as relutâncias do ferro do rotor (a) e do ferro do anel de retorno (d).

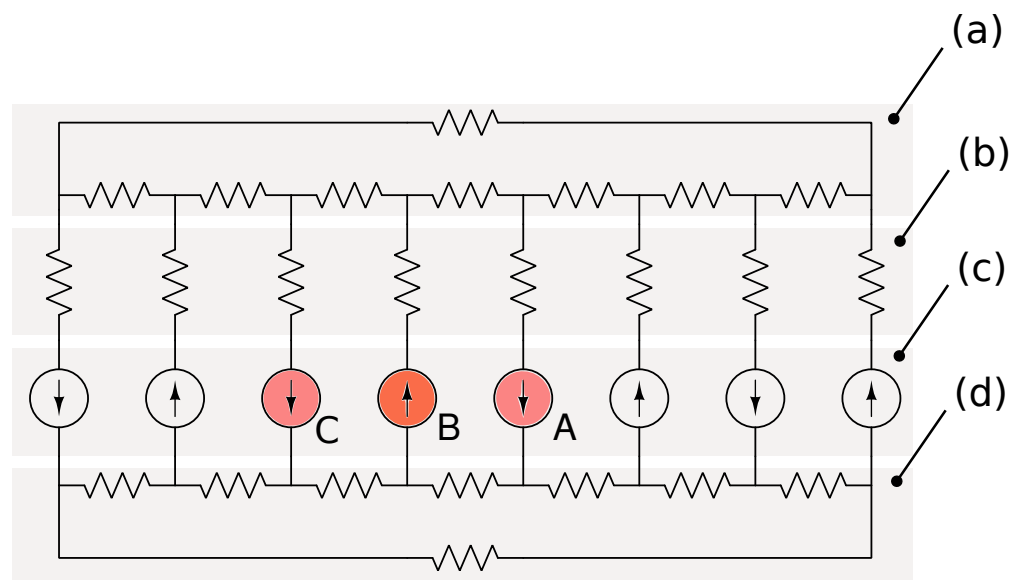

Figura 2.9: Circuito eletromagnético estator interno e rotor: (a) relutâncias do rotor, (b) relutâncias do entreferro, (c)

Dois tipos de acionamento e embobinamento podem ser realizados para a implementação do atuador. O primeiro considera independência de cada polo, possuindo uma eletrônica exclusiva para o seu acionamento. O segundo, envolve a criação de uma única bobina por atuador, similar aos polos de um motor elétrico onde o mesmo fio é compartilhado entre o polo primário e os polos secundários, resultando em uma bobina de maior resistência e indutância.

A vantagem da escolha do segundo método seria a simplificação da eletrônica já que seriam necessárias apenas quatro eletrônicas de potência para a atuação, porém implicaria em uma dinâmica mais lenta do atuador visto que as indutâncias seriam associadas em série.

Escolheu-se, neste projeto, trabalhar com eletrônicas de acionamento independente para cada polo, privilegiando assim um atuador com dinâmica mais rápida. Além da 
dinâmica, possibilita-se dessa maneira que futuros controladores atuem não só nos eixos principais $(\mathrm{x}, \mathrm{y})$ (duas entradas) mas também podendo atuar na diagonal (quatro entradas).

\subsection{Batente}

O batente é necessário por duas razões principais: evitar que, caso haja uma falha na estabilização do rotor, as partes metálicas colidam, e também limitar o tamanho máximo do entreferro, limitando por consequência a força de atração máxima que é exercida sobre o rotor. Essa é necessária para a situação em que o rotor encontra-se mais afastado do ponto de operação, sem o limite do batente o entreferro se tornaria grande o que exigiria uma potência maior das bobinas para estabilizá-lo no ponto de operação. Além de limitar a máxima translação radial, o batente é responsável por limitar também a translação axial e sua inclinação (tilt).

A Fig. 2.10 é uma ilustração do batente proposto para o mancal magnético. Este é composto de duas partes: (a) responsável por limitar o entreferro máximo entre o rotor e o estator externo; (b) flange para limitar a inclinação do rotor. Encontra-se na literatura projetos de mancais magnéticos com rolamentos. Essa escolha seria inadequada para o projeto já que a proposta é a aproximação de um projeto espacializável e a incorporação do rolamento demandaria um projeto específico.

Optou-se por instalar o batente no estator externo por duas razões distintas: facilidade na montagem, pois é o local que possui maior entreferro (portanto espaço) e também para servir de fixação para unir os ímãs e os ferros do estator externo.

O batente deve ser rígido o suficiente para suportar possíveis impactos do rotor. Será visto no Cap. 5 que essas forças são da ordem de centenas de Newtons. A utilização de Nylon ou Teflon na construção do batente é aconselhável (Schweitzer et al., 2009, Cap. 13) devido às suas propriedades de lubrificação a seco e absorção a impacto. 


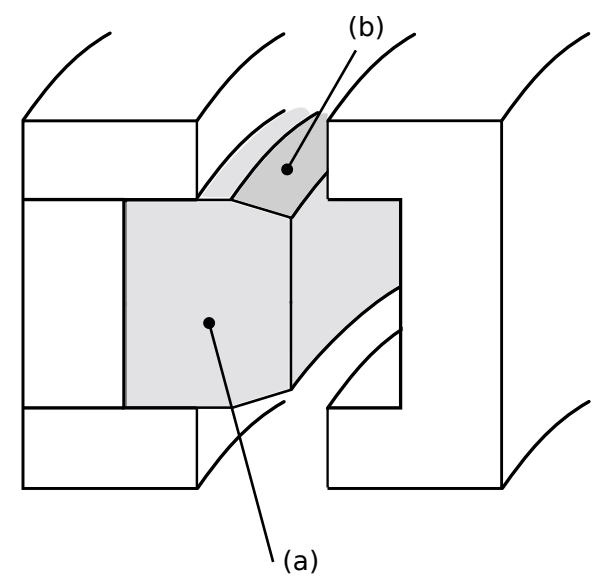

Figura 2.10: Ilustração do batente proposto

\subsection{Base}

As partes não móveis do mancal são fixas em uma base de propriedade não magnéticas (alumínio), a base serve para alinhar as partes do mancal e ao mesmo tempo possibilita a movimentação do rotor na direção axial e radial (dentro das especificações de oscilação).

\subsection{Dimensões}

Ao longo do desenvolvimento da dissertação, as nomenclaturas a seguir foram utilizadas para descrever as dimensões do mancal proposto. As nomenclaturas são esclarecidas na Fig. 2.11 e na Tabela 2.2. 


$\begin{array}{cl}\text { Símbolo } & \text { Descritivo } \\ h_{f e e} & \text { Altura do ferro estator externo } \\ w_{f e e} & \text { Largura do ferro estator externo } \\ h_{m} & \text { Altura do ímã } \\ w_{m} & \text { Largura do ímã } \\ g_{n e} & \text { Entreferro nominal externo } \\ w_{f r} & \text { Largura do ferro rotor } \\ g_{n i} & \text { Entreferro nominal interno } \\ h_{n} & \text { Altura do polo da bobina } \\ w_{n} & \text { Largura do polo da bobina } \\ w_{f e i} & \text { Largura do ferro estator interno } \\ h_{f e i} & \text { Altura do ferro estator interno } \\ r_{e e i} & \text { Raio do polo estator externo } \\ r_{r e} & \text { Raio do polo do ferro rotor } \\ r_{n} & \text { Raio do polo da bobina } \\ r_{e i} & \text { Raio do ferro estator interno }\end{array}$

Tabela 2.2: Símbolos utilizados na descrição do mancal

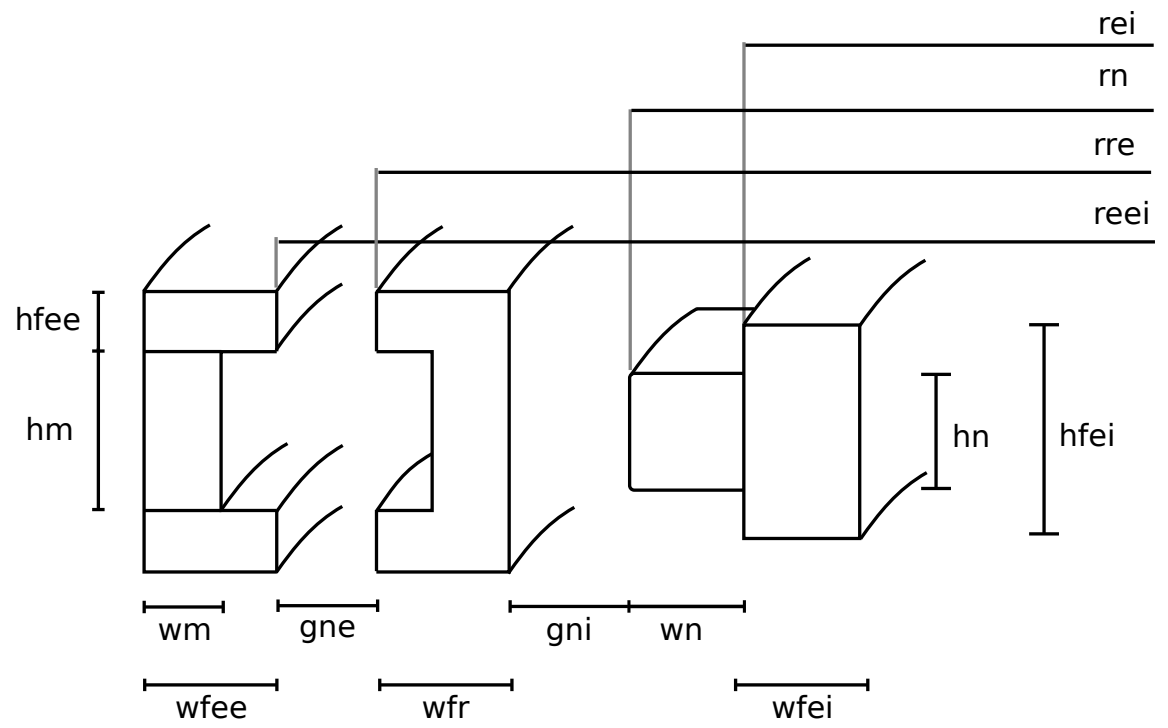

Figura 2.11

\subsection{Modelo em Elementos Finitos}

Foi utilizado como ferramenta de modelagem o Software de elementos finitos e multifísica Comsol. Nas simulações, foram utilizados a curva de histerese do Aço 1020 , as simulações foram realizadas com um sólido tridimensional e a análise realizada foi a 
estacionária. A Fig. 2.12 ilustra a malha utilizada na execução das simulações com um número aproximado de 19000 elementos.

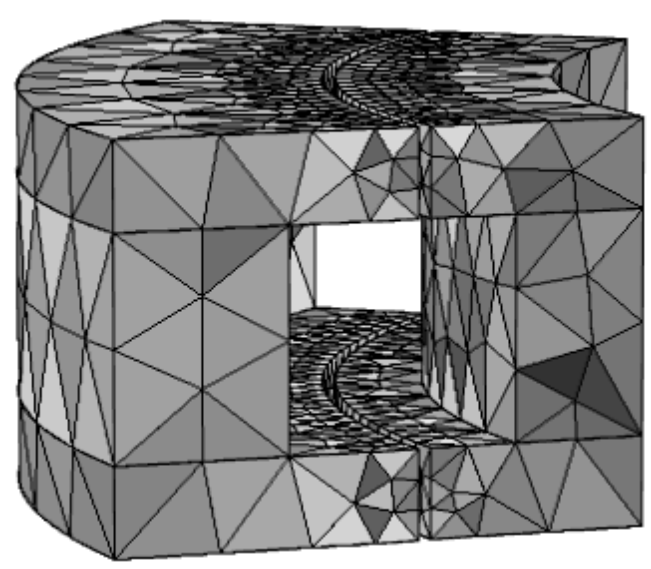

Figura 2.12: Modelo Comsol do circuito passivo Malha utilizada nos cálculos

Nas simulações em elementos finitos, o modelo criado utiliza físicas distintas para os diversos elementos do mancal. No caso dos ferros, aplicou-se a lei de Ampère com a relação BH interpolada de uma tabela (MagWeb, 2015). Nos componentes compostos por ar, a relação utilizada foi a linear $B=\mu_{0} H$.

Na simulação do ímã, utilizou-se a relação de magnetização $B=\mu_{0}(H+M)$ onde M é a magnetização do meio em A/m. Para as bobinas, o material utilizado foi o cobre e a equação para a densidade de corrente $(\mathrm{J})$ aplicada foi: $J=\frac{N I}{A}$, onde: $N$ é o número de espiras, $I$ a corrente total aplicada na bobina e $A$ a área da secção da bobina.

Optou-se por trabalhar com o mancal em três dimensões para a obtenção de um modelo de forças e campos magnéticos mais precisos, porém, em contra partida, o tempo para convergência dos resultados implicou em uma simulação relativamente demorada (10 minutos) em um computador com processador Intel i7 e 16G de memória volátil (RAM). 


\subsection{Prototipagem}

Para a prototipagem do mancal foi necessário a criação de nove diferentes peças que possibilitassem a montagem do sistema. A proposta de montagem visou minimizar a influência no circuito magnético que alteraria o comportamento das forças no rotor mas, ao mesmo tempo, buscou-se um sistema simétrico e robusto. A Fig. 2.13 é um corte da estrutura proposta, verificou-se que o estator interno (RW-M-EI) é formado por uma única peça, enquanto o rotor e o estator externo são fragmentados em mais de uma parte.

A Tab. 2.3 possui a descrição e nomenclatura das partes propostas para a prototipagem do mancal magnético.

\begin{tabular}{ll} 
Nomenclatura & Descrição \\
\hline RW-M-BA & Base do mancal \\
RW-M-C & Casca externa \\
RW-M-EEB & Estator externo base \\
RW-M-EET & Estator externo topo \\
RW-M-BT & Batente \\
RW-M-RFB & Rotor ferro base \\
RW-M-RFT & Rotor ferro topo \\
RW-M-RN & Rotor núcleo \\
RW-M-EI & Estator interno \\
RW-M-IM & Imãs
\end{tabular}

Tabela 2.3: Nomenclatura partes mancal

A não utilização de materiais laminados propicia a aparição de correntes parasitas de Foucault no circuito magnético, quando exposto a correntes variantes no tempo. Essas correntes induzidas causam uma redução na força eletromagnética e aquecem o material, alterando a relação corrente/força utilizada como parâmetro para o projeto da lei de controle. Minimizar as correntes induzidas tornam o sistema mais eficiente porém a construção de um protótipo laminado é mecanicamente difícil. Outra solução é a utilização de soft iron (Boglietti e Cavagnino, 2003), que possui propriedades que limitam a criação de corrente induzida. Em contrapartida, esses materiais normalmente 
apresentam menor permeabilidade magnética e menor valor do campo magnético para atingir a saturação (Han et al., 2013). O material escolhido para os circuitos magnéticos foi o Aço 1020 e para as partes não magnéticas utilizou-se o alumínio.

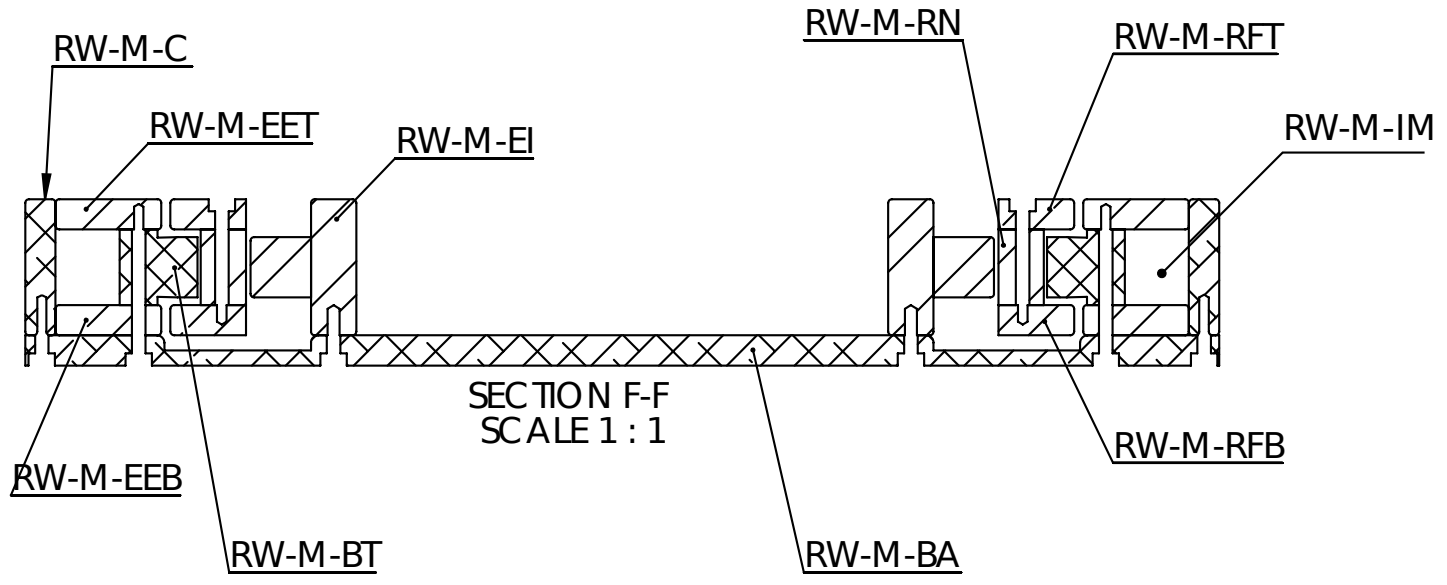

Figura 2.13: Partes do mancal

A escolha da localização e dos tipos de parafuso (magnético, não magnético) foi uma decisão de projeto, optou-se por uma localização que minimizasse a influência no circuito magnético, no caso do estator interno e utilizou-se parafusos com materiais magnéticos alinhados com os polos. Verificou-se que essa região é a que menos impacta nos campos magnéticos (analisado via elementos finitos).

No caso da fixação do estator externo, utilizou-se parafusos não magnéticos, caso contrário seriam um caminho não desejado para as linhas de campo. As partes do rotor foram montadas com parafusos magnéticos.

A prototipagem foi realizada para a verificação da arquitetura proposta analisando as estabilidades passivas e as demais forças envolvidas. Esse protótipo foi construído a partir de um estudo inicial e não possui as dimensões otimizadas encontradas nos capítulos seguintes, porém suas dimensões são da ordem de grandeza do resultado desta dissertação.

Dificuldades foram enfrentadas com essa versão, dentre elas a do embobinamento 
dos polos. Devido ao espaço restrito, não se conseguiu via métodos manuais alcançar a quantidade de bobinas prevista no projeto teórico, impossibilitando o teste da força de atração do estator interno.

A falta de precisão na usinagem causou desalinhamento das peças e diferença nos raios, dificultando a montagem. Na concepção inicial do protótipo, uma casca externa foi projetada (RM-M-C) para fixar os ímãs e impedir que eles fossem expelidos radialmente, mas devido às imprecisões mecânicas dos ímãs (causadas pelo banho de níquel) não foi possível a utilização dessa peça.

A Fig. 2.14 e 2.15 é uma imagem das partes construídas do mancal magnético, a primeira, com as partes desmontadas e a segunda com o mancal montado.

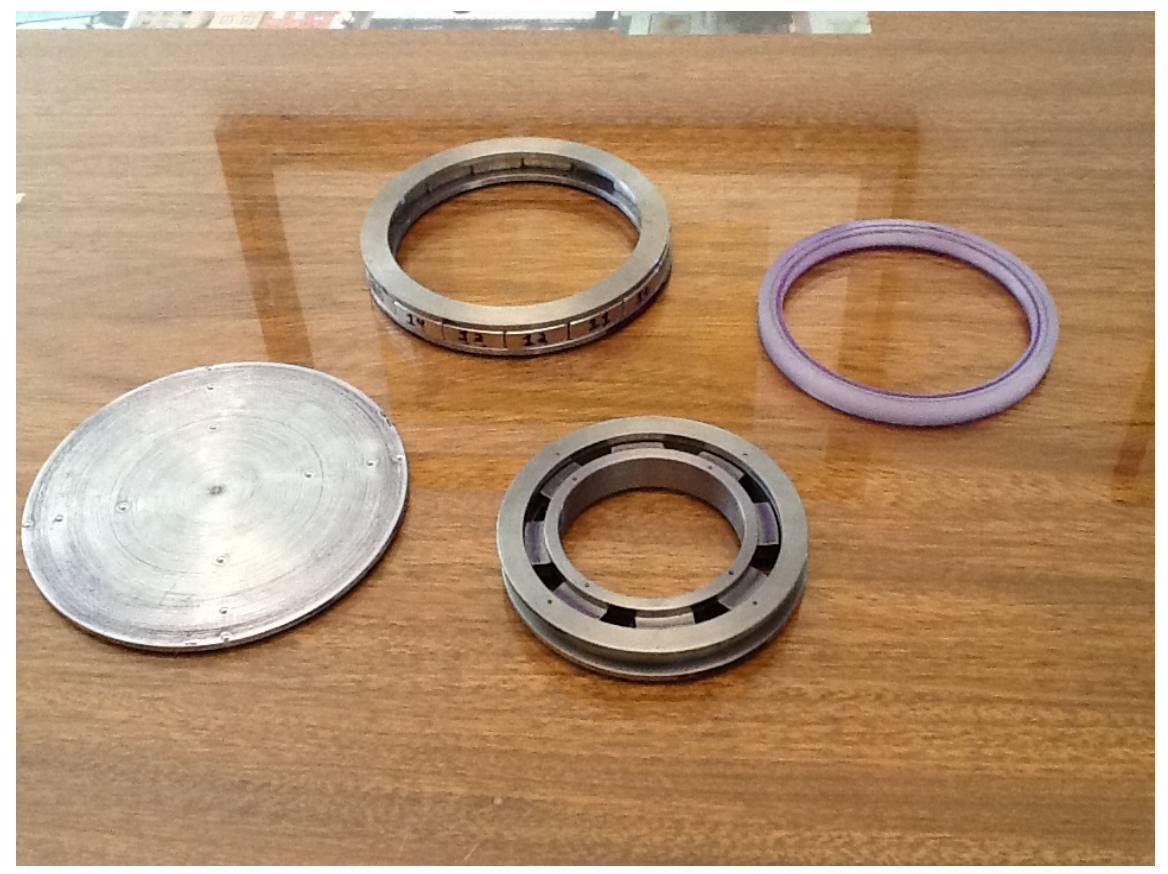

Figura 2.14: Componentes do protótipo 


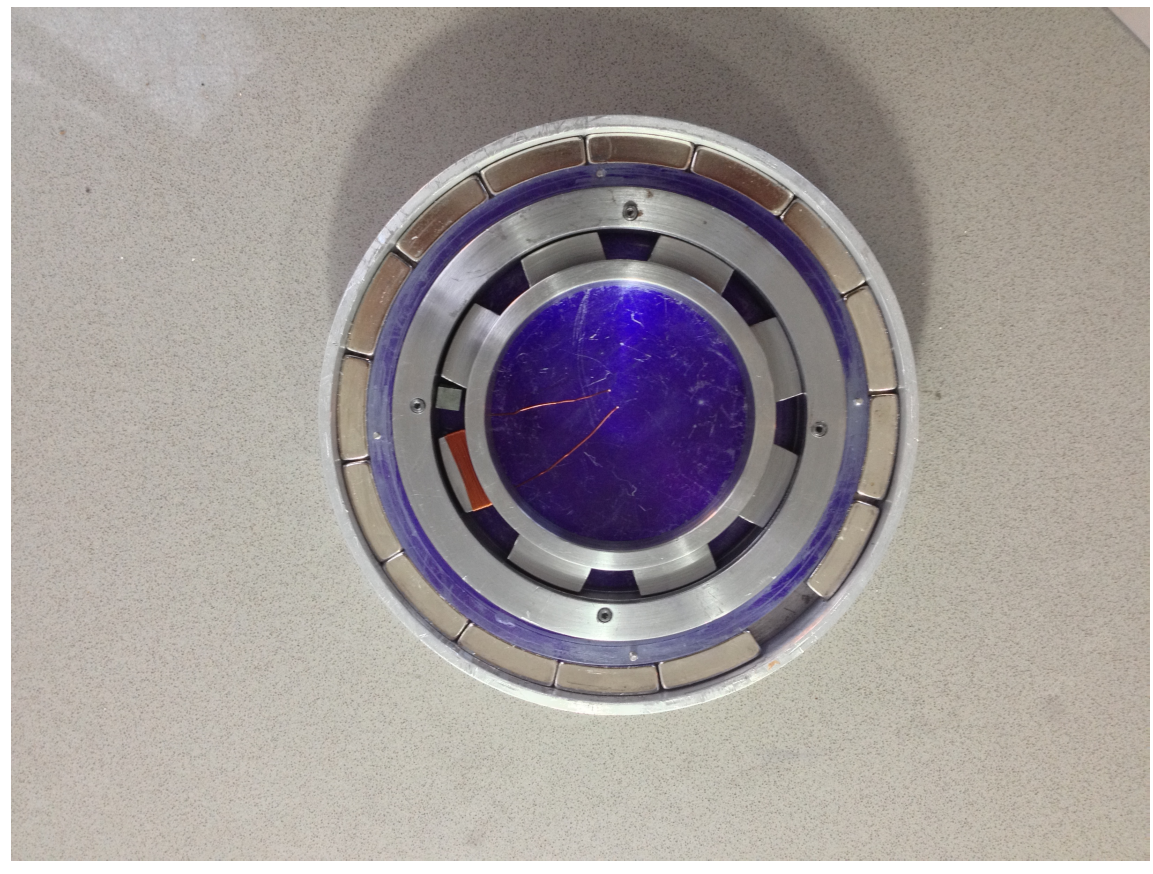

Figura 2.15: Protótipo montado, vista superior 


\section{Capítulo 3}

\section{Estator Externo e Rotor}

A parte passiva do mancal magnético, composta pelo estator externo e pelo rotor, pode ser descrita como o circuito da Fig. 3.1, onde um ímã permanente gera um fluxo magnético $\left(\mathcal{F}_{c}\right)$ que estabiliza o eixo axial (passivo). O caminho principal desse fluxo é através do entreferro $\left(R_{g e}\right)$ tanto pelos ferros do estator $\left(R_{e f}\right)$ quanto pelos ferros do rotor $\left(R_{r f}\right.$ e $\left.R_{r r}\right)$. Dois caminhos extras são considerados, um de dispersão de fluxo magnético no ímã $\left(R_{l m}\right)$ e outro em cada entreferro $\left(R_{l g}\right)$.

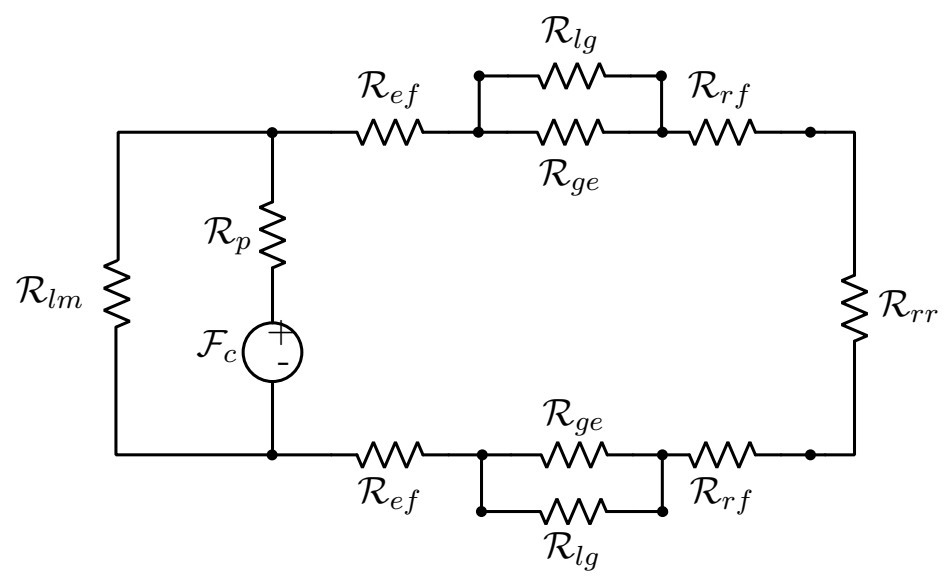

Figura 3.1: Circuito magnético passivo suposto

Um modelo fenomenológico foi inicialmente criado e nele aplicado um algorítimo de otimização a fim de encontrar um mancal ótimo para um certo funcional que valoriza 
as especificações anteriores. Com as dimensões encontradas, um modelo em elementos finitos foi gerado e as constantes de força calculadas de maneira mais precisa.

\subsection{Modelagem Magnética}

Nesse modelo, o ímã é considerado como uma fonte de fluxo magnético na forma equivalente a um circuito Thevenin. A força magnetomotriz coerciva $\left(\mathcal{F}_{c}\right)$ representa a excitação necessária para levar o ímã permanente a produzir um fluxo magnético nulo. Ímãs de terra rara (Samário Cobalto - Neodímio), possuem tipicamente uma curva linear de desmagnetização no segundo quadrante; essa curva depende de duas constantes físicas que variam com o material usado: $H_{c}$ campo coercitivo que associa o comprimento do ímã com a força coerciva $\left(F_{c}=H_{c} l_{m}\right)$ e a indução remanente $\left(B_{r}\right)$ que descreve o fluxo máximo do ímã num cenário de curto circuíto $\left(\phi_{r}=B_{r} A_{m}\right)$, ilustrada na Fig. 3.2.

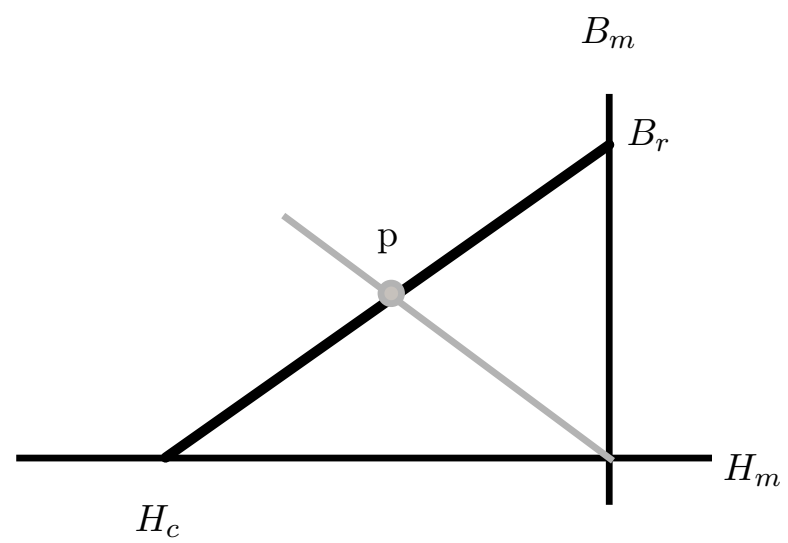

Figura 3.2: Curva de desmagnetização típica de ímãs de terra rara

A curva de magnetização é descrita como :

$$
B_{m}=B_{r}-\frac{B_{r}}{H_{c}} H_{m}
$$


A relação $\frac{B_{r}}{H_{c}}$ pode ser interpretada como a permeabilidade do meio (ímã) e possui tipicamente um valor próximo da permeabilidade do vácuo, $\mu_{0}$. O ponto de operação do ímã depende da curva de carga do circuíto magnético em que ele está inserido, para isso é necessário primeiramente calcular o valor da permeabilidade total e então identificar o ponto de operação do ímã e o seu fluxo produzido.

Considera-se nesse modelo para os materiais ferros magnéticos a curva de magnetização do ferro 1020. A curva não linear é apresentada na Fig. 3.3, nota-se que a saturação ocorre por volta de 1.3T. Essa relação pode ser descrita como:

$$
B(H)=\mu(H) H
$$

Vetor campo magnético (T) x Campo Magnético $(\mathrm{A} / \mathrm{m})$

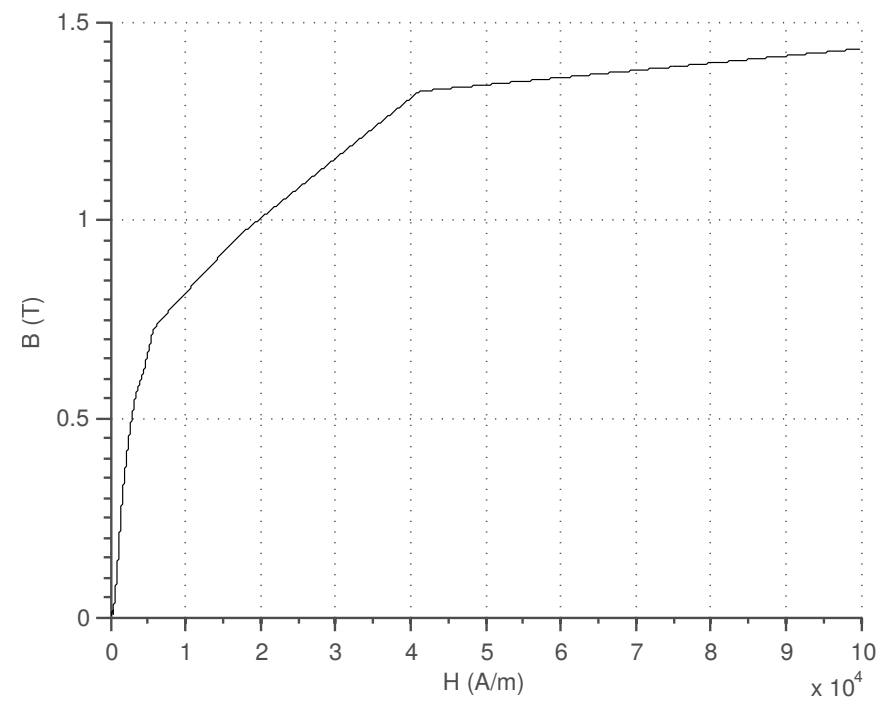

Figura 3.3: Curva de magnetização para o ferro 1020 


\subsubsection{Campo Magnético no Entreferro}

A relutância magnética é proporcional ao comprimento da linha de campo no meio e inversamente proporcional à permeabilidade do meio e à área em que o campo está estabelecido. Com isso, calculam-se as relutâncias principais do circuíto :

$$
\begin{aligned}
R_{p} & =\frac{h_{m}}{\mu_{m} S_{m}} \\
R_{e f} & =\frac{w_{f e e}}{\mu_{e f} S_{e f}} \\
R_{r f} & =\frac{w_{r f}}{\mu_{r f} S_{r f}} \\
R_{r r} & =\frac{h_{m}}{\mu_{r r} S_{r r}} \\
R_{g e} & =\frac{g_{n e}}{\mu_{0} S_{g e}}
\end{aligned}
$$

A permeância gerada pelo vazamento pode ser calculada por (Leupold e Potenziani, 1996):

$$
\begin{aligned}
P_{l m} & =\frac{0.64 \mu_{0} r_{e e}}{h_{m} /\left(h_{m}+2 h_{e f}\right)+1} \\
R_{l g} & =P_{1}+P_{2}+P_{3}+P_{4}
\end{aligned}
$$

Sendo $R_{g / /}$ a associação paralela entre a relutância do entreferro e o vazamento associado, $R_{1}$ a soma das relutâncias do circuíto principal e $R_{T}$ a associação entre todas as relutâncias do circuíto. Sendo $\phi_{1}$ o fluxo magnético total da malha criada entre o ímã e a relutância de fuga $\left(R_{l m}\right)$ e $\phi_{2}$ o fluxo magnético na malha principal. Obtém-se as seguintes equações: 


$$
\begin{aligned}
\phi_{m} & =\phi_{1}+\phi_{2} \\
& =\frac{F_{c}}{R_{p}+R_{T}} \\
\mathcal{F}_{c} & =\phi_{1}\left(R_{p}+R_{1}\right) \\
\mathcal{F}_{c} & =\phi_{2}\left(R_{p}+R_{l m}\right)
\end{aligned}
$$

Encontra-se o campo magnético efetivo no entreferro:

$$
\begin{aligned}
\phi_{g e} & =\frac{\phi_{1} R_{l g}}{R_{g e}+R_{l g}} \\
B_{g e} & =\frac{\phi_{g}}{S_{g e}}
\end{aligned}
$$

\subsubsection{Decomposição do Vetor Campo Magnético B em X e Z}

O campo magnético acumulado no entreferro pode ser decomposto em componentes $B_{x}$ e $B_{z}$ que dependem do deslocamento do rotor em $\Delta_{x}$ e $\Delta_{z}$. Esse deslocamento implica também em um aumento no comprimento do entreferro: $l_{g}$. A Fig. 3.4 ilustra o deslocamento. Tal modelo não leva em consideração o tilt do rotor, o que implicaria em relutâncias diferentes para a parte superior e inferior do entreferro, já que os comprimentos seriam diferentes.

Os campos podem então ser derivados: 


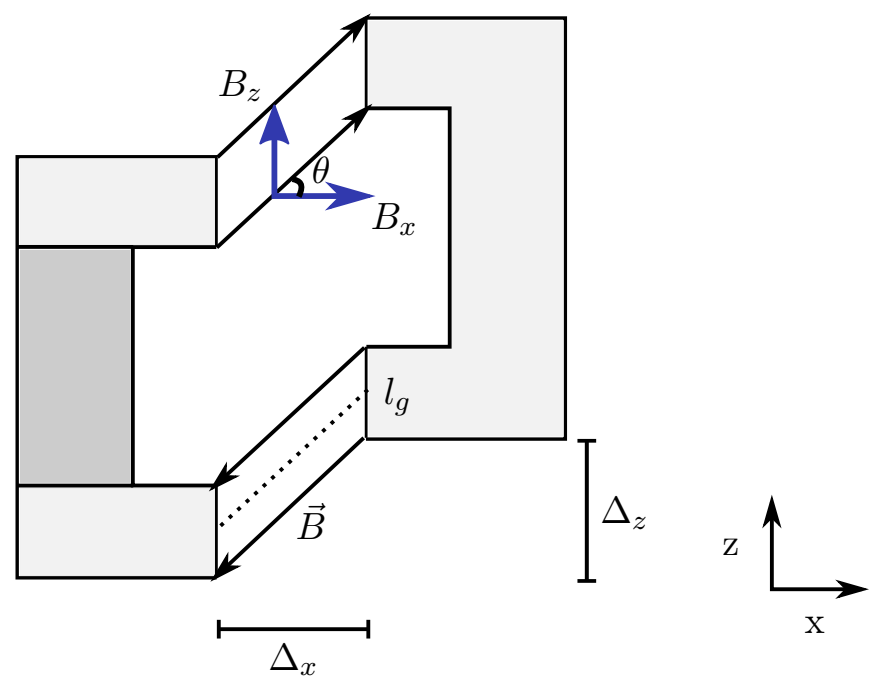

Figura 3.4: Deslocamento em X e Y

$$
\begin{aligned}
\theta_{z} & =\operatorname{tg}^{-1}\left(\frac{\Delta_{z}}{\Delta_{x}}\right) \\
l_{g} & =\sqrt{\Delta_{x}^{2}+\Delta_{z}^{2}} \\
B_{g x} & =B \cos \left(\theta_{z}\right) \\
B_{g z} & =B \sin \left(\theta_{z}\right)
\end{aligned}
$$

\subsection{Força}

A força magnética de atração do rotor pelo estator é gerada pela variação potencial da energia eletromagnética acumulada no entreferro (superior e inferior), essa força pode ser calculada através do trabalho virtual (Chiba e Fukao, 2005):

$$
\left|\vec{F}\left(l_{g}\right)\right|=\frac{\vec{B}_{g}^{2} S_{g}}{2 \mu_{0}}
$$

Sendo $B_{g}$ a área acumulada no entreferro e $S_{g}$ a secção do entreferro. 
A força resultante de atração é composta pela força dos dois entreferros (superior e inferior) que possuem mesmo módulo e direção já que os deslocamentos são simétricos.

\subsubsection{Força Radial}

Visando obter as resultantes das forças projetadas nos eixos radiais (x e y), para alcançar um modelo mais preciso das forças, o mancal foi dividido em oito partes distintas sendo que cada parte possuí um componente de campo magnético diferente das outras partes. Para obter o valor das forças radiais, calculou-se todas as forças e então decompô-las nos seus respectivos eixos (Fig. ??). Por inspeção:

$$
\begin{aligned}
& F_{x}=F_{B}+F_{A} \boldsymbol{x}+F_{C} \boldsymbol{x}-F_{F}-F_{G} \boldsymbol{x}-F_{E} \boldsymbol{x} \\
& F_{y}=F_{H}+F_{A} \boldsymbol{y}+F_{G} \boldsymbol{y}-F_{D}-F_{C} \boldsymbol{y}-F_{E} \boldsymbol{y}
\end{aligned}
$$

Onde os subscritos fazem referência as numerações das bobinas descritos na Fig. 2.7 .

\subsubsection{Força Axial}

A força perpendicular ao plano de rotação é a composição de todos os oito componentes onde não é levado em consideração o efeito de inclinação do rotor. Assim, obtém-se:

$$
F_{e z}\left(l_{g}\right)=\frac{S_{g}}{2 \mu_{0}} 2 \sum_{i=N}^{N O} B_{g i z}^{2}
$$

\subsection{Convergência}

Como a permeabilidade de materiais ferro magnéticos varia com o campo magnético induzido, é preciso realizar uma série de iterações para alcançar a convergência do valor do campo magnético em partes do circuíto. 
Nesse caso atribuiu-se um valor inicial para a permeabilidade nos três componentes do circuíto (ferro estator, ferro rotor e ferro retorno). Aplicando estes valores para o cálculo do campo magnético no entreferro obteve-se novos valores do campo magnético nestes mesmos componentes. Foi então derivado os valores para a permeabilidade através de uma interpolação linear. Calculou-se assim os novos valores da próxima interação pelo método de Newton-Raphson (Ortner et al., 2010), a Eq. 3.24 demonstra o método utilizado. A convergência é satisfeita quando for encontrada uma diferença entre os campos magnéticos inferior a 0.1 Tesla.

$$
\mu_{n+1}=\mu_{n}-\frac{H\left(\mu_{n}\right)}{H^{\prime}}\left(\mu_{n}\right)
$$

\subsection{Validação do Modelo}

O modelo obtido analiticamente foi comparado com um modelo em elementos finitos desenvolvido em três dimensões; aplicou-se a ambos os modelos as mesmas constantes magnéticas (permeabilidade, curva B-H) e parâmetros geométricos/construtivos.

Os resultados obtidos por ambos os métodos são similares, podendo confirmar a qualidade do modelo linear proposto. A Fig. 3.5 é um gráfico comparativo entre o resultado da força magnética de atração devido a um deslocamento no eixo radial entre ambos os modelos (FEM e analítico) para uma seç̧ão de 30 graus do mancal.

Os modelos também foram confrontados com a variação de parâmetros, no qual, variou-se a largura do ímã e o comprimento do entreferro. A Fig. 3.6 compara os resultados em ambos os modelos. 12 situações distintas foram simuladas e o resultado comparado a fim de validar o modelo obtido em diferentes geometrias. Os modelos foram variados conforme a seguir : 
Força de atração $(\mathrm{N})$ x Deslocamento em x (mm)

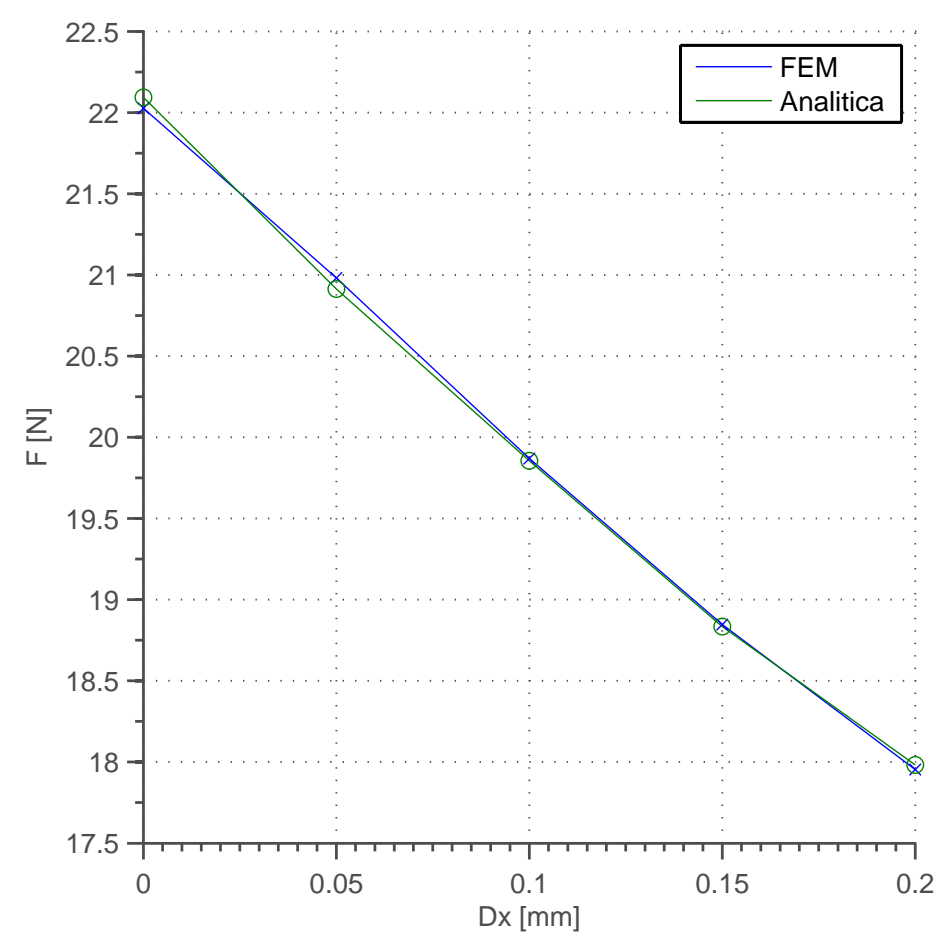

Figura 3.5: Validação do modelo, deslocamento axial.

$$
\begin{aligned}
& w_{m}=[4: 2: 10] 10^{-3} \\
& g_{n e}=[1: 0.2: 1.4] 10^{-3}
\end{aligned}
$$


Força de atração $(\mathrm{N})$ x Variação de parâmetros

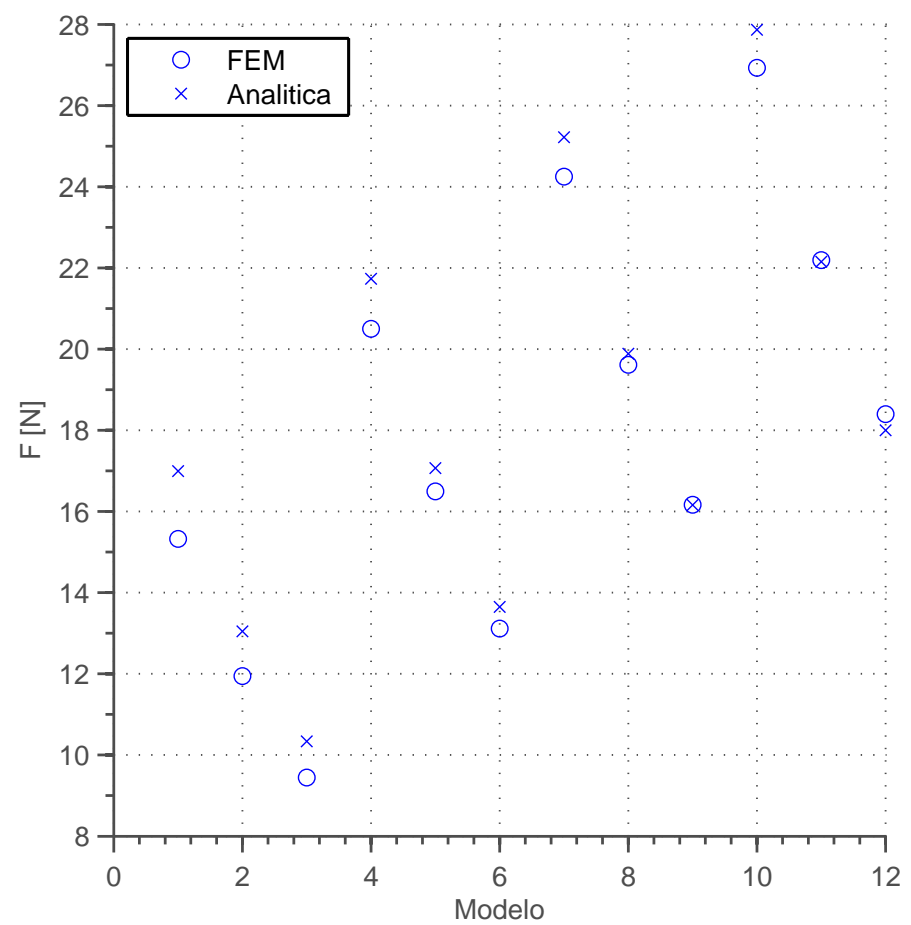

Figura 3.6: Validação do modelo, variação de parâmetros: largura do ímã e comprimento do entreferro.

\subsection{Otimização dos Parâmetros}

Buscou-se uma combinação de parâmetros que maximizasse a força de atração axial e que minimizasse a força longitudinal. $\mathrm{O}$ mancal deve possuir rigidez suficiente para suspender o conjunto inércia, o rotor do mancal e o rotor do motor. Estudos realizados com base na especificação de uma roda de reação pelo INPE estima um momento de inércia total para o sistema de $6.910^{-2} \mathrm{~kg} \mathrm{~m}^{2}$ com uma massa de $3.52 \mathrm{~kg}$ (para operar em ambiente com gravidade).

O método de otimização utilizado para minimizar o funcional foi o de NelderMead Simplex com restrição de fronteira. Nessa etapa, a otimização foi realizada com o modelo analítico levantado anteriormente, viabilizando o tempo de processamento 
já que a resolução do modelo analítico leva segundos a ser realizado enquanto a do elementos finitos chega a dezenas de minutos.

Os parâmetros escolhidos para a otimização foram todos os que definem construtivamente o circuito passivo do mancal, sendo eles: altura $\left(h_{f e e}\right)$ e largura $\left(w_{f e e}\right)$ do ferro estator externo; a altura $\left(h_{m}\right)$ e largura $\left(w_{m}\right)$ do ímã e largura $\left(w_{r f}\right)$ do ferro rotor e largura do retorno rotor $\left(w_{r r}\right)$, além do comprimento do entreferro $\left(g_{n e}\right)$ e raio externo do mancal $\left(r_{e e i}\right)$.

Para respeitar a geometria proposta durante a otimização, os parâmetros $w_{f e e}$ e $w_{r f}$ não foram manipulados diretamente na otimização, já que não podem assumir valores inferiores a $w_{m}$ e $w_{r r}$ respectivamente, caso contrário o mancal encontrado durante a otimização possuiria propriedades distintas da proposta e o modelo analítico seria inválido. Otimizou-se neste caso, duas componentes $\Delta w_{f e e}$ e $\Delta w_{r f}$ que compõem, em conjunto com seus pares, os comprimentos dos ferros:

$$
\begin{gathered}
w_{f e e}=\Delta w_{f e e}+w_{m} \\
w_{r f}=\Delta w_{r f}+w_{r r}
\end{gathered}
$$

Restrições foram impostas para evitar a otimização do mancal para um caso em que a sua construção fosse inviável mecanicamente ou para evitar um mancal que se encontrasse fora das especificações da roda de reação. A Tab. 3.1 demonstra os valores máximos $\left(L_{\text {Max }}\right)$ e mínimos $\left(L_{\text {Min }}\right)$ impostos para cada elemento do mancal, assim como o valor inicial $\left(L_{0}\right)$ utilizado na otimização.

Diversas funções méritos de foram testadas visando a obtenção de um mancal que atendesse as especificações. A função pondera seis componentes do mancal, sendo elas: forças de atração em x e y, tamanho do entreferro, raio externo do mancal, volume $\left(V_{m}\right)$ e variação no vetor campo magnético para pequenos deslocamentos $\left(\Delta B_{g}\right)$. 


\begin{tabular}{ccccccccc} 
& $h_{f e e}$ & $\Delta w_{f e e}$ & $w_{m}$ & $h_{m}$ & $g_{n e}$ & $\Delta w_{r f}$ & $w_{r r}$ & $r_{e e i}$ \\
\hline \hline$L_{0}$ & 6 & 4 & 8 & 10 & 3 & 4 & 6 & 75 \\
$L_{\text {Min }}$ & 2 & 2 & 4 & 5 & 1 & 2 & 3 & 50 \\
$L_{\text {Max }}$ & 10 & 6 & 12 & 15 & 3 & 8 & 9 & 80
\end{tabular}

Tabela 3.1: Valores iniciais, máximos e mínimos utilizado na otimização. Valores em milímetros.

Buscou-se nessa otimização uma menor força de atração axial $\left(P_{1}\right)$ e uma maior força radial $\left(P_{2}\right)$. O funcional foi ponderado para privilegiar um maior entreferro $\left(P_{3}\right)$ e um menor raio $\left(P_{4}\right)$. O volume total $\left(P_{5}\right)$ do mancal foi também ponderado no funcional, visando um mancal de dimensões menores. Para se obter uma força radial linearizada, necessita-se que o vetor campo magnético no entreferro não variasse consideravelmente para pequenos deslocamentos radiais do rotor, o $\Delta B_{g}$ foi ponderado no funcional $\left(P_{6}\right)$ . A função de mérito $(F)$ utilizada na otimização está descrito na Eq. 3.35, com as parcelas $(\mathrm{P})$ separadas por importância.

$$
\begin{aligned}
& P_{1}=F x / 2 \\
& P_{2}=125 / F y \\
& P_{3}=r_{e e i} 10^{3} / 55 \\
& P_{4}=30 /\left(G_{e} 10^{3}\right) \\
& P_{5}=V_{m} 10^{6} / 15 \\
& P_{6}=25\left|\Delta B_{g}\right| \\
& F=P_{1}+P_{2}+P_{3}+P_{4}+P_{5}+P_{6}
\end{aligned}
$$

A Fig. 3.7 mostra a evolução dos parâmetros ao longo da otimização. Verificou-se que a força de atração $F_{y}$ é maximizada ao longo das interações, porém verificou-se que é acompanhada pela força $F_{x}$ que deveria ser minimizada. Isso ocorre devido à 
correlação entre as duas forças, sendo que ambas dependem do vetor campo magnético acumulado no entreferro $\left(B_{g e}\right)$. Outra relação direta que é possível ser notada é a do tamanho do entreferro $\left(g_{n e}\right)$; quanto menor o entreferro menor a relutância do circuito magnético e maior o campo magnético acumulado no entreferro.

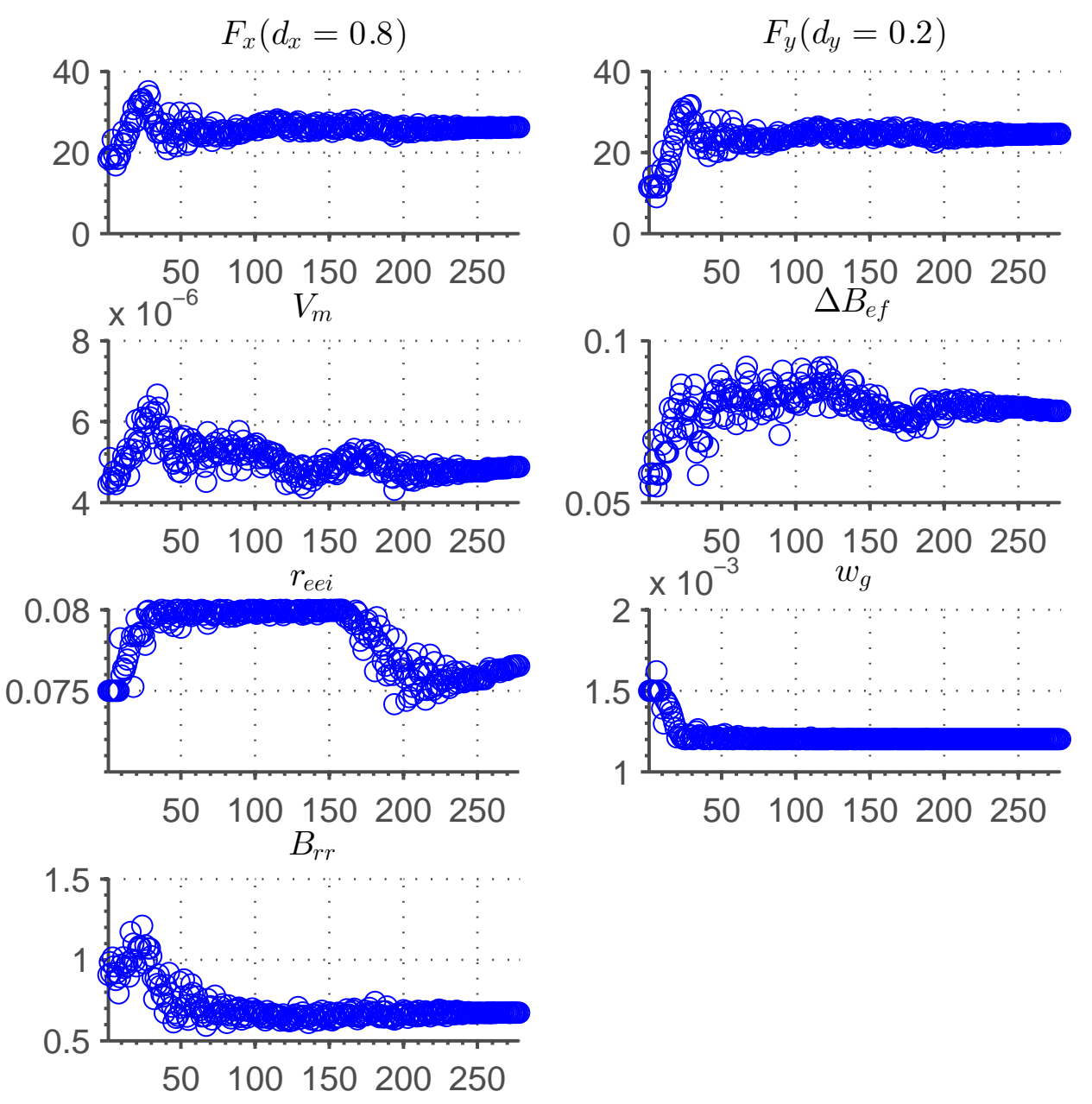

Figura 3.7: Evolução dos parâmetros ao longo da otimização

Os pesos da função de mérito ao longo da otimização são ilustrados na Fig. 3.8, verificou-se que as parcelas que mais contribuem para o valor do funcional são P1 e P2 
que estão relacionados com a força de atração. Em seguida, com uma menor ponderação em todos os demais.

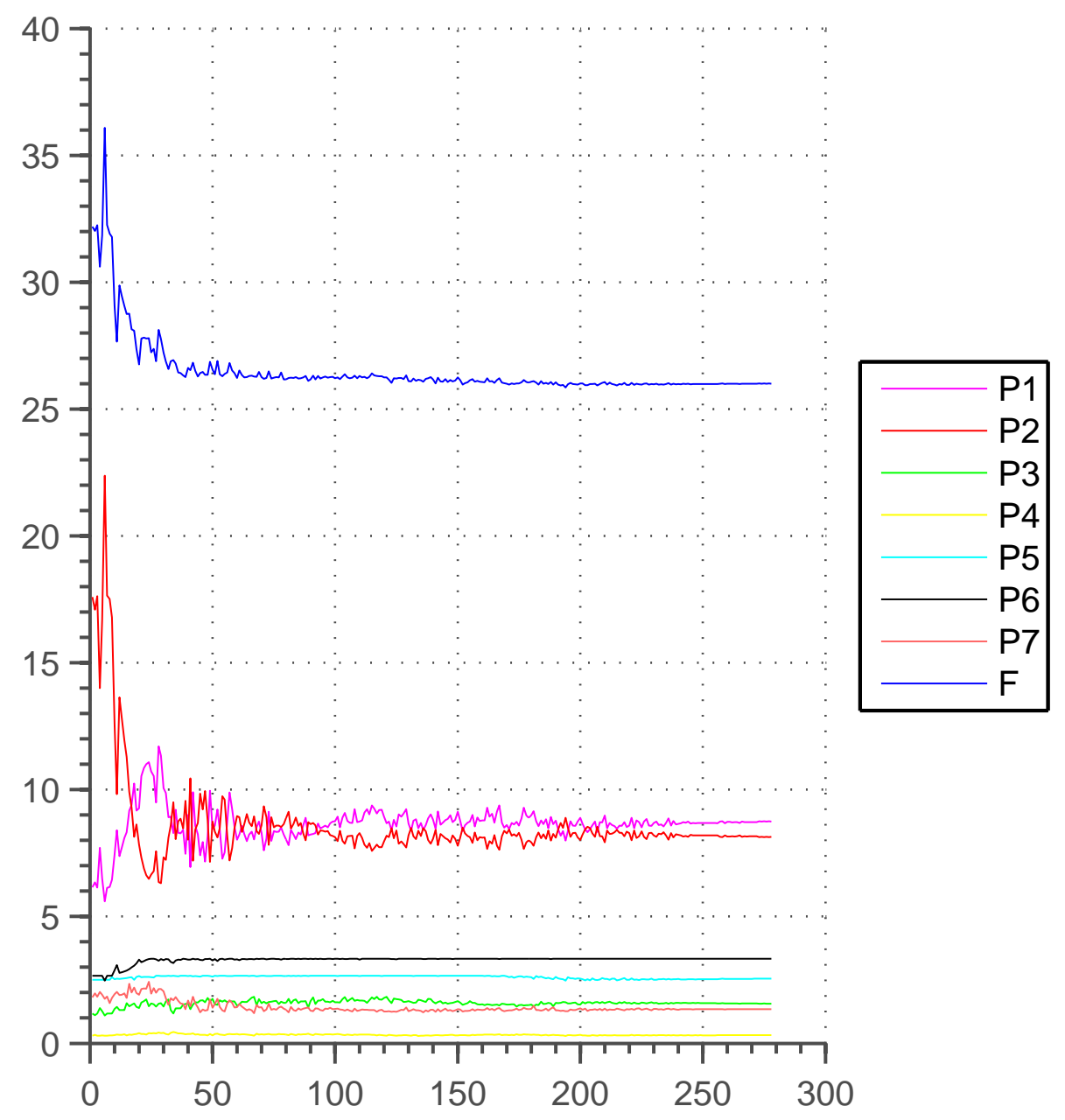

Figura 3.8: Evolução dos pesos ao longo da otimização

\subsection{Mancal Passivo Resultante da Otimização}

As dimensões alcançadas devido a otimização do mancal estão listada na Tab. 3.2, com esses resultados um modelo em elementos finitos foi criado e as forças resultantes 
levantadas de forma mais precisa (modelo em três dimensões).

\begin{tabular}{ccccccccc} 
& $h_{\text {fee }}$ & $\Delta w_{\text {fee }}$ & $w_{m}$ & $h_{m}$ & $g_{n e}$ & $\Delta w_{r f}$ & $w_{r r}$ & $r_{e e i}$ \\
\hline \hline$L_{n}$ & 4.2 & 10 & 10 & 12 & 1.4 & 7 & 6 & 70
\end{tabular}

Tabela 3.2: Dimensões obtidas pela otimização. Valores em milímetros.

Verificou-se na Fig. 3.9 o resultante da força devido a translação do rotor em apenas um dos eixos radiais e, também a linearidade da força quando o rotor trabalha em modo diferencial.

Força $(\mathrm{N}) \times \Delta_{x}(\mathrm{~mm})$ - Deslocamento Radial: $\mathrm{y}=0, \mathrm{z}=0$

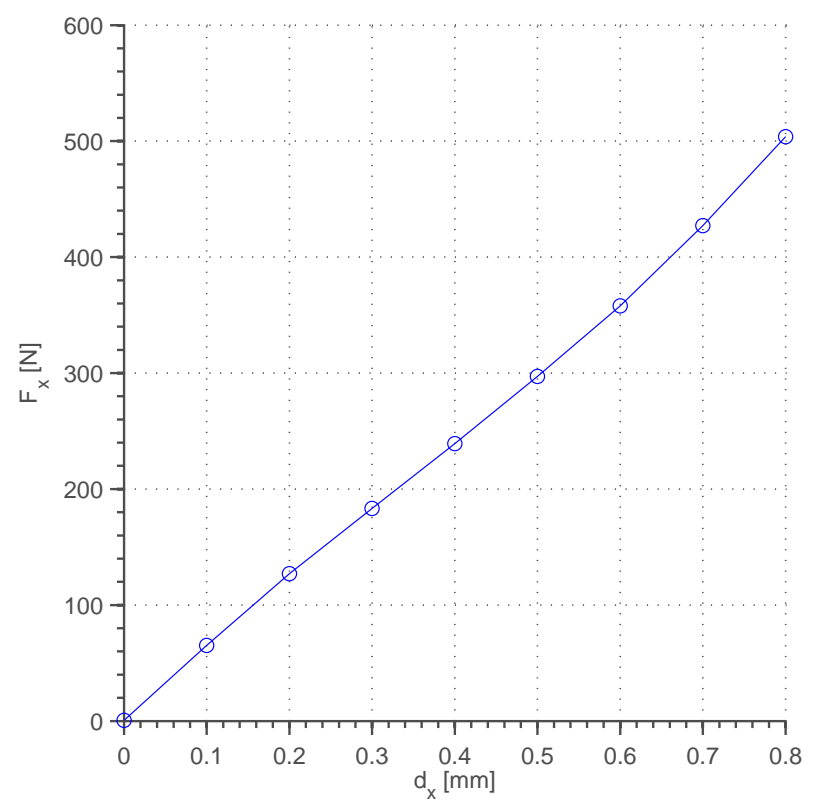

Figura 3.9: Força atuante no rotor dado uma translação radial

A força gerada pela translação axial é ilustrada na Fig. 3.10, essa força restaurativa torna a parte passiva do mancal estável e é a responsável pela rigidez nesse grau de liberdade. Notou-se que a força necessária para deslocar $1 \mathrm{~mm}$ axialmente quando o mancal está no ponto de operação é de aproximadamente 140N. Verificou-se que a força possui um componente diferente de zero quando o rotor está alinhado com o estator 
externo $(z=0)$, diferente do encontrado via modelo analítico. Explica-se esse fenômeno pelo erro numérico causado pela malha de cálculo.

$$
\text { Força }(\mathrm{N}) \mathrm{x} d_{z}(\mathrm{~mm}) \text { - Deslocamento axial: } \mathrm{x}=0, \mathrm{y}=0
$$

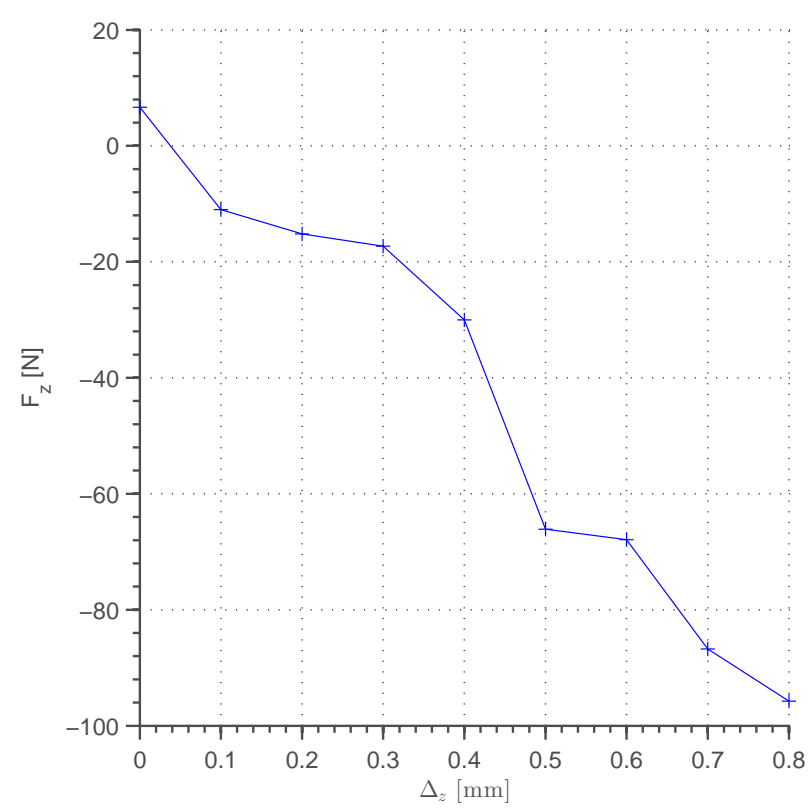

Figura 3.10: Força atuante no rotor dado uma translação axial

Um mapa do módulo da força radial no plano x,y é ilustrado na Fig. 3.11. Notou-se que a força é praticamente nula em torno do ponto de operação. Porém, quando o rotor encontra-se em algum de seus extremos, a força de atração é da ordem de centenas de Newtonm o que influencia na definição do circuito ativo que tem que ser capaz de vencer essa força.

A Fig. 3.12 ilustra o resultado da simulação através de elementos finitos onde o rotor é transladado verticalmente a $0.8 \mathrm{~mm}$. Verificou-se que as linhas de campo não sofrem inclinação proporcional ao deslocamento do rotor; essas deformações apresentam um erro no modelo analítico já que supos se na Subsec. 3.1.2 que as linhas de campo poderiam ser decompostas em x e z e que essa decomposição é diretamente relacionada 


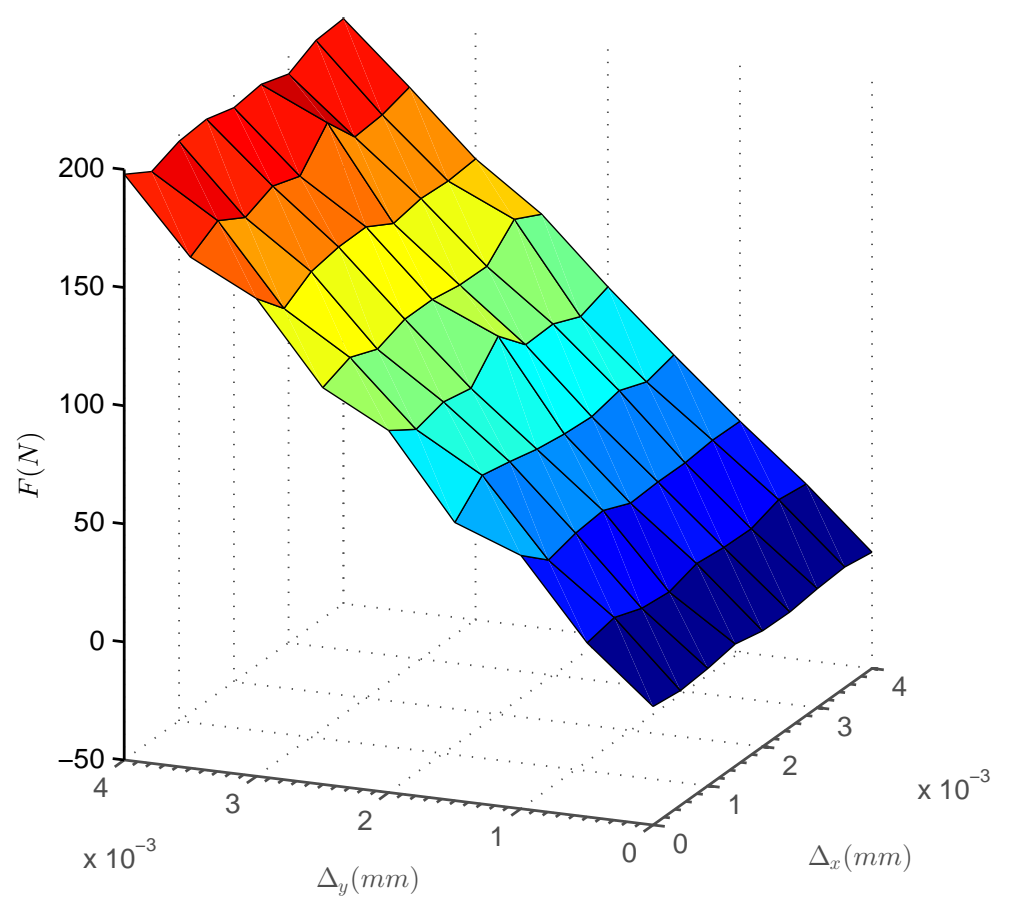

Figura 3.11: Mapa de forças devido a movimentação no plano

com o deslocamento do rotor $(\theta)$.

Na Fig. em anexo A.1 tem-se o resultado da simulação FEM para o deslocamento radial do rotor. Nota-se nessa simulação que o fluxo magnético é contido nos ferros e que ocorre pouca dispersão das linhas de campo. Observa-se também, a saturação dos ferros em todos os casos, essa saturação é necessária para forçar a linearidade da força de atração quando trabalhado em modo diferencial. Além disso, verificamos que a área do entreferro $\left(S_{g}\right)$ possui um pequeno espraiamento causando um aumentado no volume em que o campo magnético está acumulado e por consequência uma diminuição da força.

A massa do rotor $(\mathrm{m})$ é calculada pelo volume obtido das otimizações, sendo o volume $47940 \mathrm{~mm}^{3}$ e a densidade do material utilizado de $7.8\left[\mathrm{~g} / \mathrm{cm}^{3}\right]$, a massa do sistema é: 


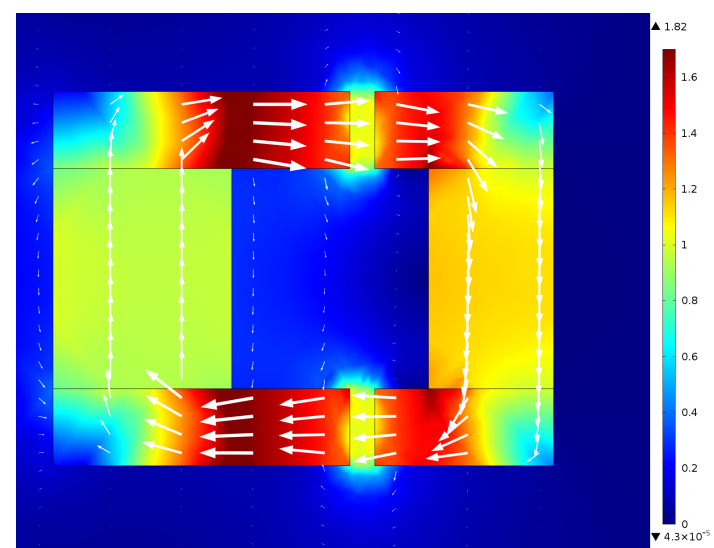

(a) $\Delta_{x}=0 \mathrm{~mm}$ e $\Delta_{z}=0 \mathrm{~mm}$

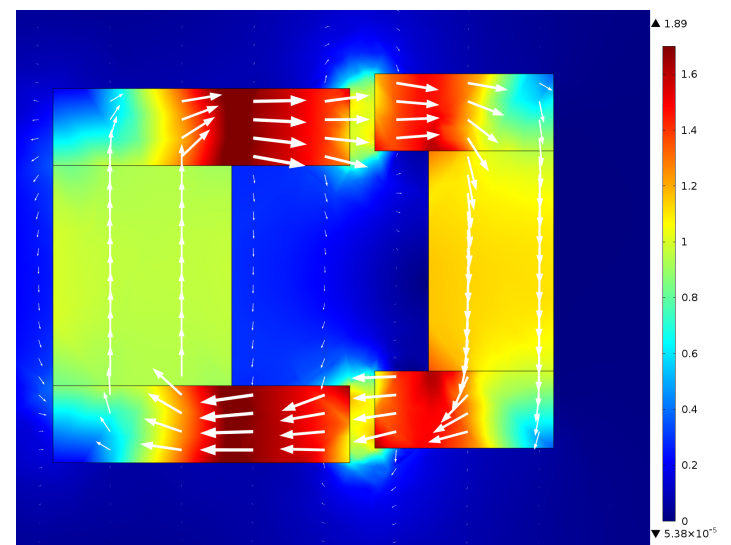

(b) $\Delta_{x}=0 m m$ e $\Delta_{z}=0.8$

Figura 3.12: Campo magnético via simulação em elementos finitos para deslocamentos na vertical

$$
m=0.375[K g]
$$

Verificada a estabilidade na inclinação axial, analisou-se a estabilidade para tilt, projetando o deslocamento angular em deslocamentos radial e axial. Dada a propriedade plana do mancal proposto, obteve-se um grande deslocamento axial comparado com o radial, gerando assim a estabilidade do rotor. Para o caso da inclinação máxima do rotor (um grau, limitada pelo batente) o deslocamento radial é de $0.0107 \mathrm{~mm}$ e o 
deslocamento axial é de $1.2 \mathrm{~mm}$, gerando assim uma recuperação mais forte axial que radial, o que impede o rotor de entrar em instabilidade.

Em simulação de elementos finitos, calculou-se que o torque restaurativo para uma inclinação de um grau em torno de um dos eixos é de $3 N . m$, ou seja, o resultante da força em z devido à inclinação é de 42N. O gráfico da Fig. 3.13 ilustra a força restaurativa gerada devido à inclinação do rotor.

Torque (N.m) por inclinação (grau)

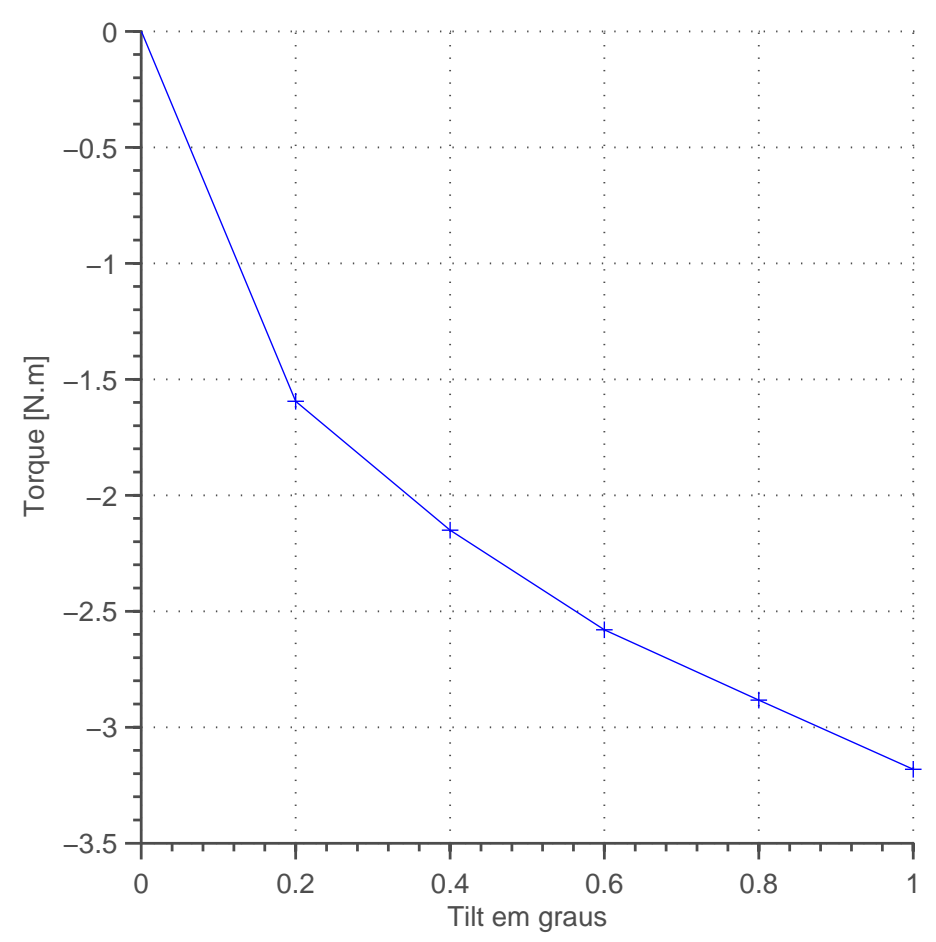

Figura 3.13: Torque resultante da inclinação do rotor 


\section{Capítulo 4}

\section{Estator Interno}

O desenvolvimento do circuito ativo visou obter um atuador capaz de agir sobre o rotor fazendo com que o mesmo se mantivesse em sua posição de equilíbrio $\left(d_{x}=0 ; d_{y}=0\right)$ através de forças geradas por campos eletromagnéticos via oito diferentes núcleos.

Cada núcleo age em colaboração com os núcleos vizinhos, sendo quatro núcleos principais e quatro secundários. Os núcleos principais estão localizados nos eixos radias do mancal $(\mathrm{x}, \mathrm{z})$, os núcleos secundários estão posicionados a uma distância angular de $45^{\circ}$. Essa topologia permitiu a maximização do fluxo magnético no eixo de interesse.

A parte ativa tem que ser capaz de vencer a força de atração gerada pelo circuito passivo quando o rotor estiver em sua excursão máxima. Para isso, criou-se um modelo analítico que representa essa parte do mancal e uma otimização numérica foi realizada visando a obtenção de um atuador dentro das especificações. 


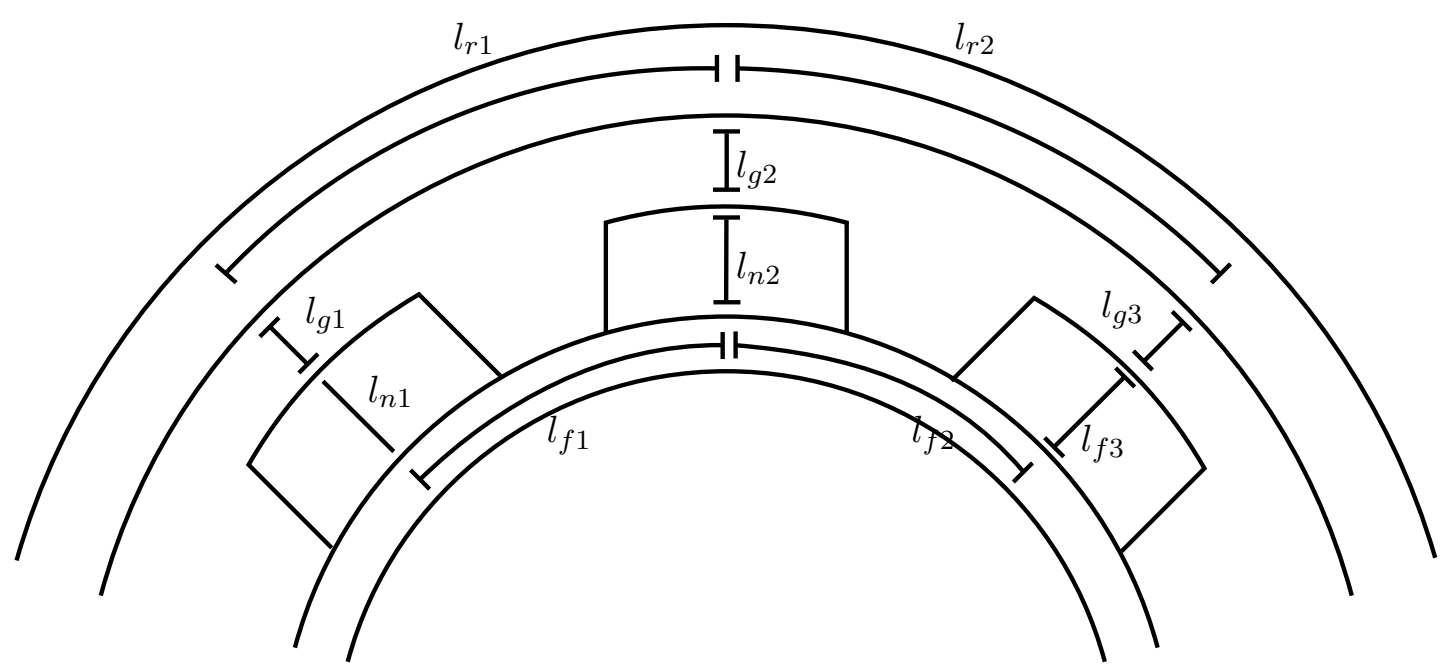

Figura 4.1: Dimensões do mancal

\subsection{Modelagem Magnética}

Partindo da premissa que todas as linhas de campo magnético estão contidas nos componentes listados anteriormente e que o rotor encontra-se em sua posição de equilíbrio axial $\left(d_{z}=0\right)$ e sem inclinação, realizou-se o acionamento nas bobinas com uma tensão contínua e se considerou o campo magnético estático.

A modelagem da parte ativa (atuadores) foi realizada considerando o circuito magnético da Fig. 4.2, onde: $\mathcal{F}$ é a força magnetomotriz gerada pela bobina; $R_{n}$ a relutância magnética associada ao núcleo da bobina; $R_{g i}$ a relutância do entreferro; $R_{r i}$ a relutância entre dois núcleos pelo ferro do rotor e $R_{f i}$ a relutância de conexão entre dois núcleos pelo estator interno.

O desenvolvimento da modelagem foi realizado via análise de malhas. Adotando correntes internas no mesmo sentido, a cada malha pode-se escrever a seguinte equação geral:

$$
\left(\sum R_{m}-\sum R_{a}\right) \phi_{m}=\sum F_{E M}-\sum F_{C E M}
$$




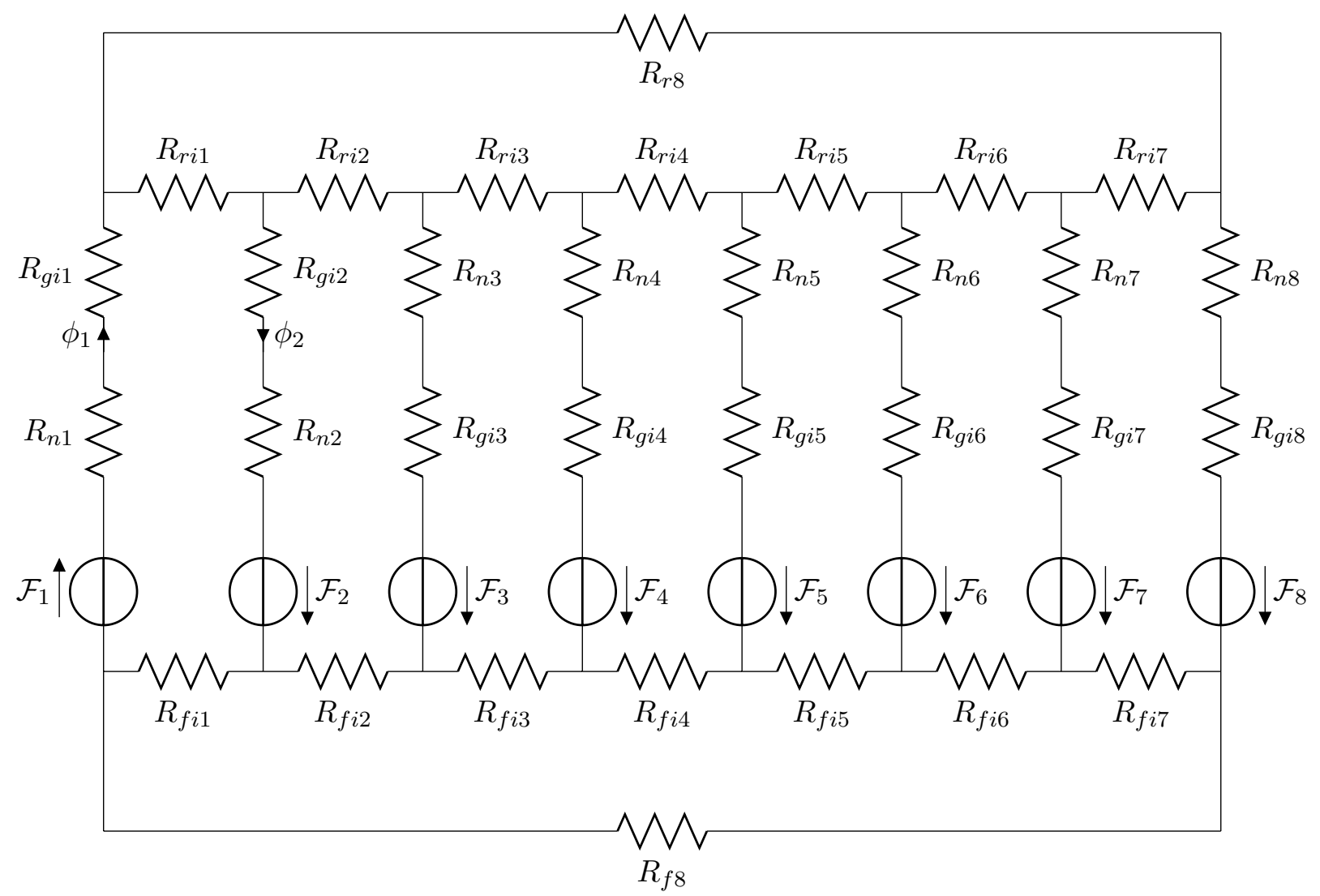

Figura 4.2: Circuito magnético do circuito ativo

Sendo $\sum R_{m}$ e $\phi_{m}$ respectivamente, a relutância e o fluxo interna de cada malha, $R_{a}$, $\phi_{m}$ a relutância e a corrente adjacente da malha, $F_{E M}$ a força magnetomotriz (sentido horário) e $\sum F_{C E M}$ a negativa. Obteve-se as matrizes que representam o circuito: 


$$
\phi_{m}=\left[\begin{array}{c}
\phi_{1} \\
\phi_{2} \\
\phi_{3} \\
\phi_{4} \\
\phi_{5} \\
\phi_{6} \\
\phi_{7} \\
\phi_{8}
\end{array}\right]
$$

$$
R_{m}=\left[\begin{array}{cccccccc}
R_{m 1} & 0 & 0 & 0 & 0 & 0 & 0 & 0 \\
0 & R_{m 2} & 0 & 0 & 0 & 0 & 0 & 0 \\
0 & 0 & R_{m 3} & 0 & 0 & 0 & 0 & 0 \\
0 & 0 & 0 & R_{m 4} & 0 & 0 & 0 & 0 \\
0 & 0 & 0 & 0 & R_{m 5} & 0 & 0 & 0 \\
0 & 0 & 0 & 0 & 0 & R_{m 6} & 0 & 0 \\
0 & 0 & 0 & 0 & 0 & 0 & R_{m 7} & 0 \\
0 & 0 & 0 & 0 & 0 & 0 & 0 & R_{m 8}
\end{array}\right]
$$

com: 


$$
\begin{aligned}
R_{m 1} & =R_{f 1}+R_{n 1}+R_{g i 1}+R_{r 1}+R_{g i 2}+R_{n 2} \\
R_{m 2} & =R_{f 2}+R_{n 2}+R_{g i 2}+R_{r 2}+R_{g i 3}+R_{n 3} \\
& \cdots \\
R_{m 3} & =R_{f 8}+R_{n 8}+R_{g i 8}+R_{r 8}+R_{g i 1}+R_{n 1}
\end{aligned}
$$

e o componente devido a relutância adjacentes:

$$
R_{a}=\left[\begin{array}{c}
R_{a 1} \\
R_{a 2} \\
R_{a 3} \\
R_{a 4} \\
R_{a 5} \\
R_{a 6} \\
R_{a 7} \\
R_{a 8}
\end{array}\right]
$$

sendo as relutâncias adjacentes calculadas como:

$$
\begin{aligned}
R_{a 1}= & {\left[\begin{array}{lllllllll}
0 & R_{g i 2}+R_{n 2} & 0 & 0 & 0 & 0 & 0 & R_{g i 8}+R_{n 8}
\end{array}\right] } \\
R_{a 2}= & {\left[\begin{array}{llllllll}
R g i 1+R n 1 & 0 & R g i 3+R_{n 3} & 0 & 0 & 0 & 0 & 0
\end{array}\right] } \\
& \ldots \\
R_{a 8}= & {\left[\begin{array}{llllllll}
R_{g i 1}+R_{n 1} & 0 & 0 & 0 & 0 & 0 & R_{g i 7}+R_{n 7} & 0
\end{array}\right] }
\end{aligned}
$$


A matriz que correlaciona as forças magnetomotriz:

$$
F_{m}=\left[\begin{array}{l}
F_{1}-F_{2} \\
F_{2}-F_{3} \\
F_{3}-F_{4} \\
F_{4}-F_{5} \\
F_{5}-F_{6} \\
F_{6}-F_{7} \\
F_{7}-F_{8} \\
F_{8}-F_{1}
\end{array}\right]
$$

Pode-se resolver a equação do circuito com: $\phi_{m}=\left(R_{m}-R_{a}\right)^{-1} F_{m}$, dado o resultado de cada fluxo eletromagnético nas malhas, foi possível calcular os fluxos individuais nos entreferros $\left(\phi_{g}\right)$. Uma vez encontrado o fluxo magnético, pode-se obter o campo magnético através da simples relação que engloba o fluxo e a área em que ele está distribuído.

$$
\phi_{g}=\left[\begin{array}{c}
\phi_{1}-\phi_{8} \\
-\phi_{1}+\phi_{2} \\
\phi_{3}-\phi_{2} \\
-\phi_{3}+\phi_{4} \\
\phi_{5}-\phi_{4} \\
-\phi_{5}+\phi_{6} \\
\phi_{7}-\phi_{6} \\
-\phi_{7}+\phi_{8}
\end{array}\right]
$$

As relutâncias foram calculadas utilizando as dimensões dos componentes do man- 
cal com os comprimentos das linhas de campo ilustrados na Fig. 4.1, resultando nas equações:

$$
\begin{aligned}
R_{r i} & =\frac{l_{r i}}{\mu_{r i} S_{r i}} \\
R_{n} & =\frac{w_{n}}{\mu_{n} S_{n}} \\
R_{g i} & =\frac{w_{g n i}}{\mu_{0} S_{g n i}} \\
R_{f} & =\frac{h_{f e i}}{\mu_{f} S_{w f e i}}
\end{aligned}
$$

\subsection{Forças}

A força resultante de atração referente a cada bobina pôde ser calculada pelo campo magnético acumulado no entreferro:

$$
\overrightarrow{F_{n x}}=\frac{\vec{B}_{g x}^{2} S_{g x}}{2 \mu_{0}}
$$

A força resultante projetada puramente no eixo normal ao núcleo principal é composto pela somatória das forças geradas pelos núcleos secundários, como mostrado na Fig. 4.3. Adotando que para pequenos deslocamentos no plano radial (x e y) a variação dos ângulos $\theta$ possam ser desprezíveis, obteve-se:

$$
\begin{aligned}
& \vec{F}_{y}=\vec{F}_{g n}+\sin (45)\left(\vec{F}_{g a}+\vec{F}_{g b}\right) \\
& \vec{F}_{x}=\cos (45)\left(\vec{F}_{g a}-\vec{F}_{g b}\right)
\end{aligned}
$$




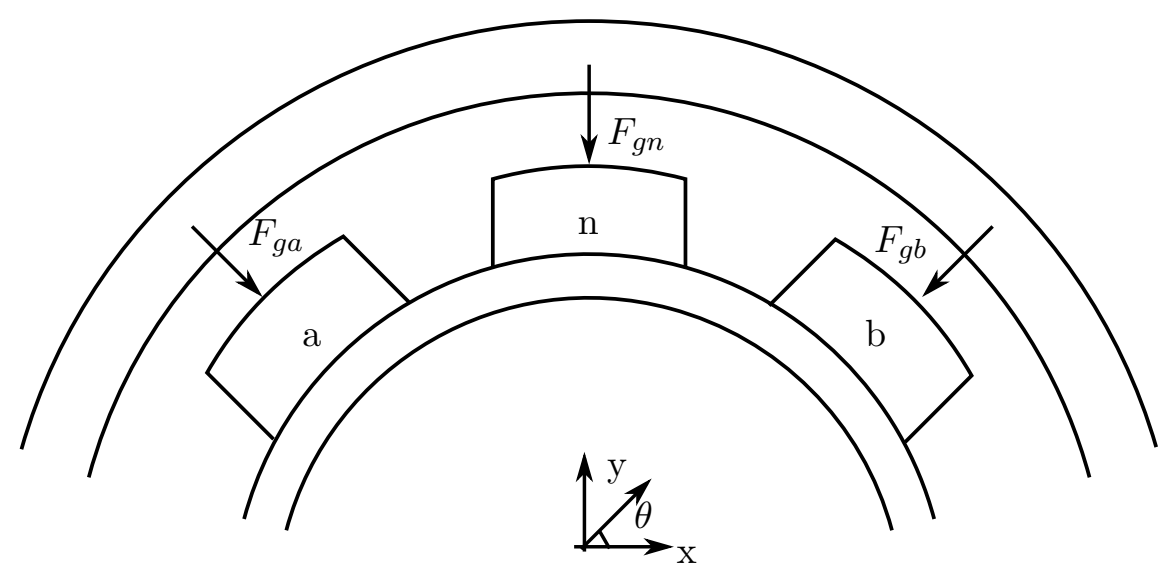

Figura 4.3: Forças resultante no rotor no eixo y

\subsection{Indutância}

O cálculo da indutância é importante pois atrela uma dinâmica ao atuador; a indutância está correlacionada à capacidade de geração de fluxo magnético de uma bobina e de sua corrente: $L=\frac{d \phi}{d i}$. Das equações de densidade de campo magnético no entreferro de cada bobina, Eq. (4.12), encontra-se o fluxo magnético em cada núcleo.

Definindo o fluxo da bobina como o número de espiras $\mathrm{N}$ pelo campo que a atravessa e a indutância própria com o fluxo concentrado dividido pela corrente aplicada a bobina, obteve-se, desconsiderando as demais fontes geradoras de fluxo, a indutância $(L)$ em cada polo:

$$
\begin{aligned}
& L_{a}=\frac{\Phi_{f a}}{I_{a}}=\left.N B_{g a}\right|_{\left(I_{b}=0, I_{n}=0\right)} S_{g a} I_{a}^{-1} \\
& L_{b}=\frac{\Phi_{f b}}{I_{b}}=\left.N B_{g b}\right|_{\left(I_{a}=0, I_{n}=0\right)} S_{g b} I_{b}^{-1} \\
& L_{n}=\frac{\Phi_{f c}}{I_{n}}=\left.N B_{g n}\right|_{\left(I_{a}=0, I_{b}=0\right)} S_{g n} I_{n}^{-1}
\end{aligned}
$$

Sendo: $L_{a}$ a indutância no polo principal; $L_{b}$ e $L_{c}$ as indutâncias nos polos secundários; $B_{a}$ o vetor campo magnético no polo primário; $B_{b}$ e $B_{c}$ os vetores campo 
magnéticos nos polos secundários; $I_{a}, I_{b}$ e $I_{c}$ as correntes aplicadas em cada bobina.

As indutâncias mútuas $(M)$ são calculadas como sendo o fluxo que atravessa a bobina produzida por outras fontes:

$$
M_{a b}=\frac{\Phi_{b \rightarrow a}}{I b}=\left.N B_{g a}\right|_{\left(I_{a}=0, I_{n}=0\right)} S_{g a} I_{b}^{-1}
$$

Via modelo de elementos finitos, a indutância é calculada a partir da energia magnética acumulada no volume do polo $\left(W_{m}\left[\mathrm{~J} / \mathrm{mm}^{3}\right]\right)$, sendo: $W_{m}=\frac{1}{2} L i^{2}$, alcança-se assim a indutância de cada polo.

\subsection{Convergência}

Devido ao fato do modelo apresentar componentes não lineares, dada a curva de magnetização dos componentes ferro magnéticos do circuito, utilizou-se o método de NewtonRapson e, também como no circuito passivo. Em cada nova interação, calculou-se as novas permeabilidades para os componentes compostos pelos ferros do rotor, pelo ferro do núcleo e pelo ferro do estator interno. Então, resolveu-se a equação de malha obtendo um novo resultado.

\subsection{Validação do Modelo}

O modelo analítico obtido foi validado com o modelo desenvolvido em elementos finitos de três dimensões.

Dois tipos de análises foram realizadas nos modelos, a primeira, estipulando uma dimensão fixa à parte ativa do mancal e variando a corrente nas bobinas e a posição do rotor. A segunda, mantendo a mesma corrente e posição do rotor, mas variando algumas dimensões geométricas a fim de validar a qualidade do modelo para diferentes 
geometrias.

A comparação entre os modelos no caso da variação da corrente e do deslocamento do rotor para uma determinada geometria pode ser analisado na Fig. 4.4. As forças obtidas por ambos modelos apresentam perfil e grandeza similares, porém os modelos divergem ligeiramente quando a corrente é máxima.

Isso acontece devido a saturação do ferro e o início da dispersão do campo magnético, influenciando tanto no fator de espraiamento quanto nas linhas de campo.

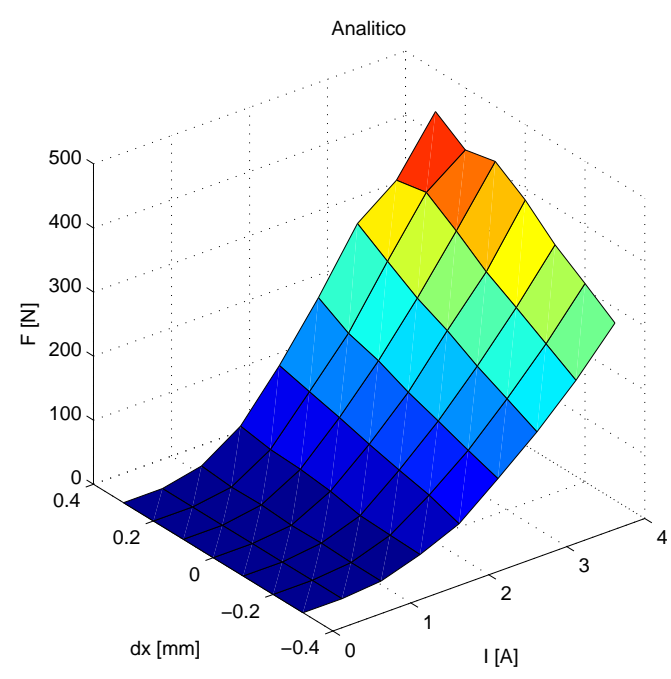

(a) Modelo analítico

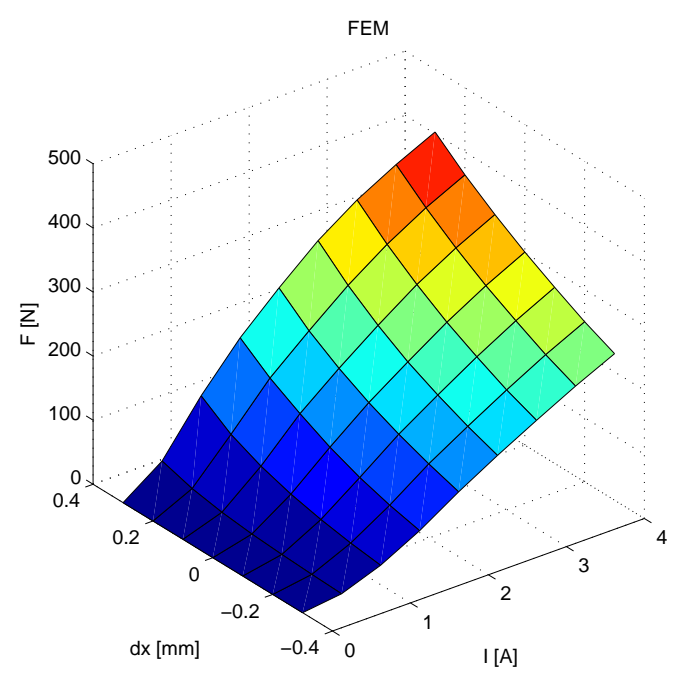

(b) Modelo em elementos finitos

Figura 4.4: Modulo da força resultante devido ao deslocamento do rotor e a variação na corrente aplicada nas bobinas

A Fig. 4.6 mostra uma comparação dos modelos quando submetidos a variação nos parâmetros construtivos, nesse caso variou-se a largura do núcleo da bobina $\left(w_{n}\right)$, sua altura $\left(h_{n}\right)$ e a largura do estator interno $\left(w_{f e i}\right)$. Nota-se a relação estreita entre os modelos quando as dimensões assumem valores maiores, a justificativa para tal fato é o desaparecimento de fluxos magnéticos não previstos no modelo analítico. Quanto mais próxima uma curva da outra, melhor é o ajuste do modelo, nesta simulação, os modelos assumem os valores da lista a seguir : 


$$
\begin{aligned}
h_{n} & =[1: 2: 8] 10^{-3} \\
w_{n} & =[10: 2.5: 20] 10^{-3} \\
w_{f e i} & =[1: 0.5: 2] 10^{-3}
\end{aligned}
$$

Figura 4.5: Força magnética $(\mathrm{N})$ x Variação de parâmetros

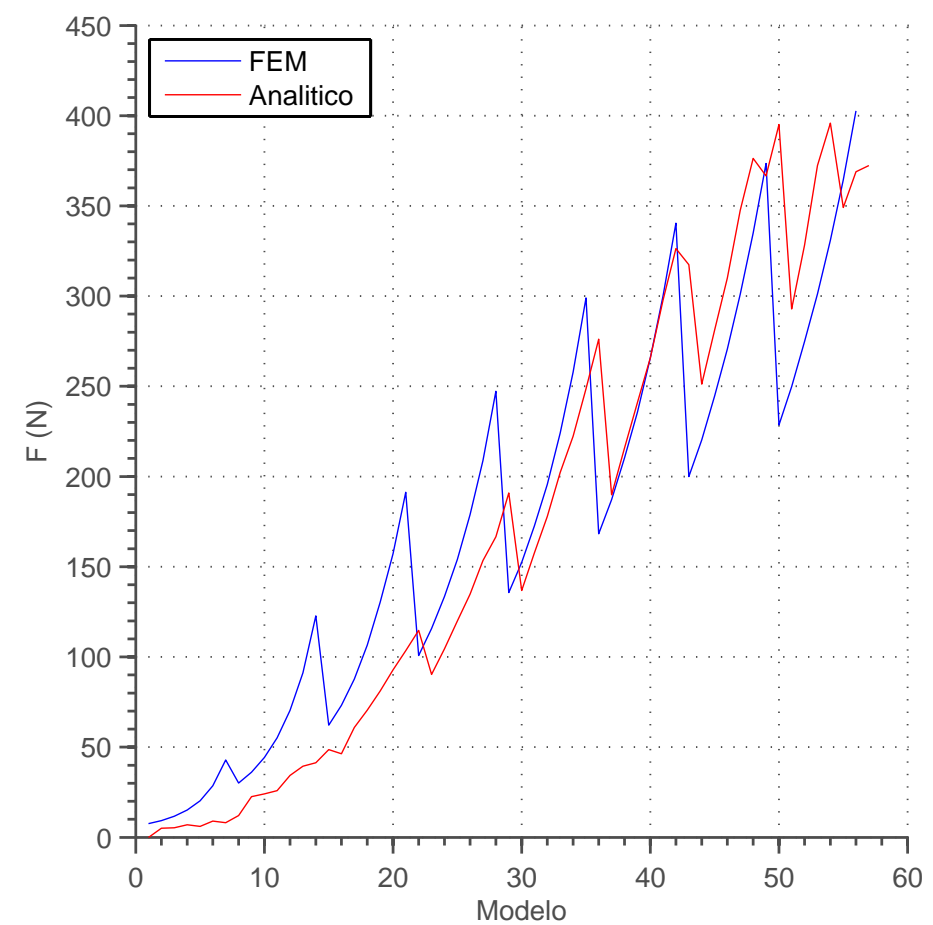

Figura 4.6: Comparativo entre modelos quanto a variação da geometria

\subsection{Otimização dos Parâmetros}

Os parâmetros que devem ser otimizados são aqueles que não influenciam na topologia definida para a parte passiva do mancal, já que a mesma foi otimizada separadamente. 
Optou-se por não realizar uma otimização de ambas as partes simultaneamente evitando o problema da dimensionalidade.

As variáveis otimizadas nesta etapa do projeto foram: o entreferro interno $\left(g_{g i}\right)$, o comprimento $\left(w_{n}\right)$, altura $\left(l_{n}\right)$ e largura $\left(h_{n}\right)$ do núcleo da bobina e a quantidade de espiras da bobina $(N)$. O atuador tem que ser capaz de vencer a força de atração de $140 \mathrm{~N}$ gerada pelo circuito passivo quando o rotor encontra-se no maior deslocamento (0.3 mm, limitado pelo batente).

Um ponto levado em consideração nessa etapa foi o da área útil das bobinas. Esse espaço restrito é limitado pelo tamanho do ferro e pela largura do núcleo da bobina. A Fig. 4.7 ilustra a área em que a bobina está localizada. O cálculo dessa área $\left(S_{b o b}\right)$ levou em consideração a secção do fio utilizado $\left(S_{f i o}\right)$, o fator de embobinamento $\left(K_{b}\right)$ e o número de espiras $(N)$, podendo ser calculado como:

$$
S_{b o b}=2 N S_{f i o} K_{b}
$$

Durante a otimização, verificou-se se a área útil para embobinamento era satisfeita, caso contrário o modelo obtido era descartado e uma nova otimização realizada.

Os parâmetros geométricos iniciais $\left(L_{0}\right)$ do estator interno foram levantados partindo da restrição de potência imposta pela especificação da Tab. 2.1. Com a potência (100W) e tensão elétrica de alimentação $(24 \mathrm{~V})$ obtemos a corrente máxima de trabalho (4A). Essa corrente elétrica deve ser suficiente para gerar uma força de atração que consiga compensar a força gerada pelo circuito passivo no maior entreferro, levantada no modelo em elementos finitos $(160 \mathrm{~N})$. Da equação de força magnética $\left(B^{2} \cdot A /(l / \mu+2 g)^{2}\right)$ foi possível encontrar uma aproximação da área do polo necessária para gerar uma força capaz de vencer a força imposta pelo ímã. Com um valor inicial da área transversal do polo, definiu-se o número de espiras necessário para gerar o fluxo magnético no entreferro. 

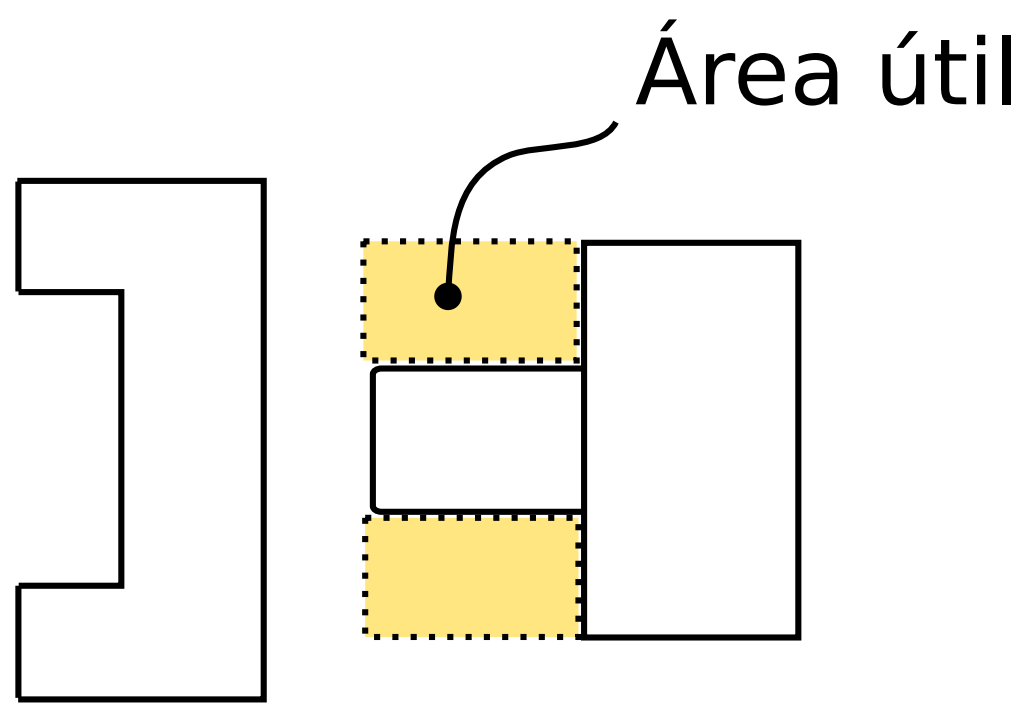

Figura 4.7: Área útil para embobinamento de cada núcleo

Com a área útil e a quantidade, definiu-se a bitola do fio com base na resistência elétrica capaz de gerar a corrente de 4A resultante em um fio AWG 23.

A otimização foi realizada via método de Nelder-Mead Simplex com restrições, limitando assim a dimensão máxima do mancal, evitando que a topologia proposta sofresse alterações ao longo da otimização e que dimensões não condizentes com as especificações fossem obtidas. A condição inicial adotada no método citado anteriormente, assim como as restrições são apresentadas na Tab. 4.1.

\begin{tabular}{ccccccc} 
& $w_{g i}$ & $N$ & $h_{n}$ & $w_{n}$ & $l_{n}$ & $r_{n}$ \\
\hline \hline$L_{0}$ & 0.6 & 300 & 10 & 22 & 6 & 12 \\
$L_{\text {Min }}$ & 0.4 & 50 & 5 & 10 & 3 & 6 \\
$L_{\text {Max }}$ & 1.2 & 600 & 20 & 30 & 10 & 22
\end{tabular}

Tabela 4.1: Valores iniciais, máximos e mínimos utilizados na otimização. Valores em milímetros.

A função de mérito utilizada no projeto do atuador engloba a força de atração $F_{b}$ resultante da aplicação de uma corrente de $4 \mathrm{~A}$ no núcleo principal e de $2 \mathrm{~A}$ nos núcleos secundários, a indutância da bobina $\left(L_{b}\right)$ e do volume do estator interno $\left(V_{m a}\right)$. Buscou-se um modelo que possuísse maior força de atração, baixa indutância e menor 
volume. As parcelas utilizadas durante a otimização são:

$$
\begin{aligned}
P_{1} & =310^{2} / F_{b} \\
P_{2} & =1510^{4} L_{b} \\
P_{3} & =10^{6} V_{m a} \\
P_{4} & =\frac{2510^{-4}}{w_{g i}} \\
F & =P_{1}+P_{2}+P_{3}+P_{4}
\end{aligned}
$$

A evolução dos parâmetros ao longo da otimização está ilustrada na Fig. 4.8. Durante o processo interativo, verificou-se o acréscimo da força de atração, com maior peso na função de mérito. A evolução do valor do entreferro assumiu uma medida média, já que seu peso influencia diretamente a força de atração. A Fig. 4.9 mostra a evolução dos pesos propostos para o funcional ao longo da otimização. Obteve-se com a otimização proposta um mancal com volume inferior ao inicialmente proposto com indutância diminuída. 

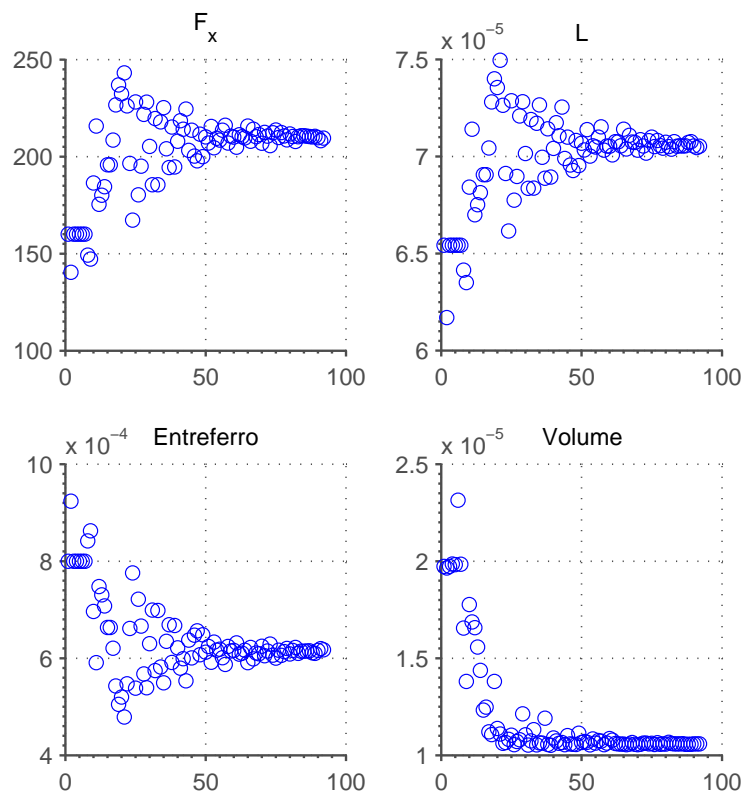

Figura 4.8: Evolução dos parâmetros construtivos do mancal ao longo da otimização

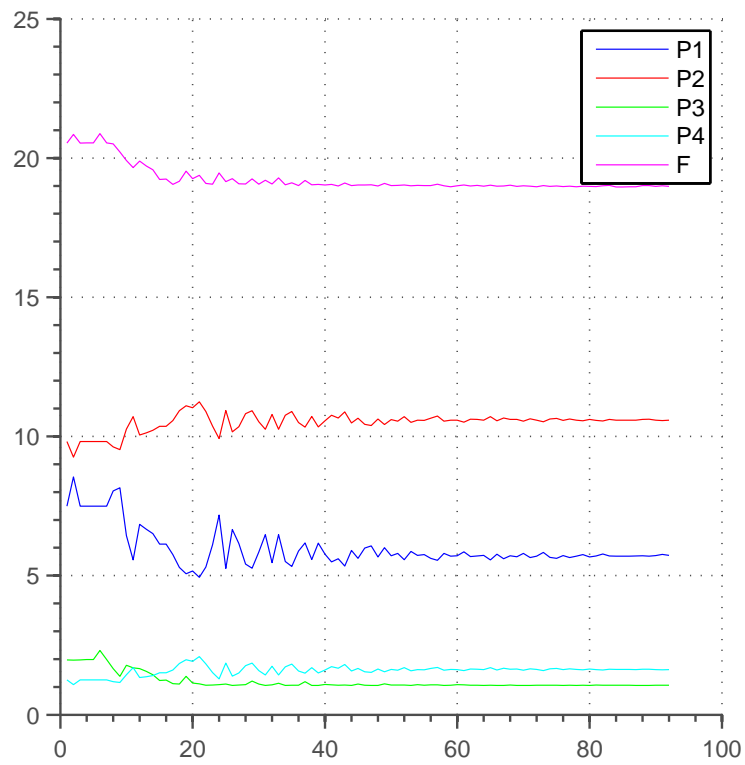

Figura 4.9: Evolução dos pesos propostos para o funcional ao longo da otimização 


\subsection{Mancal Ativo Resultante da Otimização}

O mancal ativo resultante possui as dimensões listadas na Tab. 4.2. A força de atração resultante da excitação das bobinas com uma corrente principal de $4 \mathrm{~A}$, com o rotor no seu deslocamento máximo e sob o efeito da atração oposto do circuito passivo é de $23 \mathrm{~N}$ (força resultante da soma das forças do estator externo e bobinas), ou seja, o atuador proposto é capaz de retirar o rotor de sua posição de máximo deslocamento e movê-lo para seu ponto de operação.

\begin{tabular}{ccccc}
$w_{g i}$ & $N$ & $h_{n}$ & $w_{n}$ & $w_{f e i}$ \\
\hline \hline 0.7 & 300 & 10.8 & 14.9 & 6
\end{tabular}

Tabela 4.2: Mancal ativo obtido devido a otimização, valores em milímetros

A curva de força $\left(F_{b}\right)$ por deslocamento é ilustrada na Fig. 4.10. Nessa simulação o rotor está deslocado 0.3 milímetros de sua posição nominal, as bobinas exitadas são aquelas do mesmo sentido do deslocamento do rotor, gerando assim, uma força de atração oposta à do estator externo.

Verifica-se que a força gerada pelas bobinas vence a força gerada pelo estator externo quando uma corrente superior a 3.5A é aplicada no polo principal. A curva de força por corrente nesse ponto de operação é não linear, o que dificulta o projeto do controlador.

Diversas simulações foram realizadas para caracterizar a força de atração quanto à variação da corrente e da posição, o resultado é mostrado na Fig. 4.11. Nele nota-se o comportamento similar da força de atração com o diferencial do ganho do sistema.

Através de um corte axial verificamos que as linhas de campo magnético estão contidas nos polos ativos, isso ocorre devido a polarização das correntes nos polos secundários que força o fluxo por eles. Verificamos também que o componente magnético responsável pela maior contribuição na relutância é o núcleo da bobina principal (polo). 
Força de atração $(\mathrm{N})$ x Corrente $(\mathrm{A})$

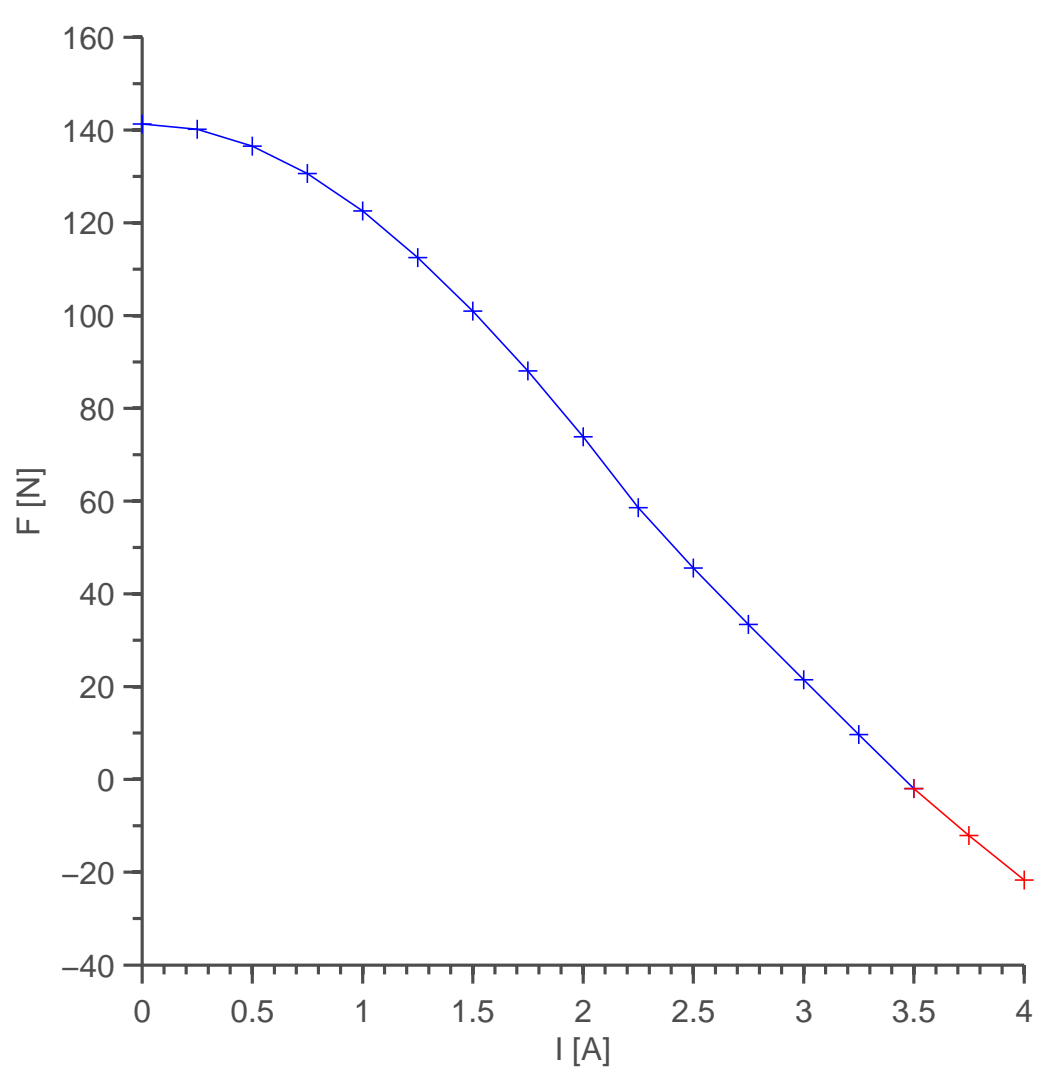

Figura 4.10: Força resultante da aplicação de uma corrente quando o rotor está deslocado $0.3 \mathrm{~mm}$ (máxima distância) 


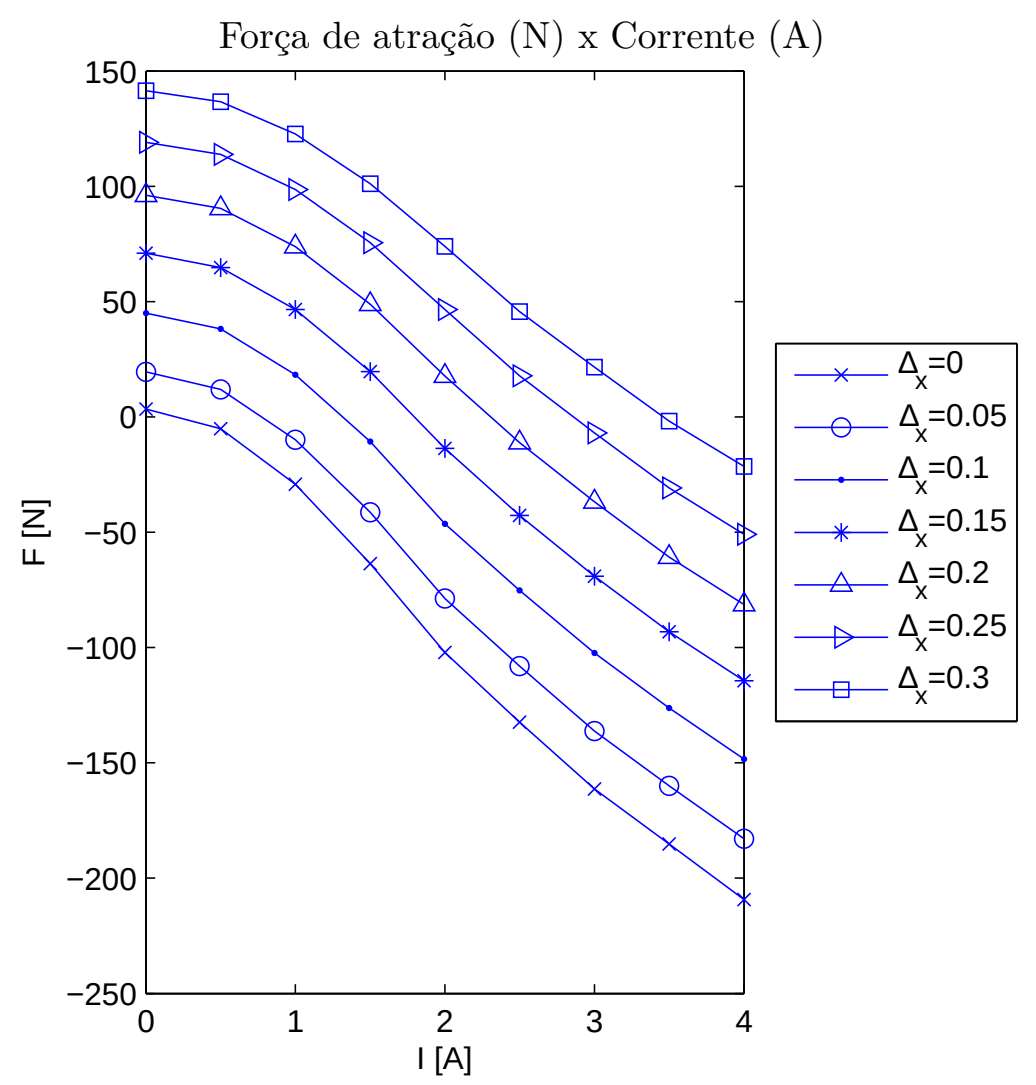

Figura 4.11: Força resultante da aplicação de uma corrente para diversos pontos de operação do rotor 


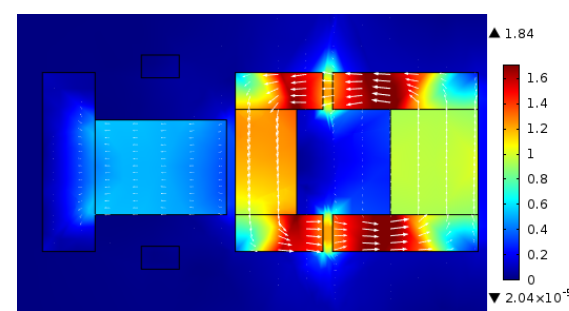

(a) I $=1 \mathrm{~A}$

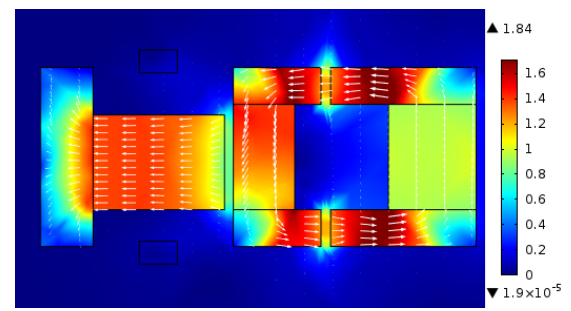

(c) $\mathrm{I}=3 \mathrm{~A}$

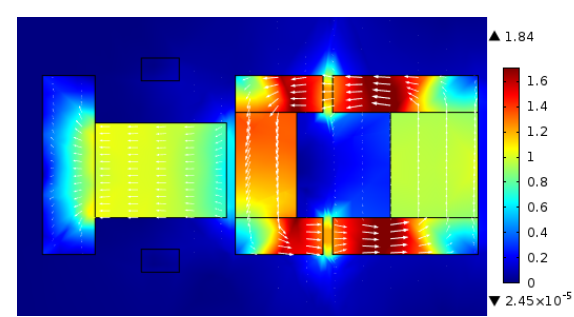

(b) $\mathrm{I}=2 \mathrm{~A}$

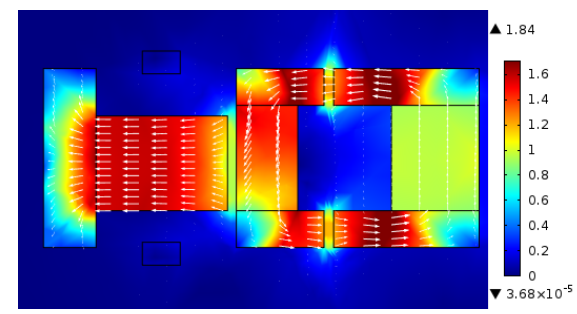

(d) $\mathrm{I}=4 \mathrm{~A}$

Figura 4.12: Vetor campo magnético no polo principal quando variada a corrente, rotor com deslocamento de $0.3 \mathrm{~mm}$ de sua posição.

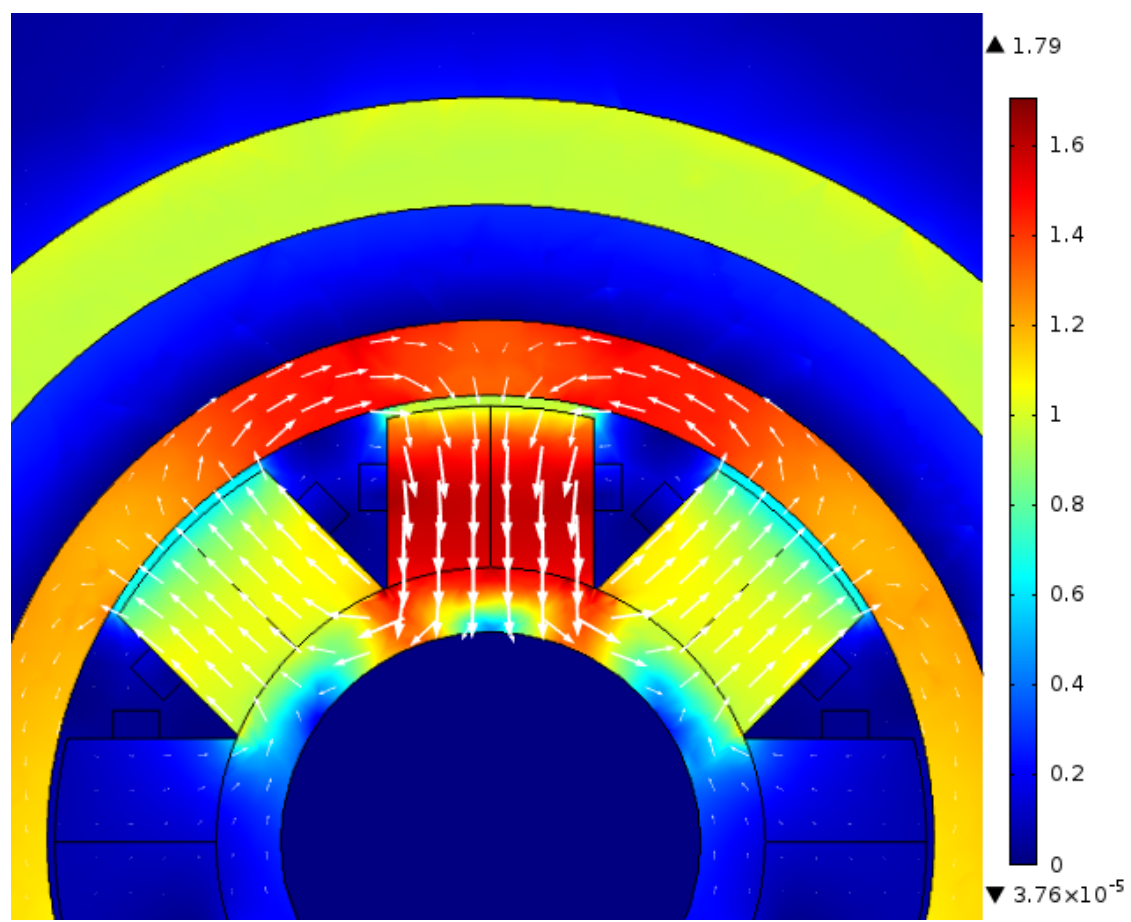

Figura 4.13: Vetor campo magnético de uma seç̧ão radial do mancal quando aplicada uma corrente de $4 \mathrm{~A}$ no polo principal 


\section{Capítulo 5}

\section{Modelagem Dinâmica e \\ Controlador}

Nesse capítulo será, abordado a modelagem dinâmica do rotor, que sofre influências das forças do estator externo e dos polos do estator interno. Um modelo linearizado no ponto de operação é apresentado para o projeto do controlador.

\subsection{Modelagem}

A dinâmica do rotor é influenciada basicamente pela sua velocidade de rotação $(\dot{\theta})$, sua inércia $(I)$, sua massa $(m)$ e posição relativa do rotor $\left(d_{x}, d_{y}, d_{z}\right)$, compondo a energia cinética $(T)$ do sistema. A parcela da energia potencial $(V)$ se dá pela sua translação axial $\left(d_{z}\right)$, pela gravidade $(g)$ e pela rigidez passiva do mancal $\left(K_{z}\right)$ calculada. A Fig. 5.1 ilustra as forças atuantes no rotor, sendo:

- $F_{p}$ : Força devido ao ímã permanente

- $F_{b}$ : Força devido a bobina

- $\tau$ : Torque de rotação devido ao motor 
- $\theta: \mathrm{O}$ angulo do rotor

- $x, y, z$ : Deslocamento do rotor no espaço tridimensional
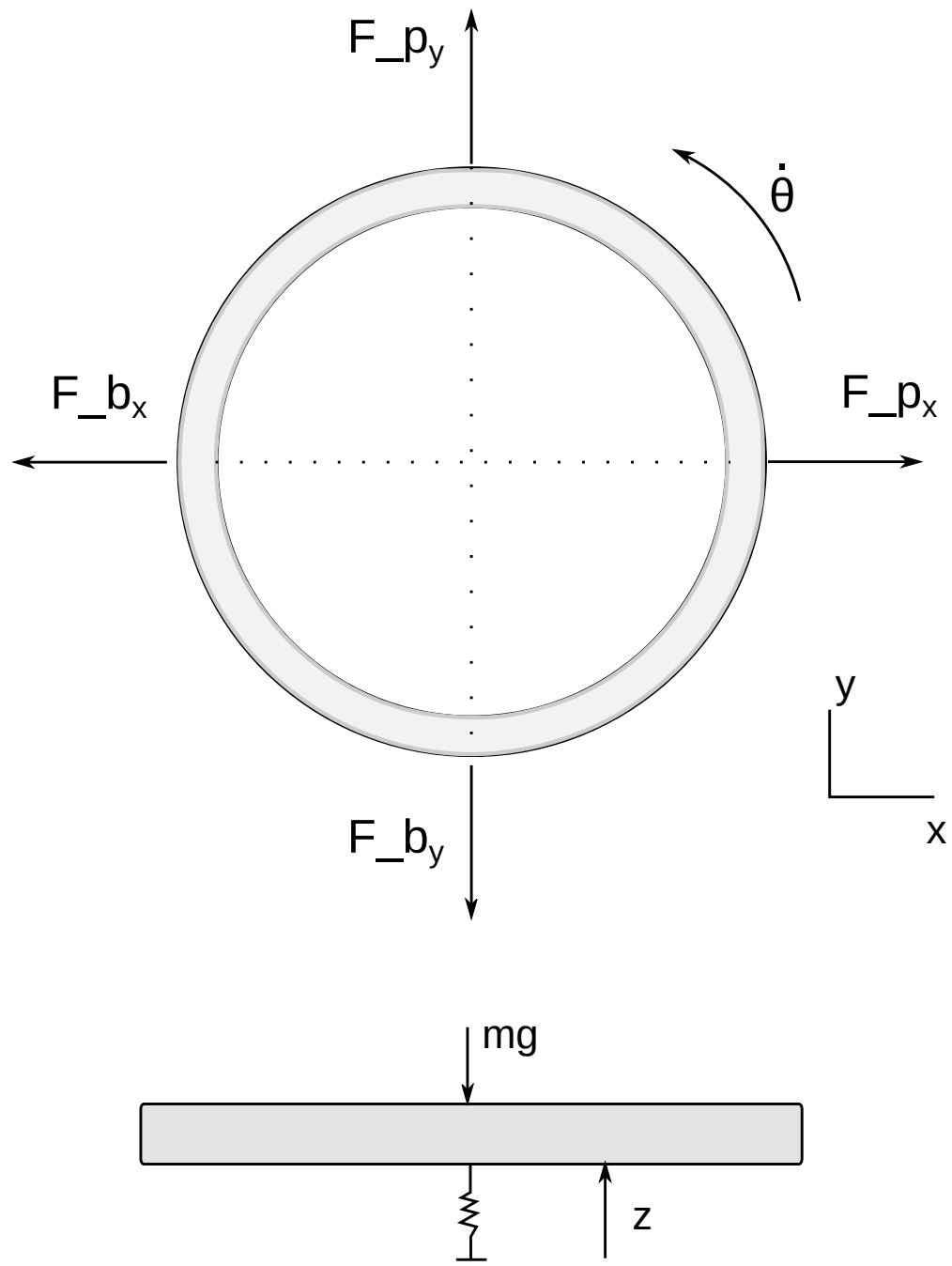

Figura 5.1: Forças atuantes no rotor

A energia cinética e potencial do rotor são dadas por : 


$$
\begin{aligned}
T & =\frac{1}{2} I_{z} \dot{\theta}^{2}+\frac{1}{2} m\left(\dot{x}^{2}+\dot{y}^{2}+\dot{z}^{2}\right) \\
V & =m g z+\frac{1}{2} K_{z} z^{2}
\end{aligned}
$$

Duas forças distintas agem no rotor: a primeira, não conservativa $\left(Q^{n c}\right)$ é causada pela força de atração $\left(F_{b}\right)$ nos atuadores, dependente da posição do rotor $(x, y, z)$ e da corrente aplicada $(i)$; a segunda, conservativa $\left(Q^{c}\right)$ é dependente somente da posição do rotor e é causada pela força de atração dos ímãs, podendo ser traduzida para uma rigidez $\left(K_{p}\right)$. Ambas as forças $F_{b}$ e $K_{p}$ são calculadas pelo modelo de elementos finitos, dadas pelas componentes

$$
\begin{aligned}
Q_{y}^{n c} & =F_{b y}(x, i) \\
Q_{x}^{n c} & =F_{b x}(y, i) \\
Q_{x}^{c} & =K_{p} x \\
Q_{y}^{c} & =K_{p} y
\end{aligned}
$$

Onde: $Q_{x}^{n c}$ e $Q_{y}^{n c}$ são as forças não conservativas projetadas no eixo x e y; $Q_{x}^{c}$ e $Q_{y}^{c}$ as forças conservativas atuantes nos eixos x e y; $F_{b y}$ e $F_{b y}$ as forças resultante das bobinas respectivamente nos eixos $\mathrm{x}$ e $\mathrm{y}$.

Com a resolução da lagrangiana dada por Eq. 5.6

$$
\begin{array}{r}
L=T-V \\
\frac{\partial}{\partial t}\left[\frac{\partial L}{\partial \dot{r}}\right]-\frac{\partial L}{\partial r}=Q^{n c}+Q^{c}
\end{array}
$$


obtivemos as equações da dinâmica do sistema Eq. 5.10):

$$
\begin{aligned}
I \ddot{\theta} & =0 \\
m \ddot{x} & =K_{p} x-F_{b x}(x, i) \\
m \ddot{y} & =K_{p} y-F_{b y}(y, i) \\
m \ddot{z} & =K_{z} z+m g
\end{aligned}
$$

Exceto pela dependência das posições nas forças, verifica-se, pelas equações, o desacoplamento entre os diferentes eixos $(\mathrm{x}, \mathrm{y}, \mathrm{z})$.

\subsubsection{Rigidez Passiva: $K_{p}$}

A força exercida no rotor devido aos ímãs permanentes do estator externo pode ser aproximada por uma equação linear, como visto na Sec. 3.2.1. Para pequenos deslocamentos, pode-se representar o ganho pela decomposição:

$$
\begin{aligned}
& F_{p x}=K_{p} x \\
& F_{p y}=K_{p} y
\end{aligned}
$$

Onde $K_{p}$ é a constante de proporção entre a força e a posição e x e y são os deslocamento em torno do ponto de equilíbrio do rotor com relação ao estator externo. Obteve-se, via a simulação em elementos finitos, uma relação força por deslocamento para ambos os eixos (devido a simetria do mancal).

$$
K_{p}(d)=625 \mathrm{~N} / \mathrm{mm}
$$




\subsubsection{Rigidez Ativa : $F_{b}$}

A força de atração do rotor devido ao campo magnético gerado pelas bobinas é não linear com a posição do rotor (comprimento do entreferro) e depende da corrente de excitação aplicada às bobinas.

As tensões nas bobinas são distribuídas conforme é mostrado na Fig. 5.2 (a), onde existe sobreposição de bobinas para atuação em diferentes eixos (X e Y). É aplicada nas bobinas que possuem sobreposição a metade da tensão, limitando assim o valor das correntes totais nas bobinas para o valor máximo $\left(\mathrm{I} / 2+\mathrm{I} / 2=I_{m} a x\right)$. A Fig. 5.2 ilustra a configuração proposta. Verificamos que a tensão é aplicada em metade para as bobinas com sobreposição (A,G,E,C) e com ganho unitário nas bobinas principais $(\mathrm{H}, \mathrm{F}, \mathrm{D}, \mathrm{B})$.

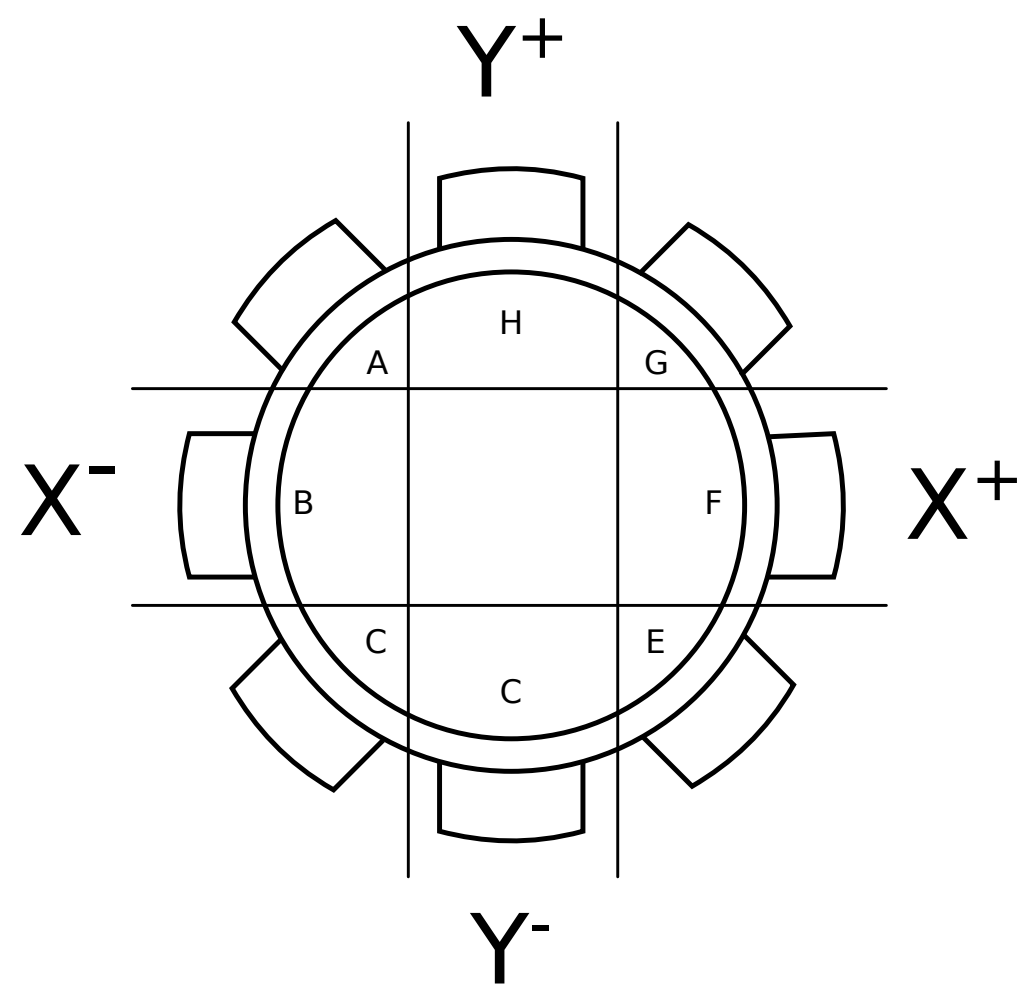

Figura 5.2: Distribuição das correntes nas bobinas

Através das forças calculadas via resultados da modelagem em elementos finitos, 
determinou-se um polinômio de segundo grau com confiança de $95 \%$ capaz de representar a curva encontrada. (Eq. 5.14) Utilizou-se os resultados demonstrado na Fig. 4.11. Os coeficientes estão descritos na Tab. 5.1.

$$
\begin{gathered}
F_{b x}(d x, I)=p_{00}+p_{10} d x+p_{01} I+p_{20} d x^{2}+ \\
p_{11} d x I+p_{02} I^{2}+p_{30} d x^{3}+p_{21} d x^{2} I+ \\
p_{12} d x I^{2}+p_{03} I^{3}
\end{gathered}
$$

$\begin{array}{ll}p_{00} & -3.25 \\ p_{10} & -5.17 \\ p_{01} & 24.13 \\ p_{20} & 98.13 \\ p_{11} & -90.04 \\ p_{02} & 22.83 \\ p_{30} & -146 \\ p_{21} & 22.29 \\ p_{12} & 9.44 \\ p_{03} & -3.79\end{array}$

Tabela 5.1: Coeficientes do ajuste à curva de ganho $\mathrm{Kb}$

\subsubsection{Dinâmica do Atuador}

Devido as bobinas dos polos do estator interno, uma dinâmica do atuador $\left(G_{a}(s)\right)$ atrelada a indutância deve ser considerada. A bobina é modelada como um circuito RL, com a dinâmica descrita na Eq. (5.15).

$$
I(s)=\frac{V(s)}{R+L s}
$$

Os valores das indutâncias são calculados como foi apresentado na SubSec. 4.3. O 
valor nominal no ponto de operação de cada bobina é de aproximadamente $76 \mu H$ e a sua resistência elétrica é de $6.3 \Omega$ causando uma frequência de corte de $13 \mathrm{kHz}$.

As tabelas 5.2 e 5.3 mostram a evolução da indutância principal (L) e da mútua (M) quando uma corrente de 4 Ampères é aplicada no polo principal.

\begin{tabular}{cc}
$\mathrm{L}[\mathrm{uH}]$ & $d_{x}[\mathrm{~mm}]$ \\
\hline \hline 78.013 & 0.00 \\
77.450 & 0.05 \\
76.890 & 0.10 \\
76.333 & 0.15 \\
75.710 & 0.20 \\
75.048 & 0.25 \\
74.381 & 0.30
\end{tabular}

Tabela 5.2: Indutância calculada para um único polo em diversos pontos de operação via elementos finitos. Corrente aplicada de $4 \mathrm{~A}$ no polo principal

\begin{tabular}{cc}
$\mathrm{M}[\mathrm{uH}]$ & $d_{x}[\mathrm{~mm}]$ \\
\hline \hline 18.693 & 0.00 \\
18.327 & 0.05 \\
17.979 & 0.10 \\
17.638 & 0.15 \\
17.303 & 0.20 \\
16.988 & 0.25 \\
16.662 & 0.30
\end{tabular}

Tabela 5.3: Indutância mutua calculada para um único polo em diversos pontos de operação via elementos finitos. Corrente aplicada de $4 \mathrm{~A}$ no polo principal

Uma aproximação linear das indutâncias foi calculada (Eq. 5.17) para a utilização na modelagem não linear. Essas equações demonstram a sensibilidade que um sensor de indutância teria que ter, em uma futura implementação, para a leitura da posição relativa do rotor via a indutância dos polos. 


$$
\begin{gathered}
L(x)=-1.20610^{-5} d x+2.80710^{-5} \\
M(x)=-6.75610^{-6} d x+1.86710^{-6}
\end{gathered}
$$

\subsubsection{Modelo Linear}

O modelo linear $\left(G_{m a}\right)$ de malha aberta para um dos eixos de movimentação no plano $\mathrm{x}, \mathrm{y}$ (radial) foi levantado em torno do ponto de equilíbrio do rotor, considerou-se as dinâmicas do rotor $\left(G_{r}\right)$ e do atuador $\left(G_{a}\right)$ deduzidas das equações (5.9) e (5.15), dadas respectivamente por :

$$
\begin{aligned}
G_{r} & =\frac{1}{s^{2} m-K_{p}} \\
G_{a} & =\frac{K_{b}}{s L+R}
\end{aligned}
$$

O modelo encontrado (linearizado em torno do ponto de operação ) é utilizado para o projeto do controlador $(C(s))$. A função transferência do modelo obtido é mostrada na Eq. (5.20), o sistema obtido possui três polos sendo nenhum deles sendo integrador puro (sistema tipo 0), dada por:

$$
\begin{aligned}
G_{m a}(s)=G_{r}(s) G_{a}(s) & =\frac{K_{b}}{\left(s^{2} m-K_{p}\right)(s L+R)} \\
& =\frac{58}{\left(s^{2} 0.375-625\right)\left(s 7.810^{-5}+6.3\right)}
\end{aligned}
$$

Os três polos estão localizados em: $[-82000,-41,41]$, onde a função de transferência é descrita na Eq. (5.20), os parâmetros utilizados foram encontrados nas secções anteriores. 
Verificou-se que o sistema é instável em malha aberta e um controlador deve ser projetado para estabilizá-lo.

\subsubsection{Modelo Dinâmico Não Linear}

Um modelo dinâmico não linear foi implementado em ambiente Matlab Simulink para a validação do controlador, esse modelo, leva em consideração as modelagens eletromagnéticas realizadas para a otimização do mancal.

A Fig. 5.3 demonstra o diagrama de blocos proposto, sendo $C(s)$ o controlador projetado. Nesse esquema, o controlador age diretamente nas bobinas aplicando a corrente necessária para estabilizar o rotor no ponto de operação.

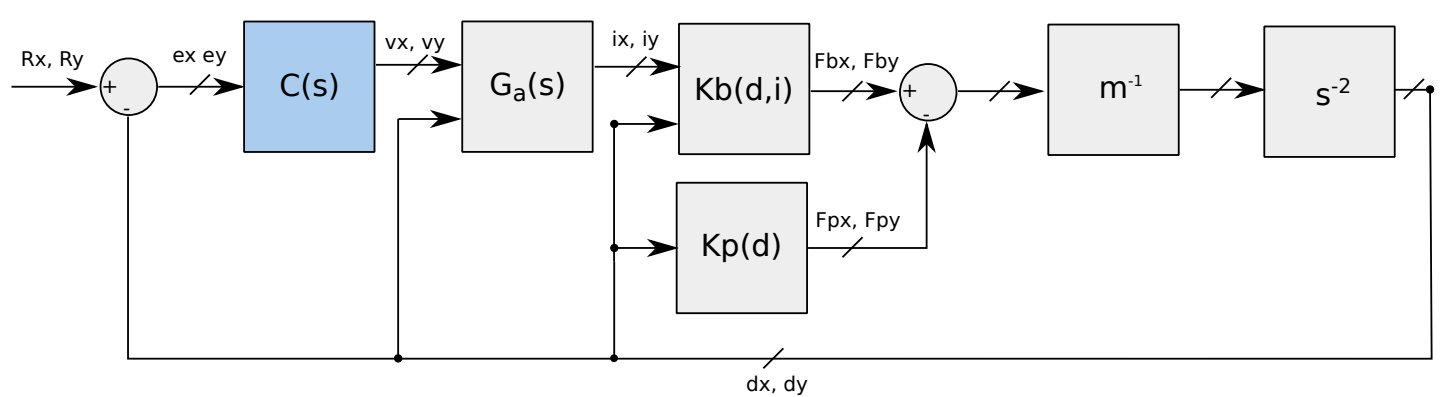

Figura 5.3: Diagrama de blocos do modelo linearizado para deslocamentos em x e y

Duas saturações devem ser consideradas: na primeira a tensão da bobina deve ser limitada ao seu valor máximo (30V), e na segunda a excursão máxima do rotor é limitada pelo batente.

\subsection{Projeto do Controlador}

Um controlador foi projetado a fim de demonstrar a controlabilidade do sistema proposto dentro das especificações impostas ao mancal. O projeto do controlador foi feito via modelo linear e validado utilizando o modelo não linear.

O controlador age diretamente sobre a posição do rotor no plano x,y através de duas 
forças ortogonais: $F_{b x}$ e $F_{b y}$. A corrente necessária para gerar essas forças foi calculada via um estimador de corrente que traduziu a força imposta pelo controlador na corrente necessária levando em consideração a posição do rotor.

\subsubsection{Estimador}

A fim de superar as não linearidades no ganho do atuador $(K b(d, i))$, um controle de força foi projetado no lugar do de corrente. A força calculada pelo controle $\left(F_{b}\right)$ foi aplicada em um estimador que calculou a corrente necessária a ser aplicada na bobina com base na posição do rotor. A Fig. 5.4 mostra o estimador de corrente proposto, que depende da área do polo $\left(S_{n}\right)$, do comprimento do entreferro $\left(l_{g}(d x)\right)$ e do número de espiras $\left(n_{n}\right)$. O equacionamento obtido através de um modelo simplificado da equação de força magnética considerando apenas um entreferro e um componente ferromagnético é dado por:

$$
I=\sqrt{\frac{2 F_{b} \mu_{0}}{S_{n}}} \frac{l_{g}(d x) \mu_{0}}{n_{n}}
$$

Um exemplo da variação do ganho do atuador $\left(K_{b}\right)$ pode ser ilustrado em dois cenários distintos, o primeiro, quando o rotor está em seu ponto de operação, sua força de atração gerada pela aplicação de uma corrente de $4 \mathrm{~A}$ é $209 \mathrm{~N}$, segundo quando o rotor encontra-se em seu deslocamento máximo $\left(d_{x}=0.3 \mathrm{~mm}\right)$ e a força resultante é de apenas $120 \mathrm{~N}$.

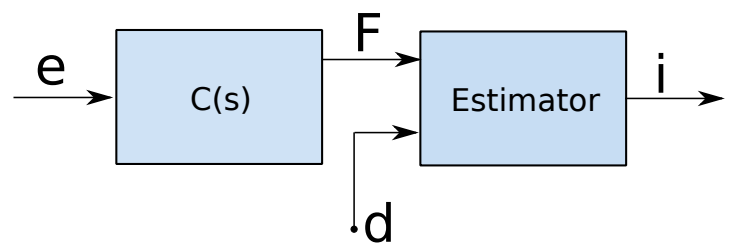

Figura 5.4: Diagrama de blocos do controlador e do estimador 


\subsubsection{Controlador}

O controlador proposto para o mancal magnético é um controle do tipo Proporcional (P), Integral (I) e Derivativo (D), com a estrutura da Eq. (5.22), um filtro (N) foi aplicado ao fator derivativo a fim de evitar que ruídos provenientes do sensor fossem amplificados pelo controlador, cuja função de transferência é

$$
C(s)=P\left(1+\frac{I}{s}+\frac{N D}{1+\frac{N}{s}}\right)
$$

O controlador foi projetado considerando o ganho unitário da bobina $\left(K_{b}=1\right)$, isso foi necessário para gerar um controlador que possuísse a força como esforço de controle e não a corrente. A saída do controlador foi aplicada ao estimador que traduziu, por sua vez, a força em tensão necessária à bobina.

Devido à instabilidade do sistema em malha aberta e as variações do ganho do atuador de forma não linear com a movimentação do rotor, optou-se por projetar um controlador privilegiando a robustez ao invés da agilidade.

Como especificação de projeto, definiu que o sistema em malha fechada deveria ter ao menos 50 graus de margem de fase e $20 \mathrm{~dB}$ em margem de ganho. Ambos os parâmetros foram escolhidos para suportar a adição de um sensor de posição ao sistema, que influenciará com uma nova dinâmica na malha de controle, impondo varições de ganho e fase na leitura da posição do rotor.

O controlador obtido via especificação possui os ganhos da Tab. 5.4:

\begin{tabular}{cccc}
$\mathrm{kp}$ & $\mathrm{ki}$ & $\mathrm{kd}$ & $\mathrm{N}$ \\
\hline \hline 1926 & 5.89 & 0.017 & 1616
\end{tabular}

Tabela 5.4: Ganhos do controlador PID

O controle obtido impôs uma estabilidade no mancal com 60 graus de margem de fase e $27.8 \mathrm{~dB}$ margem de ganho. O tempo de acomodação foi de $123 \mathrm{~ms}$ com sobressinal 
de $12 \%$.

A simulação (feita com o modelo não linear) do controlador PID com o estimador no sistema com ganhos variáveis é mostrada na Fig. 5.6, nessa simulação, o rotor tem condições iniciais não nulas. Verifica-se que o controle é capaz de estabilizar o rotor em seu ponto de operação aplicando uma corrente dentro das especificações. 


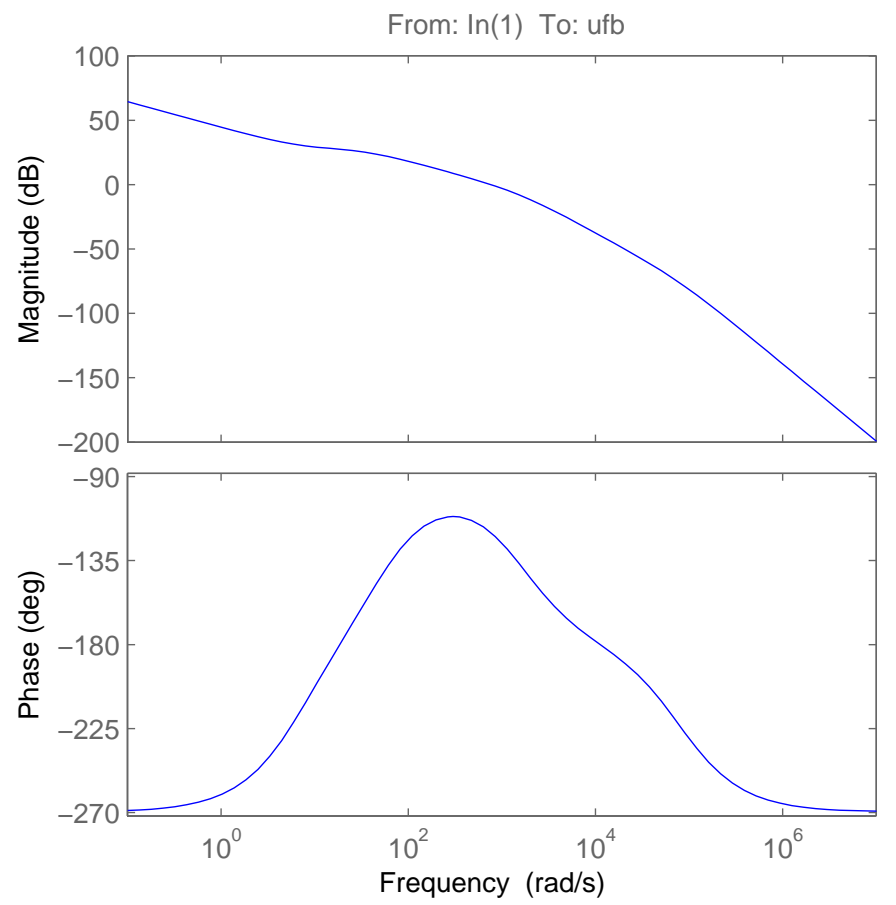

(a) Diagrama de Bode

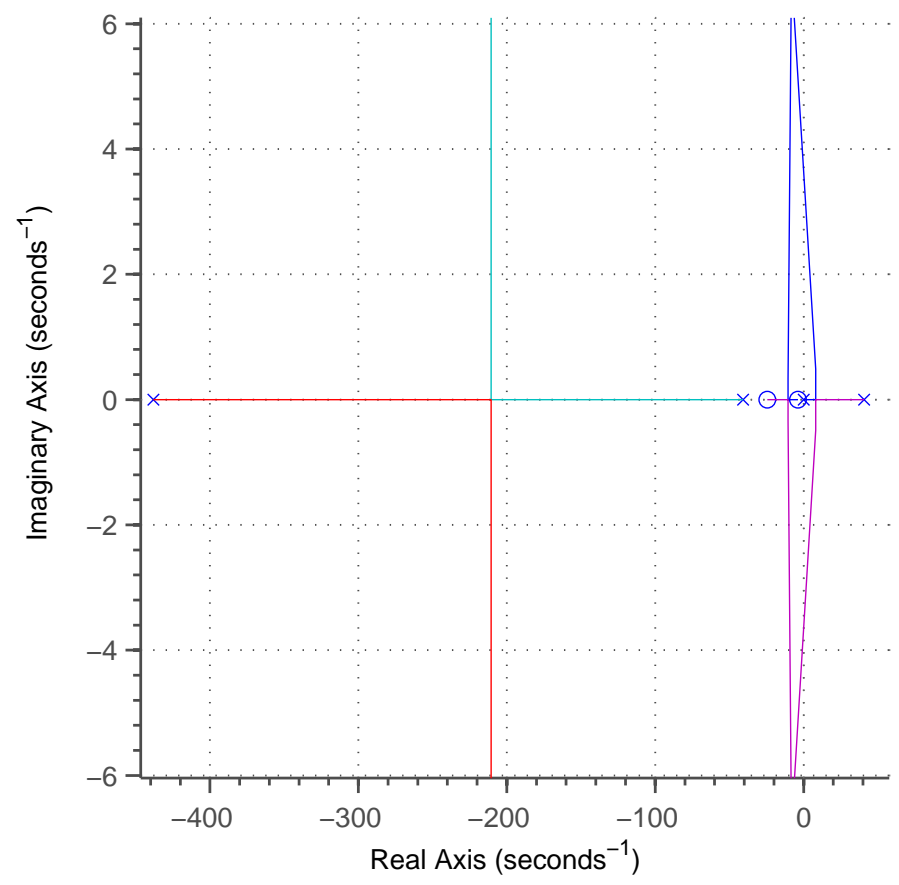

(b) Lugar das raizes

Figura 5.5: Análise do sistema controlado, diagrama de bode e lugar das raízes 


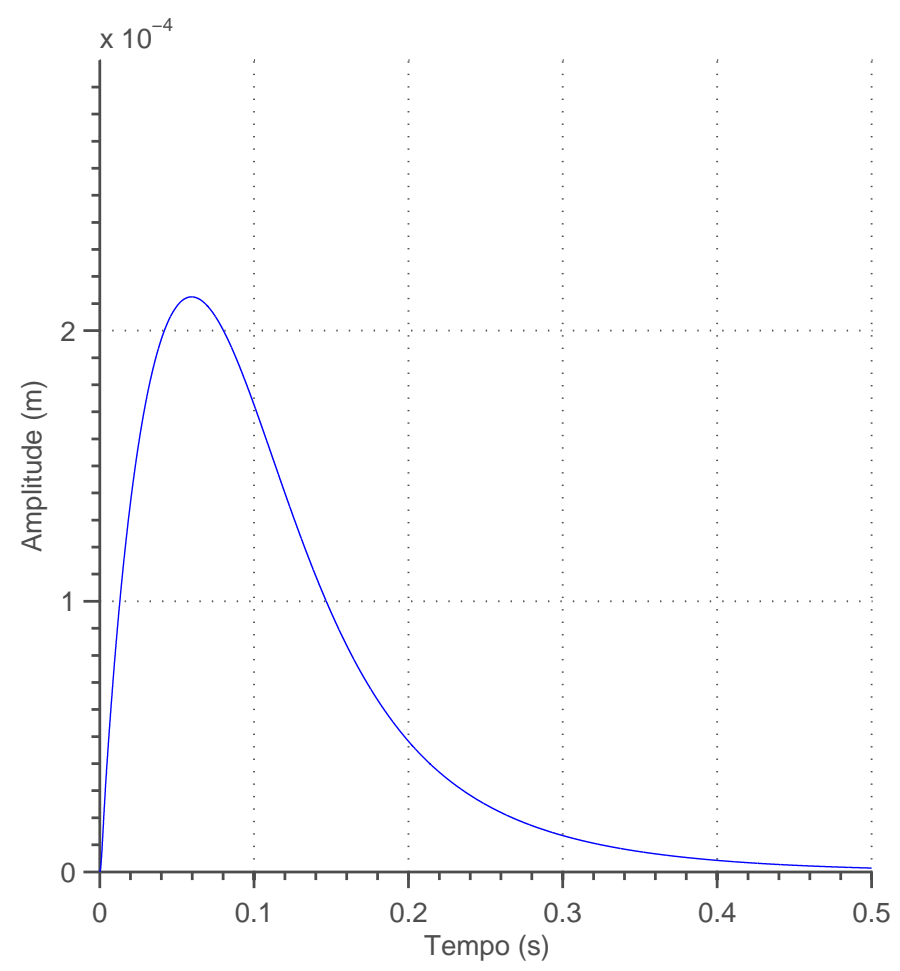

(a) Posição rotor

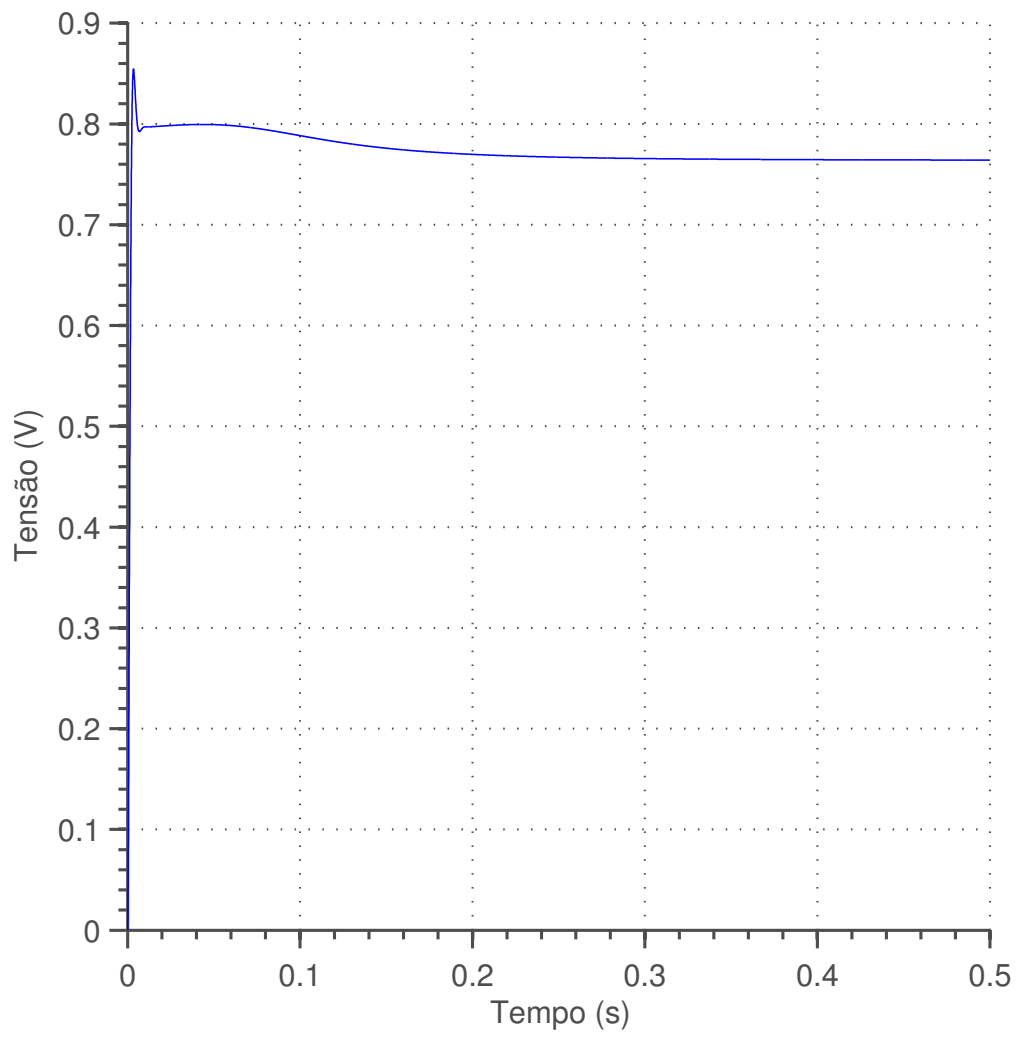

(b) Esforço de controle

Figura 5.6: Resposta temporal do sistema em malha fechada com condições iniciais não nulas 


\section{Capítulo 6}

\section{Considerações Finais}

O mancal magnético obtido com o desenvolvimento desta dissertação abre portas para a prototipagem de uma roda de reação nacional para controle de atitude de satélites 2 . Com este projeto será possível reduzir os problemas que surgem no uso de mancal convencional (mecânico) em ambiente espacial.

Em projetos aerospaciais muitas vezes especifica-se atuadores que não possuem equivalentes comerciais, em parte devido ao restrito mercado e em parte pela especificidade do problema. A metodologia aqui proposta pode ser aplicada para a especificação de mancais com diferentes características, sendo facilmente adaptável ao projeto (ou diferentes projetos) de atuadores

O processo de otimização proposto facilita a escolha dos parâmetros construtivos do mancal já que o problema é reduzido à especificação de desempenho e restrições, só possível devido ao modelo analítico dos campos magnéticos envolvidos.

A utilização de simulações em elementos finitos tornou mais preciso o resultado final, sendo uma ferramenta importante tanto para validação do modelo quanto para o entendimento das propriedades físicas do sistema, possibilitando uma forma gráfica de

\footnotetext{
${ }^{2}$ Todo o material desenvolvido ao longo dessa dissertação está disponível para consulta no site https://github.com/corsiferrao/Mancal-Magnetico
} 
análise dos resultados.

O esforço computacional associado à utilização do método de elementos finitos produziu uma ferramenta lenta, já que uma simulação leva dezenas de minutos para convergir para uma solução.

A utilização de super computadores foi cogitada durante o desenvolvimento dessa dissertação, porém esta solução não foi adotada devido a complexidade de configuração do sistema. Trabalhos futuros devem fazer uso desse recurso.

O modelo dinâmico obtido é de fácil parametrização e depende das forças magnéticas envolvidas (ímã e polos) além da massa do rotor. Sua característica de desacoplamento entre os eixos x e y possibilita a utilização de técnicas de controle do tipo SISO, de fácil implementação em sistemas digitais ou analógicos.

Essa dissertação não abordou a fundo o projeto do controlador, mas mostrou-se que é possível garantir a estabilização com o projeto de um controlador para garantir uma boa operação do sistema. As simulações realizadas mostraram que o projeto resultou robusto em face das variações de ganho do estimador, o que é essencial em sistemas aeroespaciais. A utilização de técnicas modernas de controle é um ramo fértil para esse tipo de sistema, possibilitando melhor desempenho do controlador e por consequência da roda de reação.

O desenvolvimento de um protótipo auxiliou na prova da estabilidade dos graus de liberdade passivos do mancal, porém demonstrou a necessidade de um estudo mais detalhado da topologia a ser escolhida para o mancal, desencadeando na otimização proposta.

A utilização de materiais com melhores propriedades magnéticas que a do aço 1020 deve ser considerada, por poder resultar em um mancal com menores dimensões e menos suscetível às correntes induzidas (Ravaud et al., 2009) quando submetido a um campo alternado.

Um mecanismo para embobinamento e conformidade das bobinas é necessário para 
a construção de futuros protótipos, garantindo assim que a especificação do sistema seja alcançada na prática. O embobinamento manual mostrou-se impraticável e impossibilitou a execução de mais testes.

Estudos devem ser realizados para o projeto de um mecanismo de travamento, utilizado durante o lançamento do satélite para garantir que as partes móveis não sofram com a aceleração do lançador.

Infelizmente, a ausência de financiamento impossibilitou que um mancal com as dimensões encontradas ao longo do desenvolvimento desta dissertação fosse construído com o rigor mecânico necessário a fim de dar continuidade a implementação.

Pretende-se viabilizar a construção de uma roda de reação e, por conseguinte, de um mancal magnético pelo fomento de um projeto do tipo temático (FAPESP) que está em prospecção junto ao Instituto de Astronomia, Geofísica e Ciências Atmosféricas (IAG). 


\section{Referências Bibliográficas}

Balaban, E., Saxena, A., Bansal, P., Goebel, K. F., e Curran, S. (2009). Modeling, detection, and disambiguation of sensor faults for aerospace applications. IEEE Sensors Journal, 9(12):1907-1917.

Bangcheng, H., Shiqiang, Z., Xi, W., e Qian, Y. (2012). Integral Design and Analysis of Passive Magnetic Bearing and Active Radial Magnetic Bearing for Agile Satellite Application. IEEE Transactions on Magnetics, 48(6):1959-1966.

Bernus, C., Jamain, P., e Roland, J. (1998). Magnetic bearing with alternating actuators and sensors. US Patent 5,763,972.

Boglietti, A. e Cavagnino, A. (2003). Predicting iron losses in soft magnetic materials with arbitrary voltage supply: an engineering approach. IEEE Transactions on Magnetics, 39(2):981-989.

Carrara, V. (2010). Experimental comparison between reaction wheel attitude controller strategies. Journal of Aerospace Engineering, Sciences and Applications, 2(2):1-9.

Carrara, V. e Milani, P. (2007). Controle de uma mesa de mancal a ar de um eixo equipada com giroscópio e roda de reação. V Simpósio Brasileiro de Engenharia Inercial, pgs. 97-102.

Chiba, A. e Fukao (2005). Magnetic bearings and bearingless drives. Elsevier. 
Detoni, J. G. (2012). Developments on Electrodynamic Levitation of Rotors. PhD thesis, Politecnico di Torino.

Fang, J., Wang, C., e Wen, T. (2014). Design and Optimization of a Radial Hybrid Magnetic Bearing With Separate Poles for Magnetically Suspended Inertially Stabilized Platform. 50(5).

Furlani, E. P. (2001). Permanent magnet and electromechanicl devices.

Han, B., Zheng, S., e Hu, X. (2013). Dynamic Factor Models of a Thrust Magnetic Bearing With Permanent Magnet Bias and Subsidiary Air Gap. IEEE Transactions on Magnetics, 49(3):1221-1230.

Hofer, M., Schmidt, E., e Schrodl, M. (2009). Design of a Three Phase Permanent Magnet Biased Radial Active Magnetic Bearing Regarding a Position Sensorless Control. 2009 Twenty-Fourth Annual IEEE Applied Power Electronics Conference and Exposition, pgs. 1716-1721.

Ismail, Z. e Varatharajoo, R. (2010). A study of reaction wheel configurations for a 3-axis satellite attitude control.

Jimenez-Lizafrraga, M. e Alcorta, a. (2007). Multi-Model Robust LQ Control of an Active Magnetic Bearing. $200^{\prime 7}$ American Control Conference, pgs. 5977-5982.

Krishnan, S., Lee, S.-h., Hsu, H.-y., e Konchady, G. (2010). Lubrication of Attitude Control Systems. Advances in Spacecraft Technologies, 1.

Larson, W. J. e Wertz, J. R. (1999). Space Mission Analysis and Design.

Leupold, H. e Potenziani, E. (1996). A Permanent Magnet Circuit Design Primer. US Army Research Laboratory, (July).

MagWeb (2015). Free BH Curves. 
Marble, S. e Tow, D. (2006). Bearing health monitoring and life extension in satellite momentum/reaction wheels. Aerospace Conference, 2006 IEEE, pgs. 1-7.

Mukhopadhyay, S. C. (2005). Do we really need sensors? A Sensorless Magnetic Bearing Perspective. 1st International Conference on Sensing ..., pgs. 425-431.

Ortner, M. G., Magele, C., e Krischan, K. (2010). Solver for a Magnetic Equivalent Circuit and Modeling the Inrush Current of a 3-Phase Transformer. (1):1-7.

Pilat, A. (2007). Automatic generation of Active Magnetic Bearing geometry with COMSOL Multiphysics.

Ravaud, R., Lemarquand, G., e Lemarquand, V. (2009). Force and stiffness of passive magnetic bearings using permanent magnets. Part 1: Axial magnetization. IEEE Transactions on Magnetics, 45(7):2996-3002.

Republica Brasileira, P. D. (2011). Desafios do programa espacial brasileiro. Secretaria De assuntos Estratégicos, pg. 267.

Rundell, A. E. e Drakunov, S. V. (1996). A Sliding Mode Observer and Controller for Stabilization of Rotational Motion. IEEE Transactions on Control Systems Technology, pgs. 598-608.

Rycroft, M. J. (1992). Spacecraft Systems Engineering.

Scharfe, M., Roschke, T., Bindl, E., e Blonski, D. (2001). Design and development of a compact magnetic bearing momentum wheel for micro and small satellites. Em Proceedings of the 15th Annual Utah State University Conference on Small Satellites, volume 15 , pgs. $1-9$.

Schuhmann, T., Hofmann, W., e Werner, R. (2012). Improving Operational Performance of Active Magnetic Bearings Using Kalman Filter and State Feedback Control. IEEE Transactions on Industrial Electronics, 59(2):821-829. 
Schweitzer, G., Bleuler, H., Maslen, E. H., e Cole, M. (2009). Magnetic bearings: theory, design, and application to rotating machinery. Springer.

Sivadasan, K. K. (1996). Analysis of self-sensing Active Magnetic Bearings working on inductance measurement principle. IEEE Transactions on Magnetics, 32(2):329-334.

Stassinopoulos, E. e Raymond, J. (1988). The space radiation environment for electronics.

Sun, G., a.B. Palazzolo, Provenza, A., e Montague, G. (2004). Detailed ball bearing model for magnetic suspension auxiliary service. Journal of Sound and Vibration, 269(3-5):933-963.

Taniwaki, Shigemune and Ohkami, Y. (2003). Experimental and numerical analysis of reaction wheel disturbances. JSME International Journal Series C, 46:519--526.

Tezuka, T., Kurita, N., e Ishikawa, T. (2013). Design and Simulation of a Five Degrees of Freedom Active Control Magnetic Levitated Motor. Magnetics, IEEE Transactions $\ldots, 49(5): 2257-2262$.

Veloso, E. M. e Rollemberg, R. R. (2009). A política espacial brasileira. Conselho de Altos Estudos e Avaliacão Tecnológica, 2:270.

Vischer, D. e Bleuler, H. (1993). Self-sensing active magnetic levitation. IEEE Transactions on Magnetics, 29(2):1276-1281.

Weise, D. e Pinckley, F. (1989). An Introduction and Case History Review of Active Magnetic Bearings. Proceedings of the Eighteenth Turbomachinery Symposium.

Wu, H. W. H., Xu, C. X. C., Xiao, D. X. D., e Hao, J. H. J. (2009). Magnetic field analysis and optimal design of magnetic bearing. 2009 International Conference on Mechatronics and Automation, (2):1666-1670. 
Apêndice A

Estator Externo - FEM 


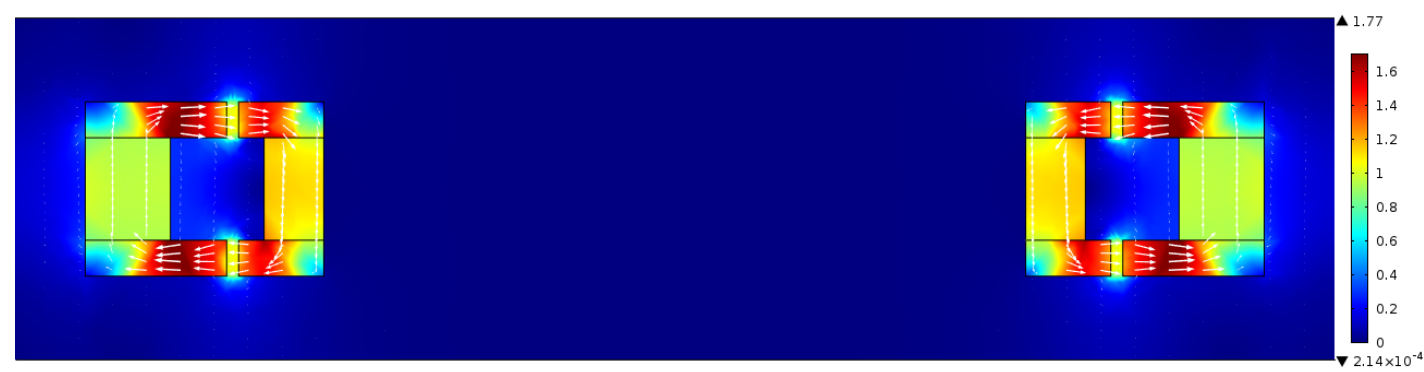

(a) $\Delta_{x}=0 m m$ e $\Delta_{z}=0 m m$

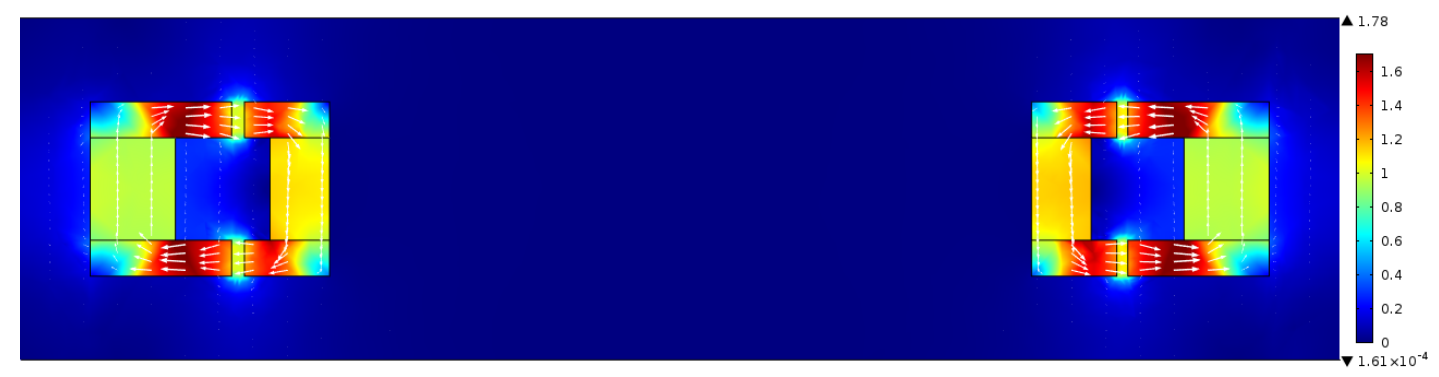

(b) $\Delta_{x}=0.1 \mathrm{~mm}$ e $\Delta_{z}=0 \mathrm{~mm}$

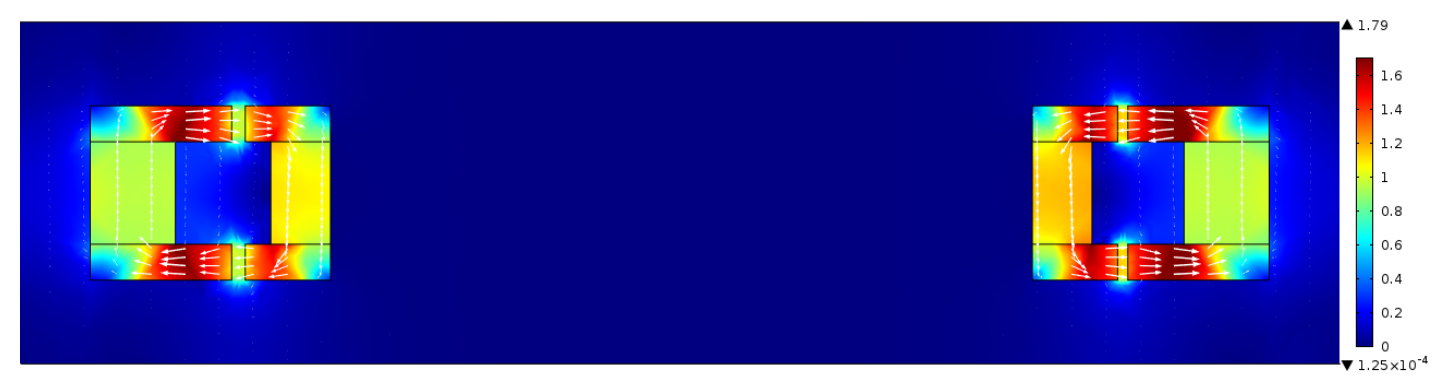

(c) $\Delta_{x}=0.2 \mathrm{~mm}$ e $\Delta_{z}=0 \mathrm{~mm}$

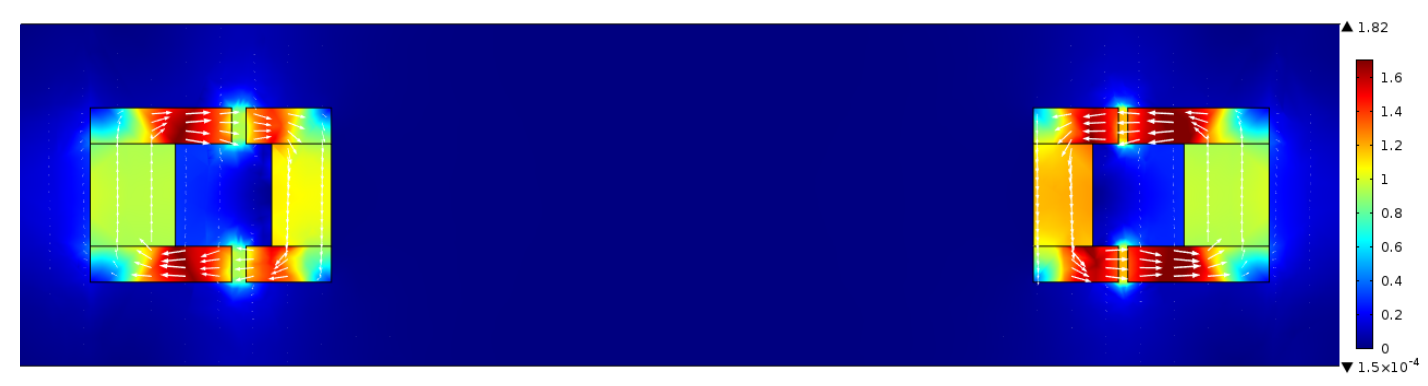

(d) $\Delta_{x}=0.3 \mathrm{~mm}$ e $\Delta_{z}=0 \mathrm{~mm}$

Figura A.1: Campo magnético via simulação em elementos finitos para deslocamentos radial 